\title{
PRELIMINARY PERFORMANCE CRITERIA FOR THE BOND OF PORTLAND-CEMENT AND \\ LATEX-MODIFIED CONCRETE OVERLAYS
}

\section{I. Knab ${ }^{1}$ \\ M. M. Sprinkel ${ }^{2}$ \\ O. J. Lane, Jr.}

${ }^{1}$ Research CIvII Englneer, NIST

${ }^{2}$ Research Sclentist, VIrginla Transportation Research Councll, Charlottesville, VA

${ }^{3}$ Testing EngIneer, lowa Department of Transportation, Ames, IA

U.S. DEPARTMENT OF COMMERCE Natlonal Instltute of Standards and Technology Center for Bullding Technology Bullding Materlals Division Galthersburg, MD 20899

U.S. DEPARTMENT OF COMMERCE Robert A. Mosbacher, Secretary NATIONAL INSTITUTE OF STANDARDS AND TECHNOLOGY

Raymond G. Kammer, Acting Director 

L. I. $\mathrm{Knab}^{1}$

M. M. Lane, Jr. ${ }^{3}$

${ }^{1}$ Research Civll Englneer, NIST

${ }^{2}$ Research Sclentlst,

Virginla Transportation Research Councll, Charlottesville, VA

${ }^{3}$ Testing Englneer, lowa Department of Transportation, Ames, IA

U.S. DEPARTMENT OF COMMERCE

Natlonal Institute of Standards

and Tochnology

Conter for Bullding Technology

Bullding Materlals Divlslon

Galthersburg, MD 20899

Sponsored by:

TrlServlce Bullding Materlals Commlttee

Headquarters,

U.S. Army Corps of Engineers

Washington, DC 20314-1000

U.S. Navy,

Naval Facllitles EngIneering Command

Alexandrla, VA 22332.2300

Headquarters, U.S. Alr Force,

Englneering and Servlces

Bolling Alr Force Base, DC 20332.5000

November 1989

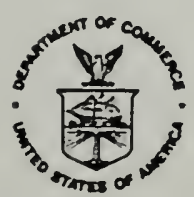

U.S. DEPARTMENT OF COMMERCE Robert A. Mosbacher, Secretary NATIONAL INSTITUTE OF STANDARDS AND TECHNOLOGY

Raymond G. Kammer, Acting Director 

Preliminary bond-strength performance criteria were developed for screening and selecting portland-cement concrete (PCC) and latexmodified concrete (IMC) materials to be overlaid on PCC pavements and PCC bridge decks subjected to normal civilian truck and automobile traffic. The criteria were developed based on direct shear bond test results from (i) field cores from pavements and bridge decks which were considered to have performed satisfactorily, and (ii) laboratory- and field-cast specimens with PCC and LMC overlay materials. The criteria consist of minimum direct shear bond strength levels and corresponding minimum compressive strength levels. A direct shear "guillotine"-type performance bond test method, developed at the Brookhaven National Laboratories, was specified using laboratorycast specimens.

The criteria are preliminary because: (i) the criteria are based on very limited field-and laboratory-based bond strengths and should be further verified by being correlated with field performance, including various service conditons (temperature, moisture, wheel loading, etc.)., (ii) the criteria need to be assessed with regard to repeatability within, and reproducibility among laboratories, (iii) the effects of material variables (aggregate, cement, mix design, etc.), surface preparation, placement procedures, curing conditions, and curing duration on the criteria need to be evaluated. Therefore, the criteria are a starting point and should be evaluated on a trial basis; most likely, the criteria will need to be modified as additional field performance results and laboratory experience are obtained.

A notable limitation of the "guillotine" performance test method is its relatively poor precision, as evidenced by relatively large coefficient of variation values associated with the test method. Although the limitation of imprecision exists, the "guillotine" test method is still considered to be the best available performance bond test method for which field performance data exist. Field-performance data need to be obtained for other bond test methods with potentially better precision, such as the uniaxial tension test method, which was also investigated in the laboratory and reported in this report.

Key Words: Bond Strength,Bridge Decks, Direct Shear Bond Test Method, Latex-Modified Concrete, Overlay, Pavement, Performance Criteria, Precision, Portland Cement Concrete, Repair Materials 
TABLE OF CONTENTS

ABSTRACT

LIST OF FIGURES

vii

LIST OF TABLES

$\mathbf{x}$

1. BACKGROUND 1

2. PURPOSE, SCOPE, AND APPROACH 3

3. DESCRIPTION OF BOND TEST METHODS 5

3.1 Direct Shear 5

3.1.1 BNL Direct Shear Bond Test Method 5

3.1.2 IOWA Direct Bond Shear Test Method 8

3.2 Modified ASTM Slant Shear Bond Test Method 9

3.3 Uniaxial Tension Bond Test Method 9

4. TEST SPECIMENS AND MATERIALS 10

4.1 Field Cores 10

4.1.1 BNL Direct Shear Test Bond Method 10

4.1.2 IOWA Direct Shear Bond Test Method 11

4.2 Laboratory Testing 12

4.2.1 Comparative Test Series I: Direct Shear Bond Test Methods

4.2.2 Comparative Test Series II:

BNL Direct Shear, slant Shear, and

Uniaxial Tension Bond Test Methods

4.2.3 BNL Direct Shear Bond Strength versus overlay Compressive Strength (VTRC) 13

5. TEST RESULTS AND ANALYSIS 14

5.1 Field Cores $\quad 14$

5.1.1 BNL Direct Shear Bond Test Method 14

5.1.2 IOWA Direct Shear Bond Test Method 15 
5.2 Laboratory-and Field-Cast specimens

5.2.1 Comparative Test Series I: Direct Shear Bond Testing

5.2.1.1 Failure Patterns 16

5.2.1.2 Precision and Magnitude of the Bond strength

5.2.1.2.1 Effect of Age at Testing 18

5.2.1.2.2. Precision of the Test

Methods

5.2.1.2.3 Magnitude of the Bond strength

5.2.1.3 Relationship Between IOWA and BNL Test Results

5.2.2 Comparative Test Series II: BNL Direct Shear, Slant Shear, and Uniaxial Tension

5.2.3 Relationships of BNL Direct Shear Bond Strength to Compressive Strength

6. DEVELOPMENT OF PRELIMINARY PERFORMANCE CRITERIA

6.1.1 Portland Cement concrete Bonded overlays

6.1.2 Latex Modified Concrete Bonded overlays

6.2 Selection of a Direct Shear Performance Test Method

6.2.1 Limitations of BNL Direct Shear Test Method

6.3 Development of Preliminary Performance Criteriafor the BNL Test Method

6.3.1 Data Based on Field Cores

6.3.2 Data Based on Laboratory- and FieldCast specimens

6.3.3 Recommended Preliminary Performance Criteria

6.3.3.1 Selection and Discussion of Performance Criteria

6.3.4 Limitations of Performance Criteria

6.3.4.1 Limited Field and Laboratory Data

6.3.4.2 Imprecision 
7.2 Research Needed for Improving the Preliminary Performance Criteria

8. REFERENCES

APPENDIX A. MATERIALS, MIXING, AND CURING

Al. Comparative Test Series I: Direct Shear Bond Tests (BNL and IOWA)

A1.1 Base Concrete

A1.2 Bond Test Specimens

A2. Comparative Test Series II: BNL Direct Shear, Slant Shear, and Uniaxial Tension Bond Test Methods

A2.1 Base Concrete

A2.2 Bond Test Specimens

A3. BNL Direct Shear Bond Strength versus Compressive Strength for PCC Overlays

APPENDIX B. RESULTS AND ANALYSIS OF COMPARATIVE TEST SERIES II

B1. Test Results

B2. Analyses of Test Results

B2.1 Effect of Age at Testing

B2.2 Precision of the Test Methods

B2.3 Bond Strength Comparisons

B2.4 Ratio of Slant Shear Bond Strength to Compressive Strength of Base Concrete

\section{TABLES}


Figure 1. BNL direct shear bond apparatus with holding frame and loading ram. A 3-in. diameter bond specimen is shown prior to inserting it into the holding frame. This test setup was used for all NIST tests (bond specimens, plain overlay material, or base concrete sheared). A somewhat similar test setup was used for the Virginia Transportation Research Council testing - see section 3.1.1. and references 12 and 13 .

Figure 2. A 3 in.-diameter bond specimen inserted in holding frame showing the 1 in.-thick overlay section to be "guillotined" in direct shear. A 2 in.-thick steel wall thickness was used to hold the the specimen. This was the NIST test setup - see section 3.1.1.

Figure 3. BNL direct shear bond test apparatus with a bond specimen in apparatus ready to apply a shear load, by applying a compressive force to the loading ram. Note the use of a 1.0 in.wide by $3 / 16$ in.-thick by $3-1 / 8$ in.-long steel bearing plate which rested on top of the loading ram. The front face of the bearing plate ( $3 / 16$ by $3-1 / 8$ in.) was flush with the front face of the loading ram, and centered with respect to the width of the loading ram, and also centered with respect to the sphericallyseated bearing block (not shown) of the testing machine. (The thickness and length of the bearing plate varied (thickness: $3 / 16$ and $1 / 2$ in.; length: $3-1 / 8$ and 4 in.). A 1 in. width was always used.). The purpose of the plate was to help transmit the applied load to the center of the overlay being sheared.

Figure 4. IOWA testing jig, not in testing machine.

Figure 5. Specimen in IOWA testing jig, which is in testing machine.

Figure 6. Slant shear bond specimen being compressed. One half of the specimen is base portland cement concrete and the other half is overlay material.

Figure 7. Uniaxial tension bond test setup. Pipe caps were screwed on the pipe nipples, then installed in a screw-driven testing machine, and pulled in tension. Two pipe nipples were used: one was bonded to the base concrete and the other bonded to the overlay material. A rubber "O"-ring provided about $3 / 16$ in. spacing between the pipe nipples at the bond plane. A universal ball and socket connection was used at each end of the specimen (see reference 4 for details). 
Figure 8. Direct shear bond strength vs. age at testing for 1-Day old PCC overlay material for the IOWA (figure $8 \mathrm{a}$. ) and BNL

(figure 8b.) test methods. The solid lines are the least-squares linear regression lines for specimens with sawn surfaces, where the individual data are shown by the number "1"; similarly, the dashed lines are the least-squares linear regression lines for specimens with sandblasted surfaces, where the individual data are shown by the number " 2 ".

Figure 9. BNL direct shear bond strength vs. IOWA direct shear bond strength for 1- and 3-Day old PCC overlay material. The dotted line is a least-squares linear regression line fitted to average bond strengths based on 8 (or in one case 9) replicates, where the individual averages are shown with open symbols. The solid line is a least-squares linear regression line fitted to average bond strengths based on the highest two bond strengths out of 8 (or in one case 9) replicates, where the individual averages are shown with solid (filled-in) symbols. See section 5.2 .1 .3 for details.

Figure 10. BNL Direct Shear Bond Strength vs. Compressive Strength of overlay Material (see section 5.2.3 for details).

Figure 11. Probability of misclassification based on a specified "average" BNL bond strength of 325 psi (Class I, table 10) with a sample size of 8 replicates. Curves are given for three assumed coefficient of variation values (CV) of 10,20 , and 30 percent. The probability of supposedly meeting the criteria when, in fact, the criteria were not met is given by the curves to the left of the specified "average" bond strength (325 psi) and the probability of supposedly not meeting the criteria when, in fact, the criteria were met is given by the curves to the right of the specified "average" bond strength.

Figure 12. Probability of misclassification based on a specified "average" BNL bond strength of 375 psi (Class II, table 10) with a sample size of 8 replicates. Curves are given for three assumed coefficient of variation (CV) values of 10,20 , and 30 percent. The probability of supposedly meeting the criteria when, in fact, the criteria were not met is given by the curves to the left of the specified "average" bond strength (375 psi) and the probability of supposedly not meeting the criteria when, in fact, the criteria were met is given by the curves to the right of the specified "average" bond strength. 
Figure 13. Probability of misclassification based on a specified "average" BNL bond strength of 425 psi (Class III, table 10) with a sample size of 8 replicates. Curves are given for three assumed coefficient of variation (CV) values of 10,20 , and 30 percent. The probability of supposedly meeting the criteria when, in fact, the criteria were not met is given by the curves to the left of the specified "average" bond strength (425 psi) and the probability of supposedly not meeting the criteria when, in fact, the criteria were met is given by the curves to the right of the specified "average" bond strength.

Figure Bl. (Appendix B) Bond strength vs. age at testing for 2 Day-old PCC overlay material for the BNL (figure BI(a)), uniaxial tension (figure $B I(b)$ ), and slant shear (figure BI(c) bond test methods. The solid lines are the least-squares linear regression lines for specimens with sawn surfaces, where the individual data are shown by the number "1"; similarly, the dashed lines are the least-squares linear regression lines for specimens with sandblasted surfaces, where the individual data are shown by the number " 2 ".

Figure B2 (Appendix B) Bond strength vs. age at testing for 1 Day-old LMC overlay material for the BNL (figure BI(a)), uniaxial tension (figure BI(b)), and slant shear (figure BI(c) bond test methods. The solid lines are the least-squares linear regression lines for specimens with sawn surfaces, where the individual data are shown by the number "l"; similarly, the dashed lines are the least-squares linear regression lines for specimens with sandblasted surfaces, where the individual data are shown by the number "2". 


\section{LIST OF TABLES}

Table 1. Data on Bridges and IMC Overlays

Table 2. BNI Direct Shear Bond Strength Data for LMC Overlays (VTRC Data) for Field Cores

Table 3. Bond Strength Data for IOWA Direct Shear Bond Test Method - 3 in. Thick PCC Overlays on PCC Slabs on Grade (Field Cores)

Table 4. Bond Strength and Location and Amount of Failure Surface for 1 Day-old Portland Cement Concrete overlay Material Bonded to 43 Day-old Portland Cement Concrete

Table 5. Bond Strength and Location and Amount of Failure Surface for 3 Day-old Portland Cement Concrete overlay Material Bonded to 45 Day-old Portland Cement Concrete

Table 6. Average Bond Strength and Coefficient of Variation Values for the IOWA and BNL Direct Shear Bond Test Methods for 1and 3- Day Old PCC Overlay Materials

Table 7. Values of the "t" Statistic and the Ratio of the Bond stremgth of the BNL Test Method to the IOWA Test Method

Table 8. Compressive - Bond strength Data for PCC overlays (Tested at the Virginia Transportation Research Council Laboratories)

Table 9. Summary of the Direct Shear Bond Strength Results from Field cores Tested using the IOWA and BNL Test Methods

Table 10. Preliminary Performance Criteria for PCC and IMC Overlay Materials Based on the BNL Direct Shear Test Method

Table Al (Appendix A) Mix Proportions and Properties of Base Concrete and overlay Materials used in Comparative Laboratory Testing (Test series I) of the IOWA and BNL Direct Shear Test Methods

Table A2 (Appendix A) Mix Proportions and Properties of Base Concrete and Overlay Materials used in Comparative Laboratory Testing (Test series II) of the BNL Direct Shear, Uniaxial Tension, and slant Shear Bond Test Methods

Table BI (Appendix B) Bond Strength and Location and Amount of Failure Surface for 2 Day-old portland cement concrete overlay Material Bonded to 50 Day-old Portland Cement Concrete 
Table B2. (Appendix B) Bond Strength and Location and Amount of Failure Surface for 1 Day-old Latex Modified Concrete Overlay Material Bonded to 70 Day-old Portland Cement concrete

Table B3 (Appendix B) Summary of Bond Strength Data for the Three Bond Test Methods and Two Overlay Materials Tested in Comparative Test Series II 



\section{BACKGROUND}

The ability of a bonded overlay to bond to its base concrete during the lifetime of the overlay is one of the most important performance requirements $[1,2,3]$ which can be quantified. There is a need for performance tests and criteria for screening and selecting materials for overlaying portland cement concrete (PCC) $[2,4]$. For example, there are existing ASTM test methods and specifications for using epoxy-resin bonding systems (C 881 [5], C $882[6], C 883[7], C 884$ [8]) and latex bonding agents and systems (C 1042 [9], and C 1059 [10]) with PCC. However, these test methods and specifications are not appropriate for other types of overlay materials, such as plain portland cement concrete (without the use of a bonding agent) and latex-modified concrete (IMC) materials.

The Tri-Service (U.S. Army, Navy, and Air Force) Building Materials Investigational Program has sponsored research at the National Institute of Standards and Technology (NIST) to develop performance tests $[4,11]$ and in the current study, to develop preliminary performance criteria for concrete overlay materials.

In one of the previous studies [11], a test method was developed to determine the uniaxial tensile bond strength. That study concentrated primarily on the bond strength of new portland cement paste to old portland cement paste. In the other study 
[4], three bond strength test methods were evaluated for concrete: two uniaxial tensile bond strength test methods and a slant shear bond strength test method. In Reference 4, it was concluded that both the slant shear test method and one uniaxial tensile test method (the pipe nipple grips test method) were promising bond test methods for screening and selecting portland cement concrete or latex-modified concrete-type repair materials for overlaying or patching PCC. While these two methods were promising, particularly with regard to precision, a major drawback to developing performance criteria for these test methods was that their results have not been related to field performance.

With the direct shear bond test method, however, there exist bond strength results for field cores taken from pavements and bridge decks $[3,12]$. In addition, bond specimens cast in the field were tested using a direct shear bond test method [13]. Two direct shear bond test methods were investigated in the laboratory in the current study. Based on results from field cores and laboratory- and field-cast specimens, preliminary performance criteria were developed based on one of the direct shear bond tests, the BNL test, developed by the Brookhaven National Laboratories (described in Section 3.1.1). The preliminary performance criteria were also based on bond strength - compressive strength relationships, which were derived from testing laboratory- and field-cast specimens. The criteria 
developed in the current study were seen as a first step in the process of developing needed performance criteria for the various applications and materials used in repairing concrete.

In addition, in the current study, a comparison between laboratory-based results for the uniaxial tension and the BNL direct shear bond test methods was made. The comparison, when combined with field performance data and additional laboratory data, should be useful in the future development of performance criteria based on the uniaxial tension bond test method.

A laboratory-based comparison was also made between the results for the BNL direct shear bond and the slant shear bond test methods. Because it is difficult to obtain and test field cores in the slant shear configuration, it would be difficult to develop field-based performance criteria for the slant shear test method. However, the fraction of the strength of the slant shear composite specimen (overlay and base concrete) relative to that of the base concrete has the potential to provide useful auxillary bond information, which could be used in conjunction with performance criteria based on another bond test method.

2. PURPOSE, SCOPE, AND APPROACH

The purpose of the current study was to develop preliminary performance criteria for the strength of the bond between overlay 
materials and PCC pavements and bridge decks.

Preliminary performance criteria were developed for PCC- and LMCoverlay materials. The performance test used to specify the criteria was the BNL direct shear bond test.

Preliminary performance criteria were developed based on (i) field core results from pavements and bridge decks which were considered to have performed satisfactorily, and (ii) on results from laboratory- and field-cast bond specimens with PCC and LMC overlay materials. The field cores and laboratory- and fieldcast specimens were tested using the BNL and the IOWA direct shear bond test methods (described in Chapter 3). Only laboratory-cast specimens were tested in the current study. The laboratory test results included the bond strength and compressive strength (of the overlay material) and were used to: (i) establish an approximate relationship between the bond strength and compressive strength (of the overlay), which was used in developing the performance criteria and, (ii) to correlate the IOWA and the BNL direct shear bond test methods so that the field performance information of both test methods could be used in developing the performance criteria. (The field cores tested using the IOWA bond test method were from PCC overlays on pavements while field cores tested using the BNL test method were from LMC overlays on bridge decks. The performance criteria developed covered both PCC and LMC overlay 
materials.)

In addition, and for reasons given in Chapter 1, comparisons between the uniaxial tension and the BNL direct shear bond test methods, and also between the slant shear and the BNL direct shear bond test methods, were made based on laboratory-cast specimens.

3. DESCRIPTION OF BOND TEST METHODS

3.1 Direct Shear

3.1.1 BNL Direct Shear Bond Test Method

The BNL direct shear bond test method was used in the laboratory to test both field cores and laboratory- and field-cast specimens. Details of the test specimens and materials are given in Chapter 4 .

Figures 1 to 3 provide pictures and diagrams of the test apparatus. The apparatus can be fabricated to accomodate different diameter specimens, but a separate apparatus is needed for each specimen diameter used. In this test method, the cylindrical specimens are subjected to a "guillotine" direct shear force. 
All field core specimens tested using the BNL test method were tested at the Virginia Transportation Research Council, VTRC, [12] using 4 in.-diameter cores approximately 5.5 in. long. Laboratory- and field-cast, 4 in.-diameter by 4.6 in.-long specimens were tested at the VTRC. (The base concrete for the field-cast bond specimens was cast in the VTRC laboratory.) Laboratory-cast, 3 in.-diameter specimens were tested at the NIST and at the Iowa Department of Transportation. (The testing at the Iowa DOT was part of Comparative Test series I, described in section 4.2 .1$.

The field cores and laboratory- and field-cast bond specimens were tested at the VTRC in the following way. Special care was used to align the bond plane with the inside vertical face of the holding frame (figure 2) and the front face of the guillotine loading ram (figure 3), which was placed over the overlay. Prior to starting the test, the center of the loading ram was placed under the center of the upper head of the testing machine and a 1/16 in.-thick neoprene pad was placed between the head and the top of the ram. The average thickness of the overlays for the field cores ranged from 1.1 to $1.9 \mathrm{in}$. and the thickness of the overlay for the laboratory-and field-cast specimens was 2 in. After the field core or laboratory- or field-cast specimen had failed, the broken parts were removed from the holding frame and the percentages of the failure surface which failed in the overlay, through the bond plane, and in the base concrete were 
estimated. To obtain the shear strength of the base concrete, the base concretes of the field cores and laboratory- and fieldcast specimens were tested in a similar manner. The base concrete section of the field core or a 4 in. diameter by 4 in. long laboratory-cast specimen of base concrete was placed in the holding frame so that approximately 1.5 in. of the bottom, baseconcrete portion of the core or $1.5 \mathrm{in}$. of the laboratory-cast specimen of base concrete was under the ram and was loaded to failure. Likewise, to obtain the shear strength of the overlay material cast on the laboratory- and field-cast specimens, a 4 in. diameter by 4 in. long specimen of overlay material was placed in the holding frame so that approximately $1.5 \mathrm{in}$. of the specimen was under the loading ram. The nominal shear strength was calculated by dividing the failure load by the crosssectional area $\left(12.57 \mathrm{in.}^{2}\right)$ of the specimen. With all the VTRC shear tests, a compressive load which caused the shear failure was applied at the rate of $10,0001 \mathrm{bf} / \mathrm{min}$.

The NIST test setup for the BNL direct shear bond test differed from the VTRC procedure in that 3 in. diameter specimens were used; an additional steel bearing plate was used (figure 3); a neoprene pad was not used; a 1 in. thickness of overlay, plain base concrete, or plain overlay material was used (i.e. three different locations sheared - at bond plane, in plain overlay, or in plain base concrete); the load rate was about 1100 to 1200 $1 \mathrm{bf} / \mathrm{min}$. for specimens sheared at the bond line as well as for 
those sheared in the plain overlay material; and the load rate was about $6300 \mathrm{lbf} / \mathrm{min}$. for specimens sheared in the plain base concrete.

For all NIST and VTRC testing, 2 in. of base concrete was secured in place by the wall of the holding frame (figure 2).

3.1.2 IOWA Direct Shear Bond Test Method

A direct shear bond testing jig was developed by the Iowa Departmentment of Transportation [14]. It consists of a two-part collar (figure 4) that fits over a 4 in. diameter core or bond specimen with the junction of the two sliding parts lined up over the bond plane. The testing jig containing the bond specimen was then placed into a hydraulic testing machine and the two ends of the tester pulled in tension (figure 5) until the load required to shear the specimen was attained. The load rate used was about 5000 to $6000 \mathrm{lbf} / \mathrm{min}$. in Comparative Test Series I. The nominal shear strength was calculated by dividing the failure load by the cross-sectional area of 12.57 in. $^{2}$.

The overlay thickness was 3 in. for the field cores and about 2 in. for the laboratory-cast specimens. The length of the base concrete for the laboratory-cast bond specimens was about 2 in. (The overlays for the laboratory-cast specimens were cast and tested at the Iowa Department of Transportation laboratory in 
Aimes, Iowa). The plates that transmitted the shearing force (through bearing) were about $1-3 / 16$ in. thick.

\subsection{Modified ASTM Slant Shear Bond Test Method}

A modification of the ASTM C 882 [6] slant shear bond strength test consisted of replacing one-half of the slant shear test specimen with overlay material, resulting in one-half of the specimen being overlay material bonded to the other half, which was base concrete. The angle of the shear plane was approximately $30^{\circ}$ with respect to the longitudinal axis of the cylinder. Figure 6 shows a slant shear specimen being compressed. The total specimen dimensions (overlay and base concrete) were $3 \mathrm{in.}$ in diameter by 6 in. long.

\subsection{Uniaxial Tension Bond Test Method}

A summary of the method used to apply uniaxial tensile stress to bond strength specimens using pipe nipple grips ${ }^{a}$ is given below; a detailed description of the test method is given in reference 4. A bond strength specimen consisted of a 3 in.-diameter by

a This method was developed at Dow Chemical Co. by L. Kuhlmann. Certain manufacturers' names, and names of commercial equipment, instruments, and materials are identified in this report to adequately specify the experimental procedure. Such an identification does not imply recommendation or endorsement by the National Institute of Standards and Technology, nor does it imply that the equipment, instruments, or materials identified are necessarily the best available for the purpose. 
approximately 3 in.-long cylinder of overlay material bonded to a 3 in. diameter by approximately 3 in.-long cylinder of base PCC. A screw-driven testing machine was used to conduct the uniaxial tensile tests at a deformation rate of $1 \mathrm{~mm} / \mathrm{minute}$.

The circumference of the base PCC cylinder, with a sawn or sandblasted surface, was bonded with epoxy inside of a nominal 3 in. inside diameter by 3 in.-long, black steel pipe nipple. A rubber "O"-ring was placed on top of the pipe nipple. After the epoxy had cured, a similar empty pipe nipple was mounted on top of the base concrete-pipe nipple "O"-ring assembly, and the overlay material was cast into the empty pipe nipple. After curing, the overlay material had bonded to the base concrete and to the inside of the pipe nipple. In order to attach the specimen to the testing machine, pipe caps with special attachments, including universal ball and socket connections, were screwed on the pipe nipples at both ends (figure 7).

\section{TEST SPECIMENS AND MATERIALS}

\subsection{Field Cores}

4.1.1 BNL Direct Shear Bond Test Method

Three cores, $4 \mathrm{in}$. in diameter by approximately $5.5 \mathrm{in}$. in length, were removed from the shoulder, right wheel path and left 
wheel path from each of 10 bridges being evaluated to determine the long-term performance of the bond of latex modified concrete overlays [12]. Information on the bridges and the overlays from which the 30 cores were taken is shown in tables 1 and 2 . At the time of the evaluation, which was done in 1983, the overlays ranged in age from 1 year to 13 years. The average thickness of the overlays ranged from $1.1 \mathrm{in.}$ to $1.9 \mathrm{in}$. Two overlays were placed on base concretes that had never been placed in service (bridges 2 and 6 , table 1 ). With these two overlays, the base concretes were screeded, cured for at least 28 days, and subsequently sandblasted and water soaked at least 1 hour prior to placing overlays. The other eight overlays were placed on base concretes that had been in service between 13 and 22 years. The base concretes were scarified to remove at least 0.5 in., sandblasted and water soaked at least 1 hour prior to placing overlays.

\subsubsection{IOWA Direct Shear Bond Test Method}

Table 3 lists the bond strengths of 4 in.-diameter cores of 3 in.-thick PCC overlays on PCC slabs on grade( pavements). The surface preparation of the base concrete prior to placing the overlay consisted of grinding, sandblasting, and the application of grout (either cement, sand, and water, or cement and water). 
4.2.1 Comparative Test Series I: Direct Shear Bond Test Methods

Results from the BNL and IOWA direct shear bond test methods were compared by conducting concurrent tests with the same laboratorycast PCC overlay materials. The tests were conducted at the Iowa Department of Transportation laboratories. The materials, mixing and curing procedures are given in Appendix A, Section Al. Concurrent tests were performed with the two test methods using two laboratory-prepared overlay materials: a 1 Day-old PCC and a 3 Day-old PCC. It is noted that a large value (0.85, table Al) of the water/cement ratio, as well as testing at early age, was used for the PCC overlay material in order to investigate relatively low values of bond strength.

A BNL direct shear bond specimen consisted of a 3 in.- diameter by approximately 1 in.-long cylinder of overlay material bonded to a 3 in.-diameter by approximately 2 to 4 in.-long cylinder of base PCC.

An IOWA direct shear bond specimen consisted of a 4 in.- diameter by approximately 2 in.-long cylinder of overlay material bonded to a 4 in.-diameter by approximately 2 in.-long cylinder of base PCC. 
4.2.2 Comparative Test series II: BNL Direct Shear, Slant Shear, and Uniaxial Tension Bond Test Methods

Comparative tests were performed with the uniaxial tension and BNL direct shear bond test methods as well as the slant shear and BNL direct shear bond test methods. (The rationale for performing these is given in Chapter 1.) Concurrent tests were performed with the three test methods using two laboratory-prepared overlay materials: a 2 Day-Old PCC and a 1 Day-Old LMC. The materials, mixing and curing procedures are given in Appendix A, Section A2. It is noted that a large value (0.85, table $\mathrm{A} 2)$ of the water/cement ratio, as well as testing at early age, was used for the PCC overlay material in order to investigate relatively low values of bond strength. Similarly, the IMC overlay specimens were tested at early age to study lower values of bond strength.

4.2.3 BNI Direct Shear Bond Strength versus overlay Compressive Strength (VTRC Data)

The relationship between the BNL direct shear bond strength and the corresponding overlay compressive strength for PCC and IMC overlays was needed for developing the performance criteria. The relationship was investigated by testing 4 in. diameter BNL bond and compressive strength specimens at the same age (the ages when the bond and compression specimens were tested differed by no more than 15 minutes) at the VTRC. The thicknesses of the PCC 
overlay and its base concrete were 2 in. and 2.6 in., respectively. Information on materials, and mixing and curing is given in Appendix A, Section A3 for the PCC overlays and in reference 13 for the LMC overlays.

\section{TEST RESULTS AND ANALYSIS}

\subsection{Field cores}

\subsubsection{BNL Direct Shear Bond Test Method}

The results of the BNL field core tests are shown in table 2 [12]. The data show that, based on tests of three cores from each bridge, the minimum bond strengths for each bridge ranged from 420 to $790 \mathrm{psi}$ and the average bond strengths ranged from 530 to 930 psi. Since all of the overlays are soundly bonded and performing satisfactorily it can be concluded that the values obtained from the cores are adequate for good performance.

If the data are combined for the three bridges $(2,6,14$ - table 1$)$ with an average daily traffic (ADT) less than 10,000, it is found that the average bond strength is $680 \mathrm{psi}$, the minimum individual bond strength is $420 \mathrm{psi}$, and the minimum average bond strength for 3 tests is $530 \mathrm{psi}$. If the data are combined for the seven bridges $(3,4,8,9,11,12,13)$ with an $\mathrm{ADT}$ greater than or equal to 10,000 , the average bond strength is $710 \mathrm{psi}$, the minimum individual 
bond strength is $490 \mathrm{psi}$, and the minimum average bond strength for three tests is $540 \mathrm{psi}$. These bond strengths are typical for latex-modified concrete overlays that are providing good longterm bond performance but do not preclude the possibility that good long-term bond performance could be obtained with lower bond strengths.

Also, as can be seen in table 2 , in most cases the entries for the percentage of failure for the base concrete were greater than the corresponding entries for the LMC overlay and also for the bond plane. This apparent failure preference in the base concrete suggests that the base concrete influenced the variability and magnitude of the bond strength more than either the IMC overlay or the bond plane.

\subsubsection{IOWA Direct Shear Bond Test Method}

Table 3 lists the direct shear bond strengths of the field cores tested using the IOWA test method. The cores were taken from 3 in.-thick overlays which had been cast on PCC slabs on grade. The average bond strengths ranged from 550 to $955 \mathrm{psi}$ and the minimum bond strengths ranged from 297 to 509 psi. As indicated in table 3 , the ages of the overlays when the cores were tested were not available, but it is estimated that the ages of most of the cores were less than or equal to about $1 \mathrm{yr}$. when tested. 
5.2 Laboratory- and Field-Cast specimens

5.2.1 Comparative Test Series I: Direct Shear Bond Testing

Tables 4 and 5 list the bond strength and the location and approximate amount of the failure surface from the bond testing of the 1 Day-Old PCC and the 3 Day-old PCC overlay materials, respectively, for the IOWA and BNL direct shear bond test methods studied.

\subsubsection{Failure Patterns}

The approximate percentages of the failure surface area which failed in the overlay material, in the base concrete, or on the bond plane, are given in columns 2,3 , and 4 , in tables 4 and 5 . The percentage of the failure surface area which occurred on the bond plane was further distinguished as: (i) a thin layer of overlay material which adhered on the base concrete, (ii) a thin layer of base concrete which adhered on the overlay material, or (iii) a "clean" break, where neither the overlay material nor the base concrete adhered to the other. Also, in some cases (see column 5), the failure process produced a separate piece which contained both the overlay material and the base concrete bonded together. The sum of columns $2,3,4$, and 5 is 100 percent.

Because the determinations of the percentages of the failure 
surface area were estimated visually, they are approximate values. Additional approximation occurred when determining whether a layer of overlay material or base concrete which was adhered on the bond plane should be treated as a "thin" layer on the bond plane (column 4 ) or be treated as a separate material. For example, a "thin" layer of overlay material on the bond plane could have been entered either in column 4 with an " $r$ " (designating overlay material) or in column 2 as a failure in the overlay material. (The overlay material, however, could always be distinguished from its base concrete). Despite these approximations, it was considered that the percentages and locations of the failure surfaces provided a good basis for analyzing the failure trends.

As shown in tables 4 and 5 , in most cases the failure pattern was in the overlay material, with at least 75 percent of the failure occurring in the overlay material. This failure pattern was as expected, since the average compressive strengths of the 1-Day Old and 3-Day Old PCC overlay materials (900 and 1690 psi, respectively, table Al, Appendix A) were substantially lower than that of the base concrete (6500 psi).

The importance of failure patterns in the interpretation of the variability and magnitude of the bond strength is given in 
reference 4 .

5.2.1.2 Precision and Magnitude of the Bond Strength

The average and coefficient of variation values of the bond strength for the two test methods, the two overlay materials, and the two surface preparations are given in table 6. The bond strengths of the IOWA and BNL test methods were computed by dividing the failure load by the shear cross-sectional area (12.57 in. ${ }^{2}$ for IOWA and $7.07 \mathrm{in}^{2}$. for BNL test methods).

\subsection{Effect of Age at Testing}

The effect of the specimen age at testing on bond strength is shown in figure 8 for the IOWA and BNL test methods. Based on the slopes of the least squares linear fitted lines and as expected, there appears to be a trend of increasing bond strength with increasing age with the 1 Day-old PCC overlay material. A similar trend was not evident for the 3 Day-old PCC overlay material.

When comparing the precision and magnitude of the shear bond strength obtained from the two test methods (Sections 5.2.1.2.2 and 5.2 .1 .2 .3$)$, the effect of differences in specimen age at testing was not considered significant because the specimens for both test methods were tested in approximately the same time 
span, and therefore were tested at approximately the same age. That is, with the same surface preparation and for the 1 Day-old PCC overlay material, the difference in age was (a) 10 minutes or less for the first (initial) IOWA and BNL specimens tested and (b) 36 minutes or less for the last IOWA and BNL specimens tested. With the same test method, the surface preparation was alternated (e.g., specimen with a sandblasted surface tested first, a specimen with a sawn surface tested next, etc.)

5.2.1.2.2. Precision of the Test Methods

It was considered inappropriate to use the standard deviation to measure the precision (repeatibility) because of the relatively large differences in the averages of the IOWA compared with the BNL direct shear bond tests for a given overlay material (table 6). Rather, the coefficient of variation ( = (standard deviation/average) $\times 100$ ), which is a measure of precision adjusted for the magnitude of the average, was used as a measure of the relative precision.

With each of the four overlay material-surface preparation combinations, the coefficient of variation value of the BNL test method was always less than that of the IOWA test method (table 6). 
This trend, though not statistically significant ${ }^{b}$, suggests that the relative precision of the BNL test method was better than that of the IOWA test method. There did not appear to be a significant difference in the coefficient of variation of the sawn compared with the sandblasted surfaces for the same overlay material and test type.

\subsection{Magnitude of the Bond Strength}

Based on the values in tables 4 to 6 , values of the "t"c statistic and also the ratio of the BNL to IOWA bond strengths are given in table 7 . With each of the four overlay materialsurface preparation combinations, the BNL average bond strength exceeded the corresponding IOWA average bond strength. This difference between average bond strengths for the BNL and IOWA test methods was considered statistically significant for "t" values of about 3 or more and occurred in two of the four overlay material-surface preparation combinations (table 7). This apparent trend of the BNL bond strength exceeding the IOWA bond strength was attributed primarily to the different test geometries of the two test methods (see Chapter 3 ).

b In this study, the difference in the coefficient of variation values from two samples ( 1 and 2 ) was considered to be statistically significant if the test statistic, $\mathbf{z}$, given by sach [15] $\left(z=\left|v_{1}-v_{2}\right| /\left(\left(V_{1}^{2} / 2 n_{1}\right)+\left(V_{2}^{2} / 2 n_{2}\right)\right)^{1 / 2} ; V=\right.$ coefficient of variation and $\mathrm{n}=$ sample size) was 3 or greater. Use of Sach's test statistic was an approximation because it is for "sample sizes not too small $\left(n_{1}, n_{2} \geq 30\right) "$ (compared to the sample sizes of 8 or 9 of this study) and it was assumed that the test statistic is normally distributed.

c "t" statistic values calculated from Natrella, reference 16, page $3-23$. 
5.2.1.3 Relationship Between IOWA and BNL Test Results

The relationship of the average bond strengths given in table 6 for the two methods is shown in figure 9. With one exception, each average in table 6 is based on 8 replications (see table 6). These laboratory-based average bond strength values (figure 9 ) in table 6 are lower than the lowest field-based average bond strength values for both the BNL and the IOWA test methods (tables 2 and 3 ). To compare the laboratory-based results at strength levels closer to the lowest field-based averages, another set of larger averages, based on the highest $2^{d}$ (out of 8 ) bond strength values, were also used. These larger averages, denoted by "high 2", are shown in figure 9, along with the average values based on 8 replications. As evident in figure 9, the straight lines fitted through the averages based on 8 replications and on the "high 2" almost overlap, indicating that the relationship between the test results appears to be the same using either approach.

d

With the 1-Day Old PCC specimens and for the same surface preparation, the age at testing may have affected the results, since the age at testing of the highest BNL bond strength value exceeded the age at testing of the highest IowA bond strength value by about $3 / 4$ hour, and the age of testing of the next highest BNL bond strength value exceeded the age at testing of the next highest IOWA bond strength value by about 1 hour. (These differences in age at testing applied to both surface preparations.). 
Based on figure 9, for the PCC overlay materials, bond strengths, surface preparations, and specimen geometries investigated, the bond strength of the BNL test method was, on the average, about 75 psi larger than the IOWA bond strength, when the BNL bond strength ranged from about 240 to $400 \mathrm{psi}$ (based on averages for 8 replicates). It should be noted that the comparative testing was conducted for low strength PCC overlays (average BNL bond strengths of about 240 to 400 psi, based on 8 replicates, with corresponding average overlay compressive strengths of about 900 psi (1 Day-old PCC) to 1700 psi (3 Day-old PCC), respectively). Therefore, for low strength PCC overlays, it appears reasonable to assume that a similar trend (figure 9) should occur for bond strength results of field cores of PCC overlay materials for the two test methods. Further data are needed, however, to verify that the relationship in figure 9 holds for higher strength overlays (e.g., 3000 to 5000 psi compressive strength).

5.2.2 Comparative Test Series II: BNL Direct Shear, Slant Shear, and Uniaxial Tension

The Comparative Test Series II consisted of a laboratory-based comparison of the uniaxial tension and BNL bond strength results and also a similiar comparison of the slant shear and BNL bond strength results. The laboratory based-comparisons, while useful in the future, were considered insufficient using the current information to develop performance criteria based on the uniaxial 
tension or slant shear test methods for the following reason. There is no field-core data on the performance of overlays using the uniaxial tension test method nor using the slant shear test method (it is not practical to obtain and test field cores in the slant shear configuration). Data which directly link field performance with laboratory test results are considered necessary to develop performance criteria.

The laboratory-based comparison of the uniaxial tension and BNL bond test results, when combined with field performance information and additional laboratory data ${ }^{e}$, should be useful in the future development of performance criteria for the uniaxial tension bond test method.

Although it is difficult to obtain field performance information using the slant shear configuration, the slant shear bond test method still has the potential to provide useful information (see Appendix B, Section B2.4).

Appendix B provides the results and comparisons obtained from Comparative Test series II.

- See Footnote " $n$ " in section 7.1. 
5.2.3 Relationships of BNL Direct Shear Bond Strength to Compressive Strength

Figure 10 shows the relationship between the BNL direct shear bond strength and the compressive strength of the overlay material for compressive strengths equal to or in excess of 1500 psi for laboratory- and field-cast specimens. Results based on Comparative Test series I and II are shown in figure 10. Also shown in figure 10 are the VTRC data (see table 8 and section 4.2.3) for PCC overlays. Data from two other studies $[13,17]$, including a high-early strength LMC overlay [13], are also shown in figure 10.

With the data from Comparative Test series I and II shown in figure 10, it must be realized that the failure mode of the PCC and LMC overlays differed and two surface preparations were used (sawn and sandblasted). The failure mode of the 3 Day-old PCC overlay material was primarily through the overlay while the failure mode of the 1 Day- Old LMC was primarily on the bond plane.

Information on the failure mode was not available for the VTRC

The effects of curing temperature and the addition of calcium chloride (see table 8 ) on the bond and compressive strengths were not considered in this report. The data from table 8 and shown in figure 10, however, were considered to provide relevant information regarding the relationship between bond and compressive strength. 
overlay data (table 8, figure 10), but it was believed that for most of the data, the failure occurred either in the PCC overlay or at the bond plane. This assumption regarding the failure mode appears reasonable, since most of the tests were conducted at early ages when the strength of the overlay was much less than that of the base concrete.

Data from the on-going NIST study [17] were for 1 in. thick PCC and LMC overlays, where the surfaces of 3 inch diameter specimens were sawn and for which failures were primarily on the bond plane.

Data from reference 13 were based on 4 in. diameter specimens and were for a high-early strength IMC overlay, which was 2 in. thick. The mortar fraction of the overlay was brushed onto the sawn surface of the base concrete prior to placing the overlay on the base concrete. The 28-day compressive strength of the base PCC was 5450 psi. Although specific information on the failure modes for the specimens in reference 13 was not available, it is believed that for most of specimens, failure occurred either on the bond plane or in the overlay material. This assumption regarding the failure mode appears reasonable, since most of the tests were conducted at early ages when the strength of the overlay was much less than that of the base concrete.

Four least-squares linear regression lines were fitted to the 
data in figure 10 and were labelled "l" to "4". Iine "l" was fitted to all NIST data for PCC overlays (table 5 and reference 17). Line "2" was fitted to the VTRC data for PCC overlays (table 8). Line "3" was fitted to the NIST data for IMC overlays (table B2 and reference 17). Line "4" was fitted to the VTRC, high-early strength, LMC overlay data [13].

The relationships in figure 10 are approximate due to inconsistencies, including differences in the failure mode of the specimens tested using the BNL bond test method. Another inconsistency occurred with the bond strength data corresponding to compressive strengths in excess of about $4750 \mathrm{psi}$. In this case, it is possible that the failure mode included failure in the base concrete, meaning that the base concrete compressive strength might be correlated with the bond strength (rather than the overlay compressive strength being correlated with the bond strength). However, for most of the data for which the overlay compressive strength exceeded $4750 \mathrm{psi}$, the compressive strength of the overlay was less than or about the same as that of the base concrete, indicating that there was a good chance that the failure did not occur predominantly in the base concrete ${ }^{8}$. Despite these inconsistencies, figure 10 provides an indication

8 In one of the cases where the compressive strength of the overlay exceeded that of the base concrete by about 700 psi, an average value (5795 psi) of the compressive stengths of the base concrete and the overlay was used to plot with the bond strength (620 psi). 
of the relationship between the direct shear bond strength and the compressive strength of the overlay for the overlays investigated.

CHAPTER 6 DEVELOPMENT OF PRELIMINARY PERFORMANCE CRITERIA

\subsection{Background}

The direct shear bond test method was investigated as a performance test for developing performance criteria because field cores from overlays on pavements and bridge decks had been tested using this method. Some of the overlays on the pavements and bridge decks were considered to have performed satisfactorily. The performance of these overlays is summarized below.

\section{1 .1 PCC Bonded Overlays}

Hutchinson [3] thoroughly reviewed the performance of bonded PCC resurfacings, including bond strength data from many overlays. Hutchinson's review included both "guillotine" (e.g, $[12,18])$ and the Iowa Department of Transportation [14] direct shear bond test methods. With regard to bond strength of field cores taken from projects constructed before 1976, he stated that the data "indicate a wide range of bond strengths, from 0 to 750 psi, with the strength being somewhat dependent on the type of surface 
preparation and the bonding procedure used". He summarized the various surface preparation and bonding procedures and their range in average bond strengths as follows:

(i) swept or broom scrubbed -84 to $330 \mathrm{psi}$

(ii) scarified followed by sweeping and/or air blasting - 259 to 565 psi

(iii) acid etching, either alone or in combination with scarification - 332 to 496 psi.

Hutchinson stated that, since 1976, "surface preparation has consisted primarily of some combination of scarification by milling equipment, sandblasting, and high-pressure water blasting. .... In general, the bond strength obtained by the methods used since 1976 have exceeded that obtained by the methods used on earlier projects. All the methods used, with the possible exception of sweeping alone, have usually produced bond strengths exceeding the value of 200 psi that was suggested by Felt [19] as being adequate and that has become a generally accepted value for selection and design of the bonding medium". With regard to the "200 psi" reference value, Felt stated: "The laboratory data and field work indicate that bond strengths, as determined by a shear test, may frequently be 400 psi or more, but that strengths of 200 psi or even less may be adequate."

$\mathrm{h}$ The reader is referred to Table A-9 [3] for additional bond strength data. It appears that most, or perhaps all, of the bond strengths in Table A9 [3] were obtained using direct shear bond test methods. 
Similarly, Gillette [18] stated "Cores obtained from projects using various methods of surface preparation indicate that a bond strength of $200 \mathrm{psi}$ is adequate and that when such bond is obtained, it will endure." Both Felt ${ }^{i}$ and Gillette used guillotine-type direct shear test methods which were somewhat similar.

Thus, the authors of the current report have interpreted the usage of 200 psi to be a lower limit for the bond strength based on direct shear test methods. That is, if 200 psi were chosen as a performance criterion, the bond strength of every specimen tested would need to equal or exceed $200 \mathrm{psi}$. Note that the actual performance criteria chosen in the current report for the lower limit (see section 6.3.3, table 10) ranged from 200 to 260 psi.

6.1.2 LMC Bonded Overlays

Sprinkel used the BNL direct shear test on LMC bridge overlay cores $[12,13]$. The results [12] are given in sections 4.1 .1 and 5.1.1.

i From reference 19, it appeared that a direct shear test method was used for the laboratory and field testing. 
6.2 Selection of a Direct Shear Bond Performance Test Method

The BNL direct shear bond test method was selected as the performance test method and was preferred over the IOWA direct shear bond test method because:

(i) with the overlay materials and surface preparations studied, the relative precision, as measured by the coefficient of variation was, for the BNL test method, in all cases possibly better ${ }^{j}$ compared with the IOWA test method; and (ii) the BNL test method was considered easier to perform.

6.2.1 Limitations of BNL Direct Shear Test Method

A limitation of the BNL bond strength results is that field cores with PCC overlay materials were not tested (only field cores of LMC overlays on bridge decks were tested). The laboratory results (Section 5.2.1.3), however, showed that for the PCC overlay materials and test conditions investigated, the bond strength of the BNL test method was, on the average, about 75 psi larger than the IOWA bond strength, when the BNL bond strength ranged from about 240 to $400 \mathrm{psi}$ (based on averages for 8 replicates). It should be noted that the comparative testing was conducted for low strength PCC overlays (average BNL bond strengths of about

j The relative precision was "possibly better" because of the trend of lower, though not statistically significant, coefficient of variation values for the BNL compared with the IOWA test methods (see section 5.2.1.2.2). 
240 to 400 psi, based on 8 replicates, with corresponding average overlay compressive strengths of about 900 to $1700 \mathrm{psi}$, respectively). Therefore, for low strength PCC overlays, it appears reasonable to assume that a similar trend (figure 9) should occur for bond strength results of field cores of PCC overlay materials for the two test methods. Further data are needed, however, to verify that the relationship in figure 9 holds for higher strength overlays (e.g., 3000 to 5000 psi compressive strength).

The coefficient of variation (CV) values for the BNL direct shear bond test method were relatively high in most cases for both the field cores and laboratory-cast specimens. For example, with the field cores in table 2 , the $C V$ values ranged from 19 to 32 percent in 6 of the 10 data sets. Similarly, with the laboratory-cast specimens in tables $4,5, \mathrm{B1}$, and $\mathrm{B} 2$, the $\mathrm{CV}$ values ranged from 13 to 29 percent, with 5 of the 8 values being 18.5 percent or greater. Increased $c V$ values most likely occurred in those cases where there were effects of age at testing (see sections 5.2.1.2.1 and B2.1). It is believed, however, that the variations due to the test method and materials are still relatively large.

In the NIST on-going study (reference 17), the CV values were 17 and 24 percent for two data sets of 7 replicates of PCC overlays on a PCC base and 15 percent for one data set of 5 replicates of 
a LMC overlay on a PCC base (averages shown in figure 10). It is noted that the effect of age at testing was not significant in the BNL bond tests in reference 17 and yet the $C V$ values were still relatively large.

The relatively large $C V$ values imply that the BNL test method is relatively imprecise. The implications of this imprecision with regard to performance criteria are discussed in section 6.3.4.2. Although the limitation of imprecision exists, the BNL test method is still considered to be the best available performance bond test method because (i) field performance data are only available for the direct shear bond test methods, and (ii) the relative precision of the BNL direct shear bond test method was possibly better ${ }^{k}$ compared with the IOWA direct shear test method and was considered easier to perform.

6.3 Development of Preliminary Performance Criteria for the BNL Test Method

6.3.1 Data Based on Field Cores

In developing performance criteria, direct shear bond strength results from field cores were considered to be the most important

k The relative precision was "possibly better" because of the trend of lower, though not statistically significant, coefficient of variation values for the BNL test method compared with the IOWA test method (see section 5.2.1.2.2). 
information source. Table 9 contains a summary of the bond strength results from field cores tested using the BNL and IOWA test methods. As shown in the table, the lowest minimum values of 420 and 300 psi were obtained with the BNL and IOWA test methods, repectively. The lowest average values were 530 and 550 psi for the BNL and IOWA test methods, respectively. The IOWA test method had a larger deviation between its lowest average (550 psi) and lowest minimum value (300 psi) compared-with respective values from the BNL test method (530 and 420 psi). This is believed due to a higher variability of the IOWA compared with the BNL test method (see section 5.2.1.2.2). These lowest minimum and lowest average values appear larger than the values discussed by Felt [19]: "The laboratory data and field work indicate that bond strengths, as determined by a shear test, may frequently be $400 \mathrm{psi}$ or more, but that strengths of $200 \mathrm{psi}$ or even less may be adequate." The apparent differences between the field core results in table 9 and Felt's values are believed to be caused, at least in part, by differences in overlay materials, surface preparation, strength of base concrete, placement procedures, curing, geometry of test setup, and load rate.

6.3.2 Data Based on Laboratory- and Field-Cast Specimens

Additional information on bond strength values can be obtained from figure 10, where the relationship between the BNL bond strength and compressive strength of overlays is shown. (See 
In figure 10, the data and their fitted lines show that there is an apparent increase in bond strength as the compressive strength of the overlay increases. The slopes of the fitted lines in figure 10 show that there appears to be a larger increase in bond strength per increase in compressive strength for LMC overlays than for PCC overlays. Also, with the NIST data above about 2500 psi compressive strength, the bond strength of the LMC exceeded that of the PCC overlays, when comparing at the same compressive strength and using the fitted lines. Similarly, with the VTRC data above about 3250 psi compressive strength, the bond strength of the LMC exceeded that of the PCC overlays.

Because of the apparent increase in bond strength with increasing overlay compressive strength, performance criteria were formulated in terms of a specified bond strength and a corresponding overlay compressive strength.

\subsubsection{Recommended Preliminary Performance Criteria}

Based on the field core results in table 9 and the bond strengthcompressive strength relationships given in figure 10, preliminary performance criteria are given in table 10. The criteria specify the use of only laboratory-cast specimens. The BNL direct shear bond test method is to be used to determine bond 
strength (see section 3.1.1) and ASTM C39 [20] used to determine the compressive strength. The criteria are intended for screening and selecting PCC and LMC materials to be overlaid on PCC pavements and PCC bridge decks subjected to normal civilian truck and automobile traffic. The criteria are not intended for aircraft or for heavy-weight or other unusual vehicles.

In developing the criteria, it was assumed that an overlay with a higher bond strength and compressive strength would provide better performance and a longer service life, provided that the base concrete is of comparable strength. The use of class I is restricted to when the compressive strength of the base concrete on which the overlay is placed in the field is between 3000 and 3500 psi. Classes II and III can be specified to meet higher performance levels. For example, class III could be specified for a bridge deck overlay, which may be more critical in terms of the consequences of failure than an overlay on a pavement on grade, for which class II could be specified.

Special consideration should be given when the compressive strength of the base concrete on which the overlay is placed in the field is less than the compressive strength of the overlay. In this case, the BNL test specimen may fail in the base concrete, at a bond strength less than the bond strength levels required in table 10. 
For each class, required bond strength levels are given in terms of both the "minimum" and "average" of 8 replicates (tested with the same overlay material and base concrete, surface preparation, placement procedures, curing, test method, etc.). The "minimum" level requires that 7 of the 8 replicate bond strength values must equal or exceed the level listed $(200,230$, or 260 psi) while the "average" level requires that the average of the 8 tests must equal or exceed the level listed $(325,375$ or 425 psi). (Even if a bond strength is less than the "minimum" level, it must be included when computing the average value). Both the "minimum" and the "average" requirements must be satisfied.

Further details on table 10 are given at the end of section 6.3.3.1.

6.3.3.1 Selection and Discussion of Performance Criteria

Based on the field core results (table 9) and the laboratory results in figure 10 , the 325,375 , and 425 psi values appear reasonable as estimates of acceptable lower limits for average BNL direct shear bond strengths for PCC and LMC overlays having the minimum compressive strengths shown in table 10. The 425 psi value is more than 100 psi below the lower average values of 530 psi for IMC field cores, tested using the BNL test method, and 
550 psi for the PCC field cores, tested using the IOWA ${ }^{1}$ test method (table 9). Similarly, at a value of compressive strength of $5000 \mathrm{psi}$, the $425 \mathrm{psi}$ value is about $100 \mathrm{psi}$ less than the fitted line (Iine "2"), which is an estimate of the average bond strength based on VTRC laboratory-prepared PCC overlay specimens.

The choice of lower limits for the "average" values $(325,375$, and $425 \mathrm{psi}$ ), which are lower than those predicted by fitted Iine "2", is believed justified because of the additional requirement of "minimum" bond strength values $(200,230$, and 260 psi), which are intended to reduce the liklihood of overlay material with unacceptably low quality.

Further, it should be noted that, with one exception, each data point on which fitted Iine " 2 " was based represents an average of 2 bond strength replicates (figure 10). Data points from the same population as the data represented by fitted Iine "2", but based on an average of 8 bond strength replicates (as required in table 10), should move closer to fitted Line "2" in the bond strength (vertical) direction, assuming that the position of fitted Iine " 2 " does not change substantially when the number of replicates is increased from 2 to 8 . Therefore, provided this assumption is valid, data points from the same population as the

1 Note that there may be some difference between the BNI and the IOWA bond strength test results. Comparative data were obtained only for low strength concrete (900 to $1700 \mathrm{psi}$ compressive strength - see Section 5.2.1.3 and figure 9). 
data represented by fitted Line "2" and based on an average of 8 bond strength replicates should more likely exceed the "average" limits (325, 375, and 425 psi, table 10) than data based on an average of only 2 replicates (figure 10). In the above discussion, it was assumed that the position of fitted Line "2" would not change substantially when the number of replicates increased from 2 to 8 . If the position of fitted Line "2" did change substantially, then data based on an average of 8 replicates may or may not more likely exceed the "average" limits compared with data based on an average of 2 replicates, depending on the new position of fitted Line "2". It is further noted that fitted Line "2" in figure 10 is based only on laboratory tests of PCC overlay material and that the relationship of the line to field performance has not been established.

Based on fitted Lines "2" and "4" for the VTRC data with compressive strengths exceeding about $3250 \mathrm{psi}$, the bond strength values for the LMC exceeded those for PCC overlays (figure 10). Hence, for Classes II and III, lower compressive strengths were selected for LMC compared with PCC overlays.

For a given class, the specified "minimum" values $(200,230$, and 260 psi) correspond to a deviation of about 2.0 standard deviation units below the "average" values $(325,375$, and 425 psi), assuming a CV value of 20 percent (see section 6.2.1). For example, for an "average" bond strength of $325 \mathrm{psi}$, the 
corresponding assumed standard deviation is $65 \mathrm{psi}$ and the value of bond strength corresponding to a deviation of 2.0 standard deviations below the average is 195 psi (=325 - (2.0)(65)). The 195 psi value was rounded off to 200 psi. The 200 psi "minimum" value also agrees well with the $200 \mathrm{psi}$ value discussed in Section 6.1.1.

The "minimum" value of 200 psi, which corresponds to 3000 psi compressive strength (Class I), appears reasonable when compared to:

(i) the 14 of the 16 bond strength values (from 8 sets of 2 replicates) which exceeded 200 psi for average PCC overlay compressive strengths between 2510 and 2950 psi (table 8), and (ii) minimum bond strength values of 270 psi (from 10 replicates, sandblasted surfaces), and $287 \mathrm{psi}$ (from 10 replicates, sawn surfaces), which occurred with the 1 Day-old LMC overlay (table B2) with the corresponding LMC overlay compressive strength of 2260 psi (table A2).

The "minimum" value of $230 \mathrm{psi}$, which corresponds to 3750 (IMC) to 4000 (PCC) psi compressive strength (Class II), appears reasonable when compared to:

(i) the 280 psi minimum bond strength value (from 10 sets of 2 replicates) which occurred with PCC overlay compressive strengths ranging from 3110 to 3860 psi (table 8), and (ii) the minimum bond strengths were 354 psi (from 7 replicates, 
sawn surfaces) and $365 \mathrm{psi}$ (from 7 replicates, sawn surfaces) for PCC overlays with compressive strengths of 3540 and 4040 psi, respectively [17].

Similarly, the "minimum" value of $260 \mathrm{psi}$, which corresponds to 4250 (IMC) to 5000 (PCC) psi compressive strength (Class III), appears reasonable when compared to:

(i) 7 of the 8 bond strength values (from 4 sets of 2 replicates) which equalled or exceeded $260 \mathrm{psi}$ and which occurred with PCC overlay compressive strengths ranging from 4020 to 5000 psi (table 8),

(ii) the minimum bond strength value of 631 psi (from 5 replicates, sawn surfaces) which occurred with a I.MC overlay with a compressive strength of $4770 \mathrm{psi}$ (base concrete had a compressive strength of $4610 \mathrm{psi}$ ) [17], and (iii) the minimum bond stength values of 300 and 420 psi for the field core data for the IOWA and BNL test methods, respectively (table 9).

The requirement that 7 of the 8 bond strength replicates equal or exceed the "minimum" values is intended to account for the occurrence, from time to time, of specimens with very low bond strength. This requirement may need to be modified as additonal data are obtained.

It must be kept in mind that the "minimum" and "average" bond and 
compressive strength values given in table 10 are considered to be lower limits and that overlay materials with bond and compressive strengths higher than those in class III may occur.

A load rate of $6000 \mathrm{lbf} / \mathrm{min}$. was selected, representing a value between the NIST laboratory rate $(1100$ to $1200 \mathrm{lbf} / \mathrm{min}$. used in the Comparative Test series I and II, and about $6000 \mathrm{lbf} / \mathrm{min}$. used in reference 17) and the rate used by the VTRC (10000 lbf/min., section 3.1.1).

The footnotes in table 10 treat the details of specimen preparation, maximum aggregate size, geometry, curing, testing, replicates, interpretation of results, etc.

The base concrete surface on which the overlay is cast was specified to be a sawn surface, obtained with a water-cooled saw. The sawn surface was specified because most of the laboratorycast bond specimens used in developing the performance criteria had sawn surfaces (figure 10) and sawn surfaces should help in providing a uniform bond surface.

The failure location (in overlay, on bond plane, or in the base concrete or a combination of these) and the percentage of failure surface area occurring in the bond specimens should be recorded (e.g., see section 5.2.1.1 and table 4). This information on the location and amount of failure is useful in interpreting the magnitude and variability of the bond strength results (see reference 4 for further details). 
Table 10 specifies that the bond strength specimens must be prepared and tested with overlay material, base concrete, base concrete surface moisture, grouting material (if used), placement procedures, curing time, and curing conditions (moisture, temperature, etc.) that are similar to those of the field overlay installation to be put into service (see discussion later in this section). The intent is that the strengths of the base concrete, bond interface, and overlay concrete of the laboratory-cast specimens simulate as closely as possible the strengths of the base concrete, bond interface, and overlay concrete of the field overlay when it is subjected to traffic. Table 10 specifies that the average compressive strength of laboratorycast overlay material must be based on at least three specimens tested at the same age and cured under the same conditions (moisture, temperature, etc.) as the BNL bond test specimens. The average overlay compressive strength must equal or exceed the value listed in table 10. The compression specimens are to be cast from the same batch of overlay concrete as used to cast the bond specimens.

Special consideration needs to be given to the case when traffic is permitted on an overlay at early ages when the bond and compressive strengths are below the required levels in table 10 , with the development of the required bond and overlay compressive strengths occurring at a later age. The potential damage to the overlay caused by traffic loading at early ages (before the development of the required bond and compressive strengths in table 10) would need to be considered. 
Although beyond the scope of this report, information on the proper design (overlay thickness, cases when bonded overlays can be used, etc.) and construction practices (surface preparation, moisture condition of base concrete, use of grout, etc.) for bonded concrete overlays needs to be considered when screening and selecting overlay materials and installing overlays in the field (e.g., see references $3,22,23$ and 24). For example, construction practices (surface cleaning; removal of deteriorated or contaminated material; moisture condition of base concrete, such as dry or damp (e.g., wet but without puddles of water); use of grout, etc.) will affect the quality of the bond of the overlay to the base concrete (e.g., see references 3,22 , and 24).

Application of the criteria in table 10 for evaluating new or existing overlay installations using field cores is not recommended because: (i) of the very limited number of field cores for LMC overlays tested using the BNL direct shear bond test method, and (ii) field cores for PCC overlays have not been tested using the BNL direct shear bond test method. Of key importance is the determination of the minimum level of bond strength which will provide adequate performance over a specified sevice lifetime.

6.3.4 Limitations of Performance Criteria 6.3.4.1 Limited Field and Laboratory Data

Very limited field and laboratory data bases were used to develop the preliminary performance criteria in table 10. The criteria 
will most likely need to be modified as additional field performance results and laboratory data are obtained as discussed in the following.

The bond strength values of field cores are based on very limited data from overlays on pavements (table 3 ) and bridge decks (table 2) which were considered to have performed satisfactorily. The data in tables 2 and 3 represent a limited number of field cores, reflecting limited service conditions of temperature, moisture, wheel loading, etc. In addition, there were no field core results for PCC overlays tested with the BNL method.

Bond strength values lower than those given in tables 2 and 3 may also give satisfactory performance for the service conditions under which the data were obtained. Additional field performance data would be needed to determine if lower values would provide satisfactory performance.

The laboratory-based information in Figure 10 is somewhat limited, especially for (i) LMC bond strengths and for (ii) PCC and LMC bond strengths at higher strengths (compressive strengths of 5000 to $6000 \mathrm{psi}$ ).

The criteria need to be assessed with regard to repeatability within, and reproducibility among laboratories, using a statistically designed experiment and round-robin testing. 
6.3.4.2 Imprecision

The relatively large CV values (Section 6.2.1) of the BNL direct shear bond test method can result in two types of error with regard to the sample average. The first type of error occurs when the sample average is above the specified "average" bond strength given in table 10, but the actual population average is below the specified "average" bond strength. That is, supposedly the criteria were met by the potential overlay material when, in fact, the criteria were not met. For example, if the population average of an overlay material is $375 \mathrm{psi}$ and using an assumed CV value of 20 percent, there is about a 5 percent chance that the average of a sample of 8 replicates will exceed 425 psi, the specified "average" bond strength for Class III.

The second type of error occurs when the sample average is below the specified "average" bond strength (table 10) but the population average is above the specified "average" bond strength; that is, supposedly the criteria were not met by the potential overlay material when, in fact, the criteria were met. For example, if the population average of an overlay material is $475 \mathrm{psi}$ and using an assumed $C V$ value of 20 percent, then there is about a 9 percent chance that the average of a sample of 8 replicates will fall below 425 psi, the specified "average" bond strength for Class III. 
Figures 11, 12 and 13 show the probability for a making these two types of errors, for a sample size of 8 , and assuming a " $t$ " distribution". The specified "average" bond strength values in table 10 of 325,375 , and 425 psi correspond to figures 11, 12, and 13, respectively. Probability curves are shown for three assumed $\mathrm{CV}$ values of 10,20 , and 30 percent (estimate of the population standard deviation assumed to be 10, 20, and 30 percent of the population average). In the figures, the probability of misclassification refers to either the probability of supposedly meeting the criteria when, in fact, the criteria were not met, or supposedly not meeting the criteria when, in fact, the criteria were met. As shown in the figures, the probability of misclassification increases rapidly as the population average gets close to the specified "average" bond strength, with the maximum probability for each error type equal to 50 percent at the specified "average" bond strength.

For a given population standard deviation, the probability of misclassificaton can be reduced by increasing the sample size. For example, from figure 13 and assuming a population average of $385 \mathrm{psi}$ and a CV value of 20 percent, the probability of

"The "t" statistic, with $n-1(8-1=7)$ degrees of freedom, was used: $t=(\bar{x}-u) /(s / \sqrt{n})$, where $\bar{x}=$ sample average based on $\mathrm{n}(=8)$ replicates, $\mathrm{u}=$ population average, and $\mathrm{s}=$ estimate of population standard deviation, derived from the sample, here assumed to be 10,20 , or 30 percent of the population average. 
supposedly meeting the criteria (425 psi) when, in fact, the criteria were not met is about 9 percent, based on 8 replicates. If the sample size were increased to 12 or 16 and using the same assumptions, the probability of supposedly meeting the criteria when, in fact, the criteria were not met would decrease from 9 to 5.0 and 2.8 percent, respectively.

The probability of misclassification can also be reduced by an improvement in the precision of the test method. For example, reductions in the probability of misclassification can be seen in figures 11 to 13 by comparing curves based on the higher $\mathrm{CV}$ values of 20 and 30 percent (reduced precision) to that of a lower CV value of 10 percent (improved precision). Assuming that $C V$ values of 20 to 30 percent are more representative than 10 percent for the BNL test method (see section 6.2.1), the need is seen to develop performance criteria based on another bond test method having improved precision relative to the BNL test method. One test method with potentially better precision than the BNL test method is the uniaxial tension bond test method (section B2.2).

In section 6.3.3.1, a CV value of 20 percent for the BNL direct shear bond test (Section 6.2.1) was assumed and used in determining the "minimum" bond strength values $(200,230$, and 260 psi, table 10). The "minimum" values correspond to a deviation of about 2.0 standard deviation units below the "average" values $(325,375$, and 425 psi). While the "minimum" values of 200,230 , 
and 260 appear reasonable (Section 6.3.3.1), the use of different assumptions ( $\mathrm{CV}$ value, number of standard deviations below the mean, and the permitting of 1 out of 8 replicates to be below the "minimum" value) would result in different "minimum" bond strength criteria. These assumptions and their corresponding "minimum" values may need to be modified as additional field and laboratory data become available.

\section{CONCLUSIONS AND RESEARCH NEEDS}

\subsection{Conclusions}

1. Preliminary performance criteria (table 10) were expressed in terms of minimum bond strength levels using the BNL direct shear bond ("guillotine") test method and corresponding minimum compressive strength levels. The criteria specify the use of only laboratory-cast bond and compressive strength specimens. The criteria are intended for screening and selecting PCC and IMC materials to be overlaid on PCC pavements and PCC bridge decks subjected to normal civilian truck and automobile traffic. The criteria are not intended for aircraft or for heavy-weight or other unusual vehicles. The criteria are preliminary for the following reasons.

(i) The criteria are based on very limited field- and laboratorybased bond strengths. For example, there were no field cores of PCC overlays tested using the BNL test method. 
(ii) The criteria should be verified further by being correlated with the field performance of overlays subjected to various service conditons (temperature, moisture, wheel loading, etc.).

(iii) The criteria need to be assessed with regard to repeatability within, and reproducibility among laboratories.

(iv) The effects of material variables (aggregate, cement, mix design, etc.), surface preparation and moisture condition of the base concrete, placement procedures, curing conditions, and curing duration on the criteria need to be evaluated.

(v) Bond strength values lower than the field core values given in table 2 may also give satisfactory performance for the service conditions under which the data were taken. Additional field performance data are needed to determine if lower values would provide satisfactory performance.

Based on (i) - (v) above, the criteria are a starting point and should be evaluated on a trial basis; most likely the criteria will need to be modified as additional field and laboratory results are obtained.

2. A notable limitation of the BNL direct shear bond performance test method is its relatively large coefficient of variation values, which result in relatively poor precision. The 
implications of this imprecision with regard to meeting or not meeting the criteria for a potential overlay material are discussed in section 6.3.4.2. Although the limitation of imprecision exists, the BNL test method is still considered to be the best available performance bond test method for which field performance data exist. Consideration, however, should be given to obtaining field performance data for other bond test methods with potentially better precision, such as the uniaxial tension bond test method investigated in this report.

Consideration should also be given to the ACI 503R [21] tensile pull-off test which can be performed both in the field and in the laboratory. The precision of bond testing using a modificaton of this test is currently being evaluated [17].

3. A laboratory-based comparison was made between the results for the BNL direct shear bond and the uniaxial tension bond test methods for relatively low-strength overlay materials. The comparison, when combined with field performance data and additional laboratory data ${ }^{n}$, should be useful in the future development of performance criteria for the uniaxial tension bond test method.

A laboratory-based comparison was also made between the results

"The reader is referred to the ongoing NIST investigation [17], which includes BNI direct shear bond strengths and uniaxial tension bond strengths for overlay materials with compressive strengths of about 3500 to 4800 psi. 
for the BNL direct shear bond and the slant shear bond test methods for relatively low strength overlay materials. Because it is difficult to obtain and test field cores in the slant shear configuration, it would be difficult to develop field-based performance criteria for the slant shear test method. However, the fraction of the strength of the slant shear composite specimen (overlay and base concrete) relative to that of the base concrete has the potential to provide useful auxillary bond information, which could be used in conjunction with performance criteria based on another bond test method.

4. The three types of bond test methods investigated (direct shear, slant shear, and uniaxial tension) resulted in substantially different bond strengths. These differences in bond strengths emphasized the need to use bond test method(s) with stress conditions similar to those anticipated for the inservice overlay material.

7.2 Research Needed for Improving the Preliminary Performance Criteria

1. Because of the very limited data on which the criteria are based, the criteria shoula be evaluated on a trial basis.

The criteria need to be assessed with regard to repeatability within, and reproducibility among laboratories, using a statistically designed experiment and round-robin testing. 
Additional field performance data are needed to evaluate the effects of different service conditions (temperature, moisture, wheel loading, etc.), material variables (aggregate type and maximum size, cement, mix design, etc.), surface preparation and moisture condition of the base concrete, placement procedures, curing conditions, and curing duration on the BNL bond strength values. For example, field performance information for PCC overlay cores tested using the BNL test method are needed.

Performance criteria need to be developed to cover the case when traffic is to be permitted on an overlay at early ages when the bond and compressive strengths of the overlay are below the required levels in table 10, with the development of the required bond and overlay strengths occurring at a later age.

Additional performance data based on field cores using the BNL test method are needed to determine if bond strength values lower than those in table 2 would provide satisfactory performance under the service conditions (temperature, moisture, wheel loading etc.), for which the data were obtained.

Most likely the preliminary criteria in table 10 will need to be modified as additional field performance results and laboratory data and experience are obtained using the BNL bond test method. 
2. Based on field-performance data (e.g., see 1. immediately above), criteria for the evaluation of new and existing overlays based on the bond strength of field cores needs to be developed. of key importance is the determination of the minimum bond strength that will result in satisfactory performance of the overlay over the required lifetime.

3. Because of the relatively poor precision of the BNL test method, consideration should be given to obtaining field performance data and laboratory data for other bond test methods with potentially better precision, such as the uniaxial tension bond test method investigated in this report.

Consideration should also be given to the ACI 503R [21] tensile pull-off test which can be performed both in the field and in the laboratory. If the precision of a modification of this test method, which is currently being evaluated [17], is acceptable, then field performance information would need to be obtained.

Based on field performance data and laboratory results, performance criteria based on the uniaxial tension bond test method or the ACI 503R pull-off bond test method or a combination of the test methods could be developed.

- See footnote " $n$ " in section 7.1. 
4. The development of performance criteria requiring minimum bond strength levels for specimens which have been previously exposed to various test conditions (temperature cycling, moisture cycling, wheel loading etc.) needs to be investigated. The test conditions chosen should simulate, in so far as possible, the anticipated sevice conditions of the overlay installation. 
1. Schroeder, C. J., Britson, R. A. and Bergren, J. V. "Bonded, Thin-Lift Non-Reinforced Portland Cement Concrete Resurfacing," Iowa Department of Transportation, Division of Highways, May, 1977.

2. Knab, L. I. "Factors Related to the Performance of Concrete Repair Materials," Repair, Evaluation, Maintenance, and

Rehabilitation Research Program, Technical Report REMR-CS-12, US Army Corps of Engineers, Washington D.C., 200314-1000, March, 1988.

3. Hutchinson, R. L., "Resurfacing with Portland cement Concrete," NCHRP Synthesis of Highway Practice 99, Transportation Research Board, December 1982.

4. Knab, I. I. and Spring, C. B., "Evaluation of Test Methods for Measuring the Bond strength of Portland Cement Based Repair Materials to Concrete," Cement, Concrete, and Aggregates, ASTM, Philadelphia, PA, Summer, 1989, pp. 3-14.

5. ASTM, Standard Specification for Epoxy-Resin-Base Bonding Systems for Concrete, ASTM C 881-78 (1983), ASTM, Philadelphia, PA, 1978.

6. ASTM, Standard Test Method for Bond Strength of Epoxy-Resin Systems Used with Concrete, ASTM C 882-78 (1983), ASTM, Philadelphia, PA, 1978.

7. ASTM, Standard Test Method for Effective Shrinkage of EpoxyResin Systems Used with Concrete, ASTM C 883-80 (1983), ASTM, Philadelphia, PA, 1980.

8. ASTM, Standard Test Method for Thermal Compatibility Between Concrete and an Epoxy-Resin Overlay, ASTM C 884-78 (1983), ASTM, Philadelphia, PA, 1978.

9. ASTM, Standard Test Method for Bond Strength of Latex systems Used with Concrete, ASTM C 1042-85, ASTM, Philadelpia, PA, 1985.

10. ASTM, Standard Specification for Latex Agents for Bonding Fresh to Hardened Concrete, ASTM C 1059-86, ASTM, Philadelpia, $\mathrm{PA}, 1986$.

11. Struble L. and Waters N., "Tensile Test to Measure Adhesion Between old and New Cement Paste," National Institute of Standards and Technology, Internal Report, NBSIR 87-3685, January 1988.

12. Sprinkel, M. M., "Overview of Latex Modified Concrete Overlays," Virginia Transporatation Research Council, Report Number VHTRC 85-RI, JulY 1984. 
13. Sprinkel, M. M., "High Early Strength Latex Modified Concrete overlay," Virginia Transportation Research Council, Preprint of Paper Presented at the 1988 Annual Transportation Research Board Meeting, Washington D.C.

14. "Method of Test for Determining the Shearing strength of Bonded Concrete," Test Method No. Iowa 406-B, September 1984 , Iowa Department of Transportation, Highway Division (2 pages).

15. Sach, I., Applied Statistics, Springer-Verlag New York Inc., 1982 .

16. Natrella, M. G., "Experimental Statistics," Handbook 91, National Institute of Standards and Technology, Gaithersburg, MD, 1966.

17. Unpublished data from an ongoing NIST Tri-service project on bond strength of overlays.

18. Gillette, R. W., "A 10-Year Report on Performance of Bonded Concrete Resurfacings," Highway Research Record No. 94 ,

1965, pp. 61-76.

19. Felt, E. J., "Resurfacing and Patching Concrete Pavement with Bonded Concrete." Highway Research Board Proceedings. Vol.35. Highway Research Board, National Research Council, Washington, D.C. (1956) pp. 444-469.

20. ASTM, Standard Test Method for Compressive Strength of Cylindrical concrete specimens, ASTM C 39-86 (1988), ASTM, Philadelphia, PA, 1986.

21. "Field Test for Surface Soundness and Adhesion, Appendix A Test Methods," ACI 503R-Use of Epoxy Compounds with concrete, ACI Manual of Concrete Practice, Part 5, American Concrete Institute, Detroit, MI, 1985, pg. 503R-30 to 31 .

22. "ACI 546.1R-80, Guide for Repair of Concrete Bridge Superstructures, "ACI Manual of Concrete Practice, Part 2, American Concrete Institute, Detroit, MI, 1985, pp. 546.1R-1 to 20 .

23. "ACI 325.1R-67, Design of Concrete Overlays for Pavements," Manual of Concrete Practice, Part 2, American Concrete Institute, Detroit, MI, pp. 325.1R-1 to 5 .

24. "AASHTO-AGC-ARTBA, Joint Committee, Guide Procedures for Concrete Pavements, 4R Operations" Ch. 8, Guide Procedures, Portland Cement Concrete Bonded Overlays, 1985. 
This investigation was conducted under the Tri-service Building Materials Investigational Program and was jointly sponsored by the Headquarters, U.S. Army Corps of Engineers; U.S. Navy, Naval Facilities Engineering Command; and Headquarters, U.S. Air Force, Engineering and Services.

The authors gratefully acknowledge Mr. Curtis B. Spring of CCRLNIST, Mr. Nat Waters of NIST and the cement and concrete section of the Iowa DOT central laboratories in Ames, Iowa, under the supervision of $\mathrm{Mr}$. Ralph Kalsem for the preparation and testing of the laboratory-cast specimens. The authors appreciate the statistical consultation provided by Dr. James J. Filliben of NIST and the helpful suggestions of Dr. Nicholas Carino and Mr. Robert G. Mathey also of NIST. Ms. Denise Herbert and Ms. Karen Hozela are gratefully acknowledged for their help in the preparation of the tables and text. 
APPENDIX A. MATERIALS, MIXING, AND CURING PROCEDURES USED IN LABORATORY TESTING

A1. Comparative Test Series I: Direct Shear Bond Tests (BNL and IOWA)

The mix proportions of base concrete and overlay materials tested are given in table A1. A nominal $1 / 2$ in. maximum size, crushed

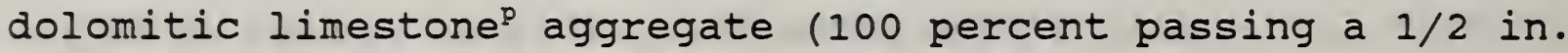
sieve and approximately 9 percent retained on a $3 / 8$ in. sieve) was used in both the base PCC and the overlay material. A concrete sand with a fineness modulus of about 2.6 and ASTM Type I portland cement were used in both the base PCC and overlay materials.

\section{A1.1 Base Concrete}

After casting, the specimens of base concrete were covered with plastic sheeting, stripped at 1 day of age, immersed in limesaturated water for 23 to 27 days, and then air dried until tested. The base concrete cylinders were sawn at $90^{\circ}$ to their longitudinal axis to a thickness of about 2 in., using a watercooled, diamond saw blade. Some of the sawn surfaces were lightly sandblasted. The sawn or sandblasted sections were

As reported by the supplier. 
placed in either a 3 or 4 in. diameter plastic cylinder mold (type used for molding concrete but had been trimmed). Prior to casting overlay material on the base concrete, all sawn surfaces were sanded using sandpaper and then wiped with a damp towel to remove any debris and all surfaces (sandblasted and sawn) were airblasted with dry, oil-free air.

\section{A1.2 Bond Test Specimens}

Immediately prior to casting the overlay materials ( 1 Day-old PCC and the 3 Day-old PCC) onto the sawn or sandblasted surface of the base concrete, a thin layer of the mortar fraction from the overlay material was applied to the base concrete surface with a brush. With specimens from the IOWA test method, a thickness of approximately 2 in. of overlay material was cast in two layers and with specimens from the BNL test method, a thickness of approximately 1 in. of overlay material was placed in one layer. In all cases, each layer was rodded. All specimens were tapped on the sides of the molds as necessary for further consolidation. After casting, the overlay materials were covered with plastic sheeting and then stripped at one day of age. Specimens which were tested at one day of age were air dried for about $1 / 2$ to 3 hr. prior to testing. Specimens to be tested at three days of age were placed in sealed plastic bags until testing and were air dried for about $1 / 2 \mathrm{hr}$. prior to testing. 
All base concrete and overlay materials were cast and cured at room temperature. The ages of the base concrete and overlay materials when they were tested are given in tables 4 and 5 .

A2. Comparative Test series II: BNL Direct Shear, slant shear, and Uniaxial Tension Bond Test Methods

The mix proportions of base concrete and overlay materials tested are given in table A2. The aggregates and their gradations and cement type were the same as those used for the comparative testing of the two direct shear tests (section Al above). In the LMC overlay material, a styrene-butadiene polymer emulsion (latex) manufactured by Dow Chemical was used in which the polymer comprised about 48 percent by weight of the total emulsion.

\section{A2.1 Base Concrete}

After casting, the specimens of base concrete were covered with plastic sheeting, stripped at 1 day of age, immersed in limesaturated water for 27 days, and then air dried until tested. The base concrete was sawn to the required geometry (either at $90^{\circ}$ or approximately $30^{\circ}$ to the cylinder's longitudinal axis) using a water-cooled, diamond saw blade. All sawn surfaces were sanded using sandpaper and then wiped with a damp towel to remove any debris. Some of the sawn surfaces were lightly sandblasted. The 
sawn or sandblasted section was placed in either a 3 in.diameter by 6 in.-long plastic cylinder mold (type used for molding concrete - special trimming procedures were used for molds for the BNL direct shear specimens) or epoxied in a steel pipe nipple.

\section{A2.2 Bond Test Specimens}

Immediately prior to casting the PCC to be tested at 2 days of age (2 Day-Old PCC) onto the sawn or sandblasted surface of the base concrete, a thin layer of the mortar fraction of the overlay material was applied to the base concrete surface with a brush. Immediately prior to placing the LMC to be tested at 1 day of age (1 Day-0ld LMC), the base concrete surface was first dampened with water and then brushed with a thin layer of the mortar fraction of the overlay material. The 1 in.-thick overlay material used with the BNL test was filled in one layer. All other specimens were filled in three layers. Each layer was rodded for all specimens. All specimens were tapped on the sides of the molds as necessary for further consolidation. After casting, the overlay materials were covered with plastic sheeting. Specimens which were tested at 1 day of age were stripped at 1 day of age and air dried for about 3 to 10 hours prior to testing. Slant shear and BNL direct shear specimens to be tested at 2 days of age were stripped at 1 day of age (air dried during the stripping operation for 5 hours or less) and 
were placed in plastic bags. About 10 to 30 minutes prior to testing, the 2 Day-Old PCC slant shear and BNL direct shear specimens were removed from their plastic bags and tested. The plastic sheeting placed on the uniaxial tension specimens remained on until 1 to 4 hours before being tested at 2 days of age.

All base concrete and overlay materials were cast and cured at room temperature.

A3. BNL Direct Shear Bond Strength versus Compressive Strength for PCC overlays

Tests were conducted by the Virginia Transportation Research Council (VTRC) to determine the relationship between the BNL direct shear bond strength and the compressive strength (Section 5.2.3, table 8, and figure 10). Type II cement was used with the base concrete while Type III cement was used with the overlay concrete. The 28-day compressive strength of the base and overlay concretes were 5280 and $5590 \mathrm{psi}$, respectively. The coarse aggregate was crushed, with a maximum nominal size of $1 / 2$ in. (100 percent passing the $1 / 2$ in. sieve). No grout or mortar fraction was applied to the base concrete prior to placing the PCC overlay. The base concrete was damp ( wet but without puddles of water) prior to placement of the PCC overlay. Table 8 provides information on the curing temperature and the addition of 2 percent calcium chloride by weight of the cement to selected batches. 
APPENDIX B RESULTS AND ANALYSIS OF COMPARATIVE TEST SERIES II

B1. Test Results

Tables BI and B2 list the bond strength and the location and approximate amount of the failure surface from the bond testing of the 2 Day-old PCC and the 1 Day-old IMC overlay materials, respectively, for the BNL, uniaxial tension, and slant shear bond test methods and for the sawn and sandblasted surfaces studied. The information given in tables $\mathrm{B} 1$ and $\mathrm{B} 2$ regarding the location and amount of the failure surface is similar to that used in Comparative Test Series I (Section 5.2.1.1).

As shown in table Bl, with the BNL and the uniaxial tension test results, the failure pattern was almost always in the overlay material, with at least 90 percent of the failure occurring in the overlay material. This failure pattern was as expected, since the average compressive strength of the 2 Day-old PCC overlay material (1.04 ksi, table A2) was substantially lower than that of the base concrete $(7.1 \mathrm{ksi})$. With the slant shear test results, the failure surface occurred both in the overlay material and on the bond plane ("clean"). Again, this appears reasonable due to the difference in strength between the overlay material and its base concrete and also to the possible preferential failure on the bond plane in the slant shear test. 
As shown in table B2, with one exception (uniaxial tension, sandblasted surfaces), the failure mode for the 1 Day-old LMC was predominantly a "clean" failure on the bond plane.

With one exception (uniaxial tension with 1 Day-old LMC), the failure pattern did not appear to be affected by the surface preparation for the same test method and overlay material (tables $B 1$ and $B 2$ ).

B2. Analyses of Test Results

B2.1 Effect of Age at Testing

The effect of specimen age at testing on bond strength for the test methods is shown in figures B1 and B2 for the 2 Day-Old PCC and 1 Day-old LMC overlay materials, respectively.

With the 2 Day-Old PCC overlay material and for both surface preparations, there appeared to be a trend of increasing bond strength as the age at testing increased for the BNL test method (figure BI (a)). As shown in figure BI (c), there appeared to be a trend of increasing bond strength as the age at testing increased for the slant shear shear test method with sawn surfaces, but not with sandblasted surfaces. Because the range in specimen age at testing for the 2 Day-Old PCC overlay tested with the uniaxial tension test method (figure Bl(b)) was shorter 
compared with the other two test methods, it was not clear if there was an aging effect.

With the 1 Day-Old LMC overlay material and for both surface preparations, there appeared to be a trend of increasing bond strength with age of testing for the three test methods (figure B2). An exception was the sawn surface preparation for the BNL test method, where there was no apparent age effect (figure B2 (a)).

When comparing the results of any two test methods, the effect of test age was taken into account by comparing specimens tested at approximately the same age. Table B3 lists the twelve possible comparisons. Each comparison number (Nos. 1 to 12) consists of the pair of test methods being compared with the same surface preparation and overlay material. Within each comparison there are two lines - one line for each of the two methods being compared. In each comparison, specimens from each of the two methods being compared were selected so that the specimens were tested in approximately the same time span, and therefore were tested at approximately the same age. These test age values are referred to as age-adjusted test age values. In addition and shown in parentheses, are entries for the test age based on the complete data set (that is, without removing specimens to obtain comparable ages). If no parenthetical values are listed in a line, then no data were removed and the age-adjusted test age 
values were the same as those for the complete data set.

In table B3, when comparing the age-adjusted test ages between two test methods (same comparison number), the maximum difference between the ages of the first specimens tested was 40 minutes and the maximum difference between the ages of the last specimens tested was also 40 minutes. These differences in age at testing were not considered to have substantially affected the comparisons.

Included in table $B 3$ are the number of replications and the average and coefficient of variation values for the bond strength based on those specimens which were tested at approximately the same age. Unless otherwise stated, these age-adjusted average and coefficient of variation values were used in the comparisons in this report. (Also included in each line are entries for the number of replications and the average and coefficient of variation values for the bond strength based on the complete data set (that is, without removing specimens to obtain comparable ages). If no parenthetical values are listed in a line, then no data were removed and the age-adjusted values were the same as those for the complete data set. See footnote "a", table B3.)

\section{B2.2 Precision of the Test Methods}

As in the case of the analysis given in section 5.2 .1 .2 .2 , it was 
considered inappropriate to use the standard deviation to measure the precision (repeatability about a given base line) because of the relatively large differences in the averages of the results for the three test methods (table B3). Rather, the coefficient of variation (=(standard deviation/average) $\times 100)$, which is a measure of precision adjusted for the magnitude of the average, was used as a measure of the relative precision.

The coefficient of variation values of the uniaxial tension and the slant shear test methods were less than that of the BNL test method in 6 of the 8 comparisons (table B3 - Comparison Nos. 1 to 8 ). This trend, though not statistically significant, suggests that the relative precision of the uniaxial tension and the slant shear test methods may be better than that of the BNL test method.

\section{B2.3 Bond-Strength Comparisons}

There were substantial differences in bond strength when comparing the test methods (Comparison Nos. 1 to 12 , table B3), which were attributed primarily to their different test geometries.

g Based on the approximation using sach's test statistic [15] as given in footnote "b" in section 5.2.1.2.2, only Comparison No. 8 was considered statistically significant. 
The bond strength comparisons given in table B3, when combined with field-performance data, should be useful in the future development of performance criteria based on the uniaxial tension bond test method.

It should be noted that all the bond strength comparisons in table B3 are for relatively weak overlay concrete, with compressive stengths of about 1000 and 2300 psi (table A2). Additional data would be needed to establish comparisons at higher concrete strengths.

B2.4 Ratio of slant Shear Bond Strength to Compressive Strength of Base Concrete

Values of the ratio of the slant shear average bond strength (computed by dividing the failure load by 7.07 in. ${ }^{2}$, tables Bl and B2) to that of the compressive strength of the base concrete (6700 to $7100 \mathrm{psi}$, table A2) were 0.17 for the 2 Day-old PCC and both surface preparations and 0.24 (sawn surface) and 0.27 (sandblasted surface) for the 1 Day-old LMC. This ratio represents the fraction of the strength of the slant shear composite specimen (overlay material and base concrete) relative to the compressive strength of the base concrete. The low ratio

I Average bond strengths were based on the complete data sets given in tables B1 and. B2 (i.e., the age-adjusted results in table B3 were not used). 
values in this study reflect the relatively low strength of the overlay material (water/cement ratio of 0.85 for the 2 Day-old PCC and corresponding 2 day- and 28 day-old compressive strengths of 1040 and 2260 psi, respectively) and also the early age of testing (either at 1 day (LMC) or 2 days (PCC).

As the strength of the slant shear composite specimen approaches that of the base concrete, the value of the ratio should approach unity. If the base concrete strength is desired to be the basis for comparison, a selected ratio value could provide auxillary bond information, which could be used in conjunction with performance criteria based on another bond test method.

As discussed earlier, it is difficult to obtain and test field cores in the slant shear configuration. Therefore, it would be difficult to develop field-based performance criteria for the slant shear method. 


\section{TABLES}

70 
ક๙

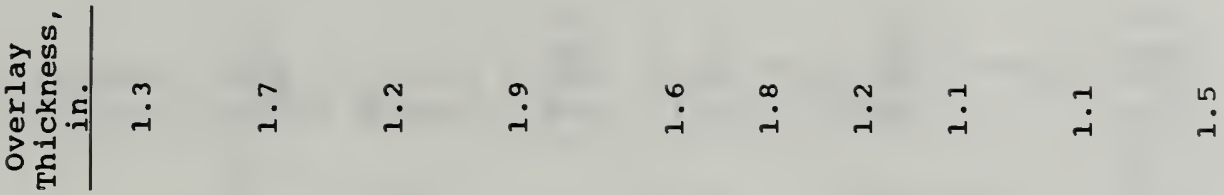

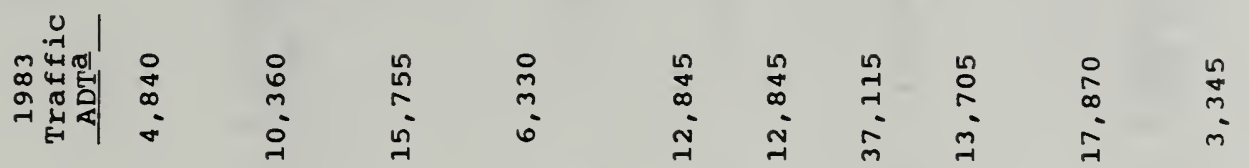

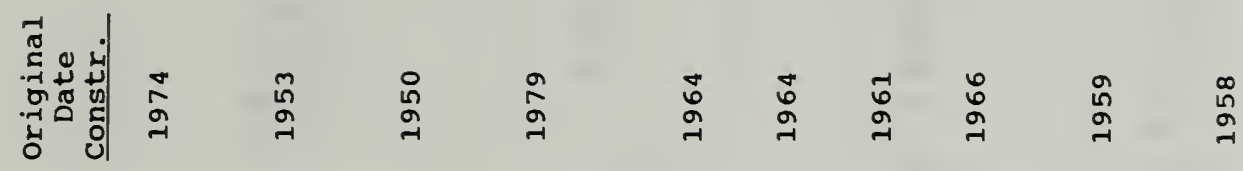

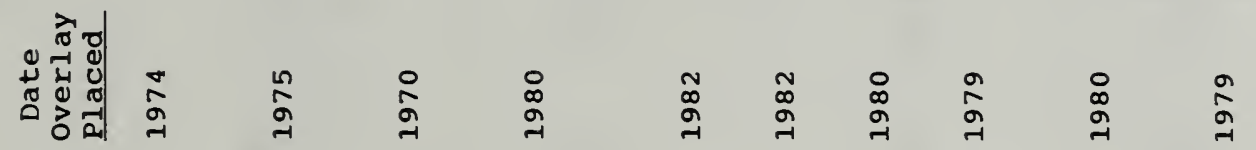

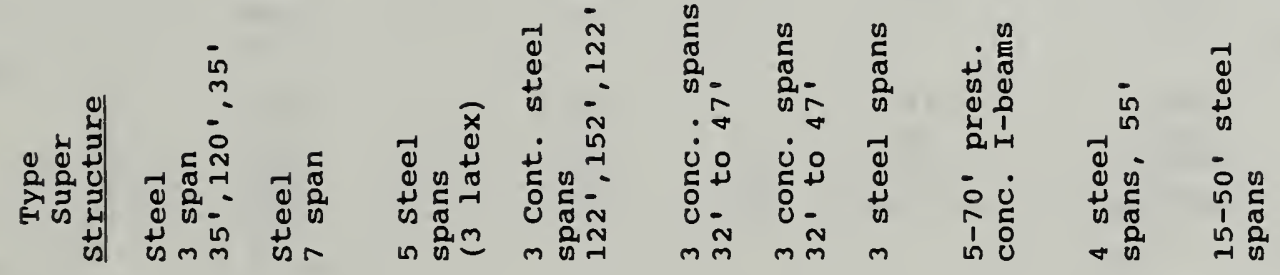

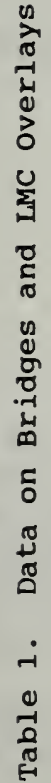

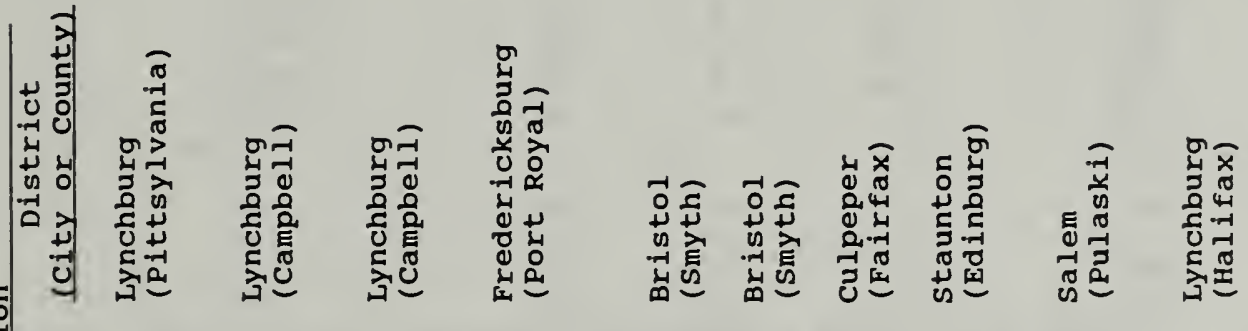

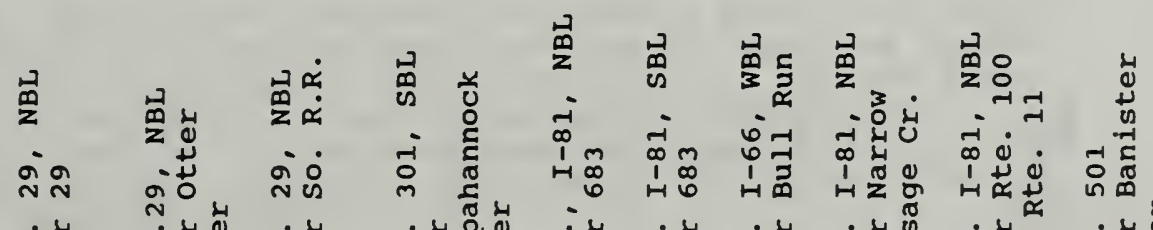

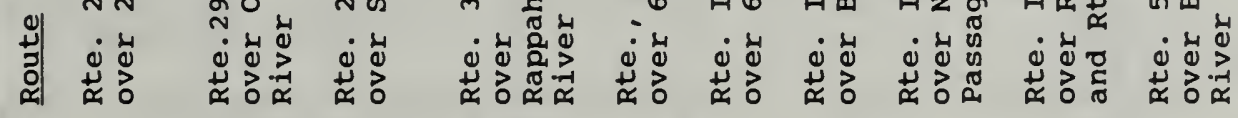

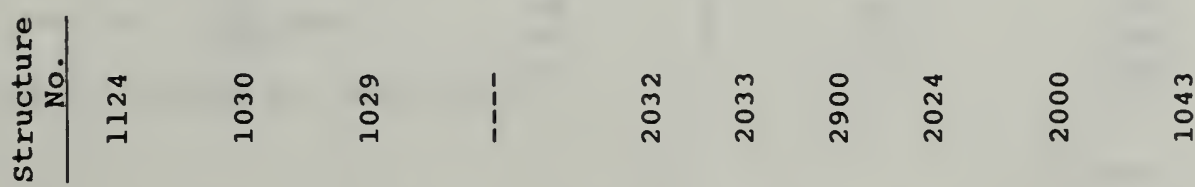

त्]

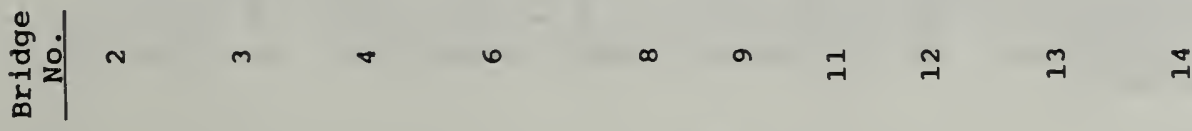


Table 2. BNL Direct shear Bond strength Data for LMC overlays (VTRC Data) for Field Cores

Bridgea Shear Bond

$2 A-670$

$2 \mathrm{~B}$

$2 \mathrm{C}$

$2 \mathrm{x}$

$2 \mathrm{~s}$

130

$3 A \quad 890$

$3 B \quad 670$

$3 C \quad 770$

$3 \mathrm{x} \quad 780$

$35 \quad 110$

$3 \mathrm{CV}(\%) \quad 14$

$4 \mathrm{~A} \quad 490$

$4 B \quad 650$

$\begin{array}{ll}4 C & 930\end{array}$

$\begin{array}{ll}4 \mathrm{x} & 690 \\ 4 \mathrm{~s} & 220\end{array}$

$4 \mathrm{CV}$ (\%) 32

$6 \mathrm{~A}$

6B 930

$6 \mathrm{C} \quad 1,110$

$6 \mathrm{x} \quad 930$

$65 \quad 180$

$6 \mathrm{CV}$ (8) $\quad 19$

$8 A \quad 760$

$8 B \quad 660$

$8 C \quad 510$

$8 \mathrm{x} \quad 640$

$85 \quad 130$

$9 \mathrm{~A} \quad 890$

$9 \mathrm{~B} \quad 790$

$9 \mathrm{C} \quad 790$

$9 \mathrm{x} \quad 820$

95

$9 \mathrm{cv}$

(z)

60

7.0

$11 \mathrm{~A}$

$11 B$

$11 \mathrm{C}$

$11 \mathrm{x}$

$11 \mathrm{~s}$

$11 \mathrm{CV}$ (\%)

$12 \mathrm{~A}$

$12 B$

$12 \mathrm{C}$

$12 \mathrm{x}$

$12 \mathrm{~s}$

$12 \mathrm{cv}$

$13 \mathrm{~A}$

$13 \mathrm{~A}$

$13 \mathrm{C}$

$13 \mathrm{x}$

135

$13 \mathrm{cV}$

$14 \mathrm{~A}$

$14 \mathrm{~B}$

$14 \mathrm{C}$

$14 \mathrm{x}$

$14 \mathrm{~s}$

$14 \mathrm{CV}$ (\%)
760

750

780

760

20

2.0

530

550

540

10

(\%)

640

850

750

150

(z) 20

530

710

510

580

110

19

\section{Failure Mode, के \\ Bond Base}

50

10

30

30

0

30

10

20
80
80
60
--

20

0
40

20

20

0

10

20

10

--

10

10

10

10

--

30

10

35

25

--

10

30

20

$--$

30

30

30

-

40
--

20

40
--
0

20

0
0
30

10

--

0
0
60

60

20

$0 \quad 70$

15

$-5$

50

70

--

50

70

60

10

10

10

10

50

$--$

90

90

90

90
Shear strength

Base Conc. . psi

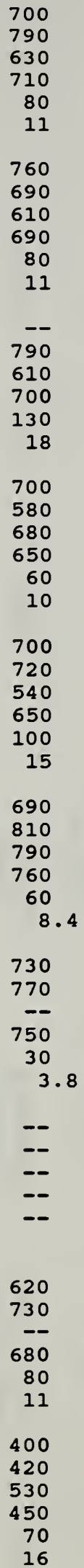

700

710

11

760

690

11

790

610

18

680

650

60
10

700

540

650

15

690

760

8.4

730

770

750

3.8

$-$

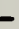

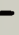

20

\begin{tabular}{ll}
30 & 620 \\
70 & 730 \\
\hline
\end{tabular}

16

a First number is bridge number from table 1 and $A, B, C$ designate replications of cores (e.g., $2 A=$ Bridge No.2, replication $A)$; $\mathrm{x}$ = average, $\mathbf{s}=$ standard deviation, $\mathrm{Cv}=$ coefficient of variation $=(\mathrm{s} / \mathrm{x}) 100 ;(\mathrm{e} . \mathrm{g}, \mathrm{,} 2 \mathrm{x}$ is average of replications $\mathrm{A}, \mathrm{B}$, and $C$ for Bridge No.2). 
Table 3 Bond Strength Data for Iowa Direct Shear Bond Test Method - 3 in. Thick PCC Overlays on PCCa Slabs on Grade (Field Cores)

\begin{tabular}{|c|c|c|c|c|c|c|}
\hline $\begin{array}{l}\text { Location } \\
\text { (County in Iowa) }\end{array}$ & $\begin{array}{l}\text { Shear Bond } \\
\text { stress (psi) }\end{array}$ & Minimum & Maximum & Avg. b & std. Dev. b & $C V(q)^{b}$ \\
\hline \multirow[t]{2}{*}{ Black Hawk } & $\begin{array}{r}297 \\
1238 \\
1337 \\
1103 \\
1205 \\
1052 \\
930 \\
760 \\
670\end{array}$ & & & & & $=$ \\
\hline & & $\begin{array}{l}297 \\
670^{c}\end{array}$ & $\begin{array}{l}1337 \\
1337^{\mathrm{C}}\end{array}$ & $\begin{array}{c}955 \\
1037^{c} \mathrm{C}\end{array}$ & $\begin{array}{l}330 \\
235^{c}\end{array}$ & $\begin{array}{l}34.6 \\
22.7^{c}\end{array}$ \\
\hline \multirow[t]{2}{*}{ Woodbury } & $\begin{array}{l}569 \\
764 \\
525 \\
509 \\
517\end{array}$ & & & & & \\
\hline & & 509 & 764 & 577 & 107 & 18.6 \\
\hline
\end{tabular}

Pottawattamie

d

550

$\begin{array}{rr}\text { Pottawattamie } & 835 \\ 505 \\ 947 \\ 963 \\ 1074 \\ 597\end{array}$

505

1074

820

224

27.3

a 4 in. diameter field cores; surface preparation prior to placing overlay consisted of grinding, sand blasting and grouting (grout was cement, sand, and water or cement and water). The grout was applied to dry base concrete just prior to placement of PCC overlays. The ages of the overlays when the cores were tested were not available, but were estimated for most of the cores to be less than or equal to 1 year.

b $\quad$ Avg. = average, std. Dev. = standard deviation, CV $(\xi)=$ coefficient of variation = (Std. Dev./Avg.) $\times 100$

C Value of 297 psi excluded

d 17 individual values not available 
Table 4. Band Strength and Location and Amount of Failure Surface for 1 Dayold Portland Cement concrete overlay Material Banded to 43-Day old portland cement concrete

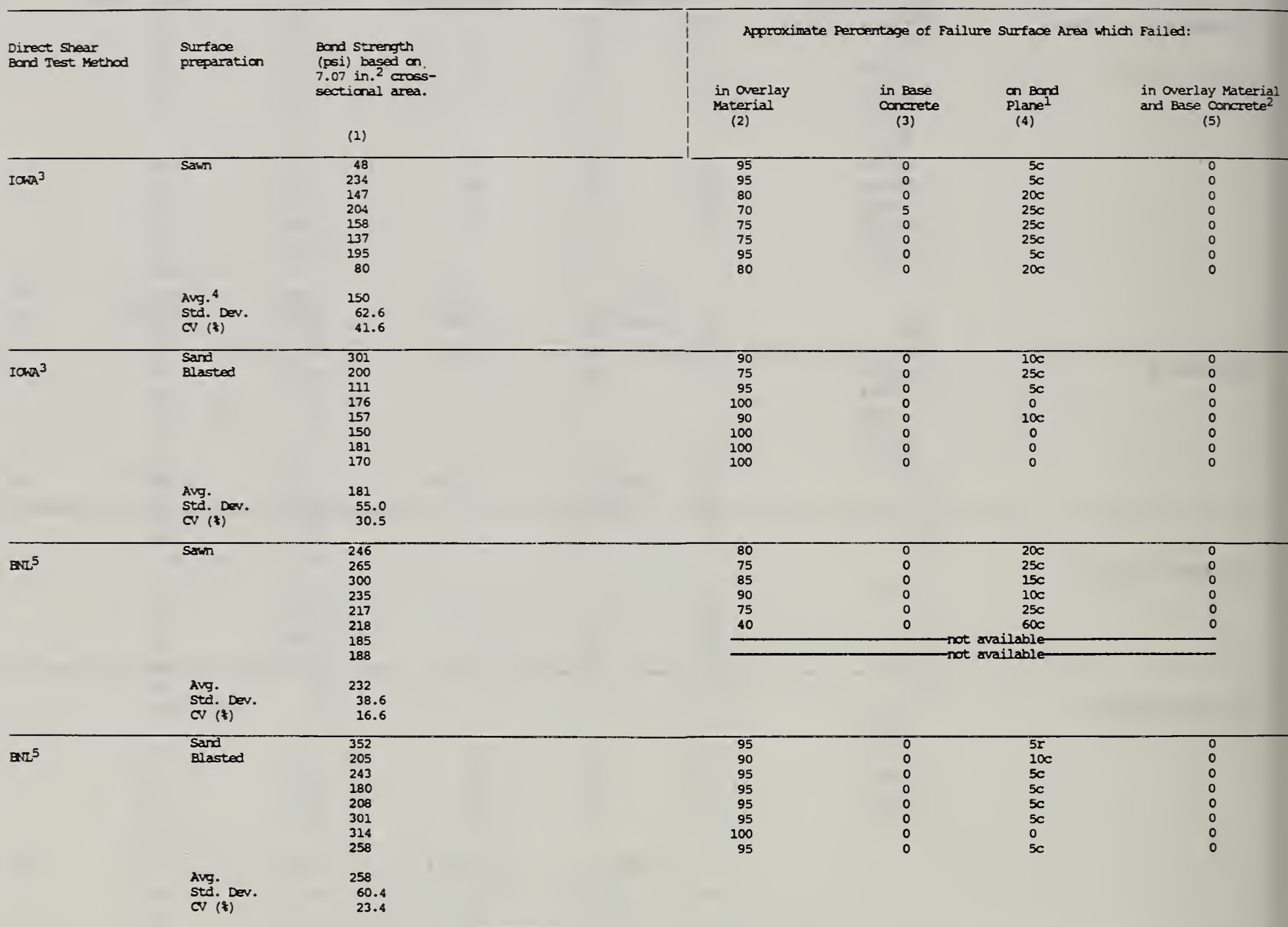

$1 \quad c=$ clean break, neither in overlay material nor base concrete; $I=$ thin layer of overlay material adhered on base concrete.

2 Failure process produced a eeparate piece which cantained both the overlay material and the base cancrete bonded together.

3 Loaded at appoximately $5300 \mathrm{lbf} . / \mathrm{min}$.

4 Avg. = average, Std. dev. = standard deviation, $c v=$ coefficient of variation = (standard deviation /average) $\times 100$.

5 Loaded at approximately $1200 \mathrm{lbf} . \mathrm{min}$. 
Table 5. Bond Strength and Location and Amount of Failure for 3 Day-old portland Cement Concrete Overlay Material Bonded to 45-Day Old Base portland cement concrete

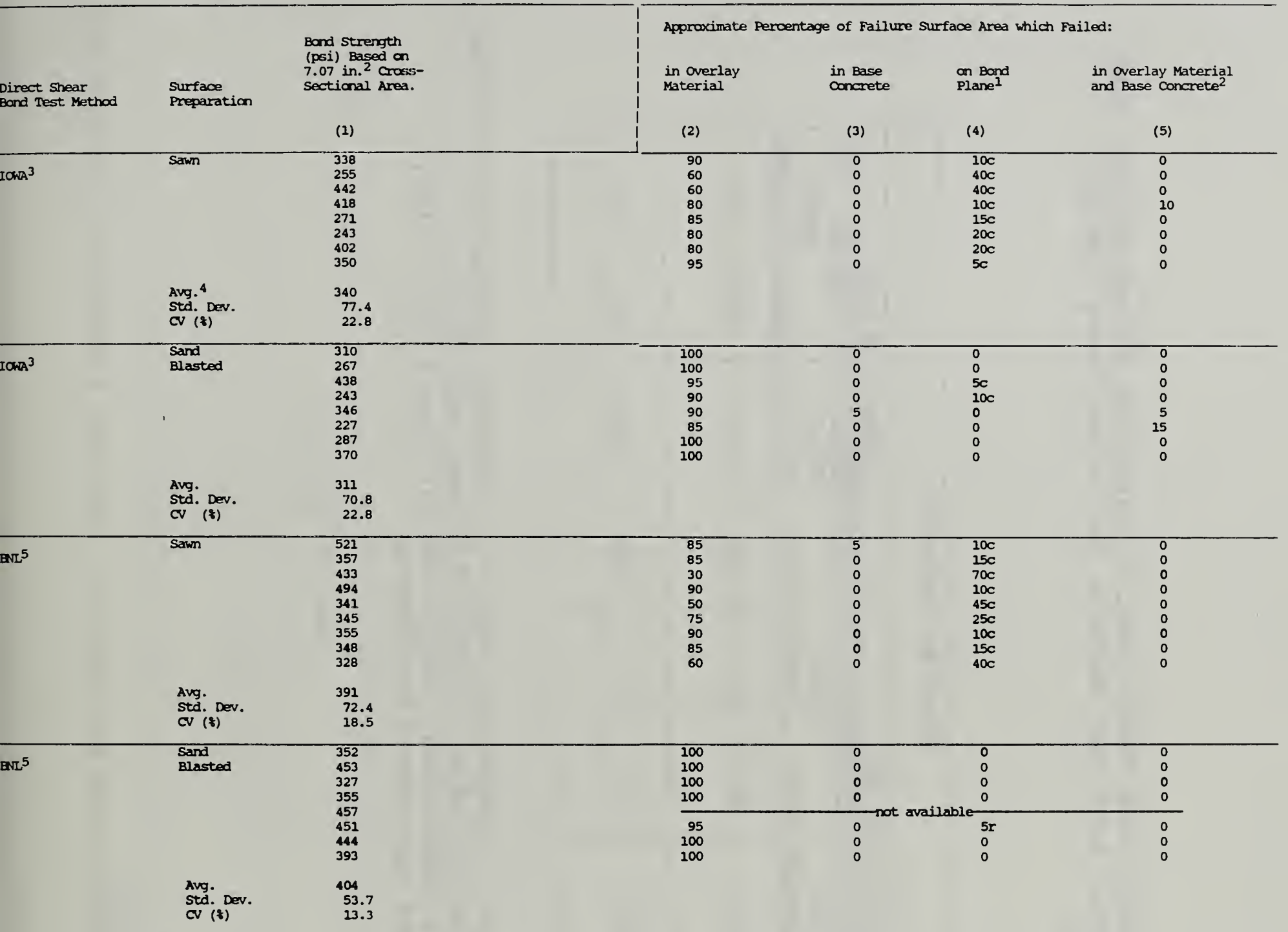

$c=$ clean break, neither in overlay material nor base cancrete; $r=$ thin layer of overlay material adhered an base concrete.

Failure process produced a separate piece which contained both the overlay material and the base cancrete bonded together.

Loaded at approximately $5300 \mathrm{lbf} . / \mathrm{min}$.

Avg. = average, std. dev. = standard deviation, $\mathrm{Cv}=$ coefficient of variation = (standard deviation/average) $\times 100$.

Looded at approximately $1200 \mathrm{lbf}$./min. 
$\frac{4}{3}$

म્

롬

U

잉

ข

(1)

ว $>$

त 0

$m$

윰ำ

+

( 1

다

$>$

44

0

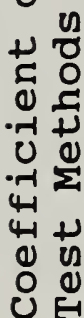

ฮี ฮี

म단

कृ

ᄃ

युำ

ए

0 L

ช 00

담

ค

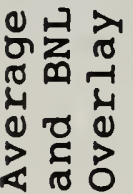

$\dot{0}$

है

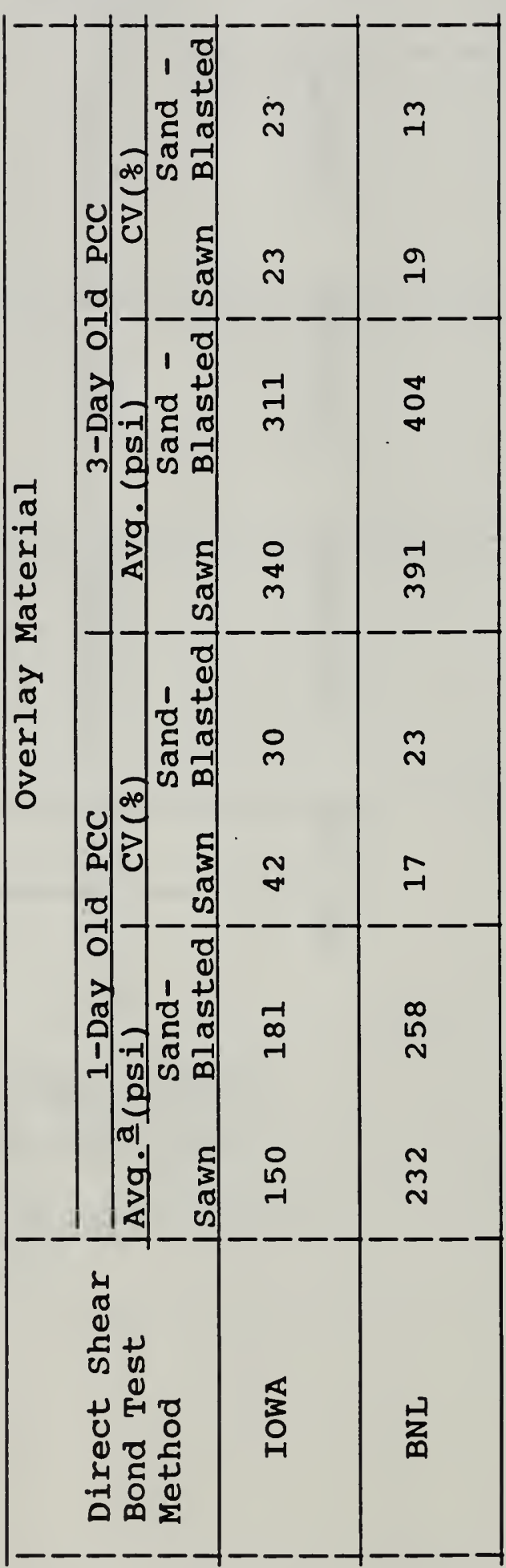

岁

苟

न 9

$>$

\&

$+$

可

正

4 का

。这

U

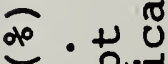

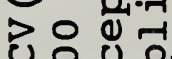

어워

¿ $x$

\% $-a$

돔

政

है

ब

$-4>-1$ U

的尔造

돈

出

0.70

ตั

कथ 0 .

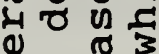

$0 \Omega$

\%

॥ ซ

ह.न-

का म

$\sum_{\alpha}$ U E

$\sigma$ 


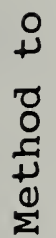

范

意

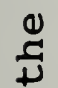

ซ

茨

F

焉

:

$\nsubseteq$

岁

吾

$\stackrel{乛}{+}$

ซ

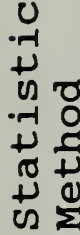

苞

岁

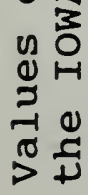

$\dot{r}$

崩

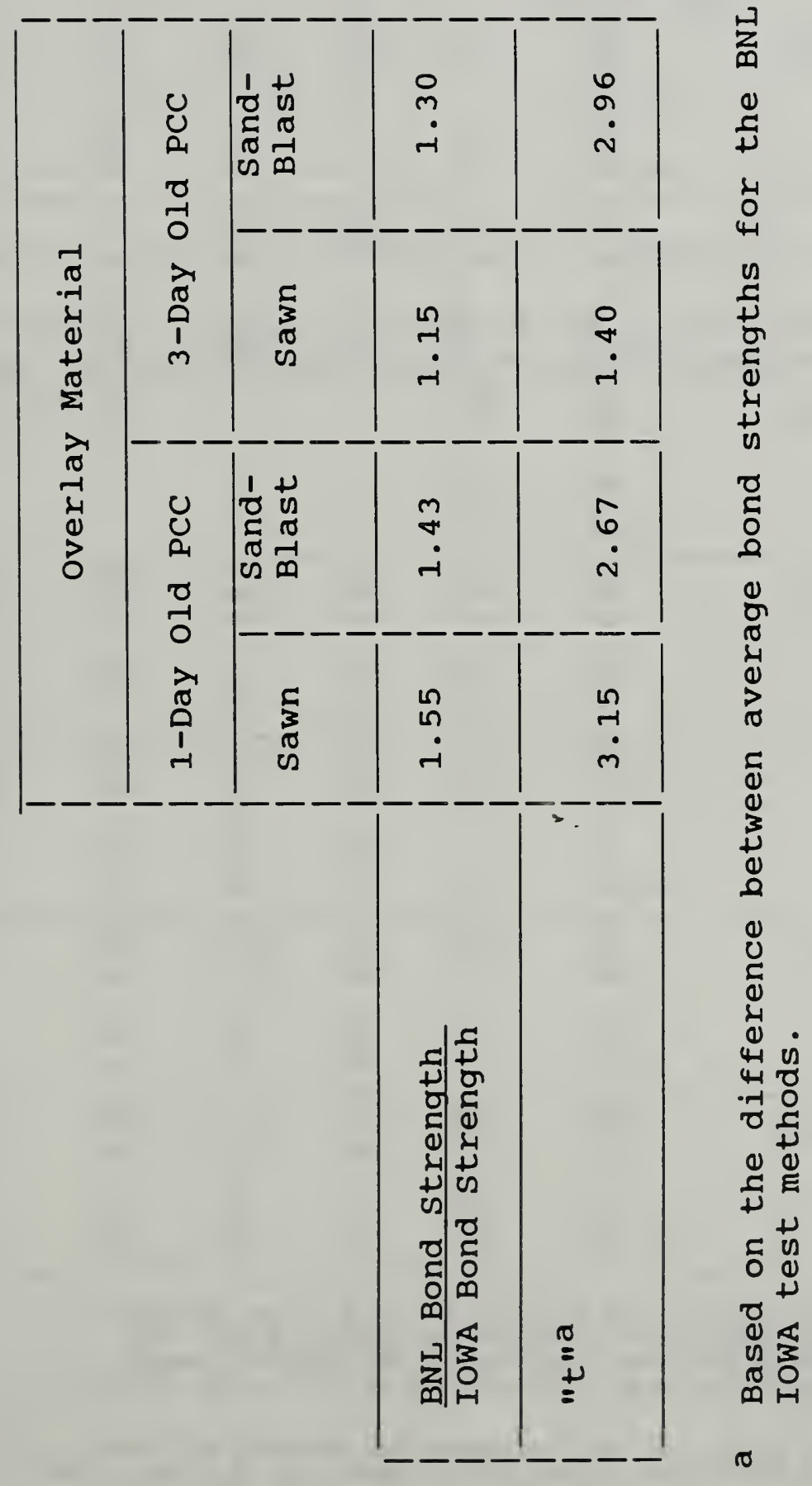


Table 8. Compressive - BNL Bond Strength Data for PCC overlays (Tested at the Virginia Transporation Research Council Laboratories)

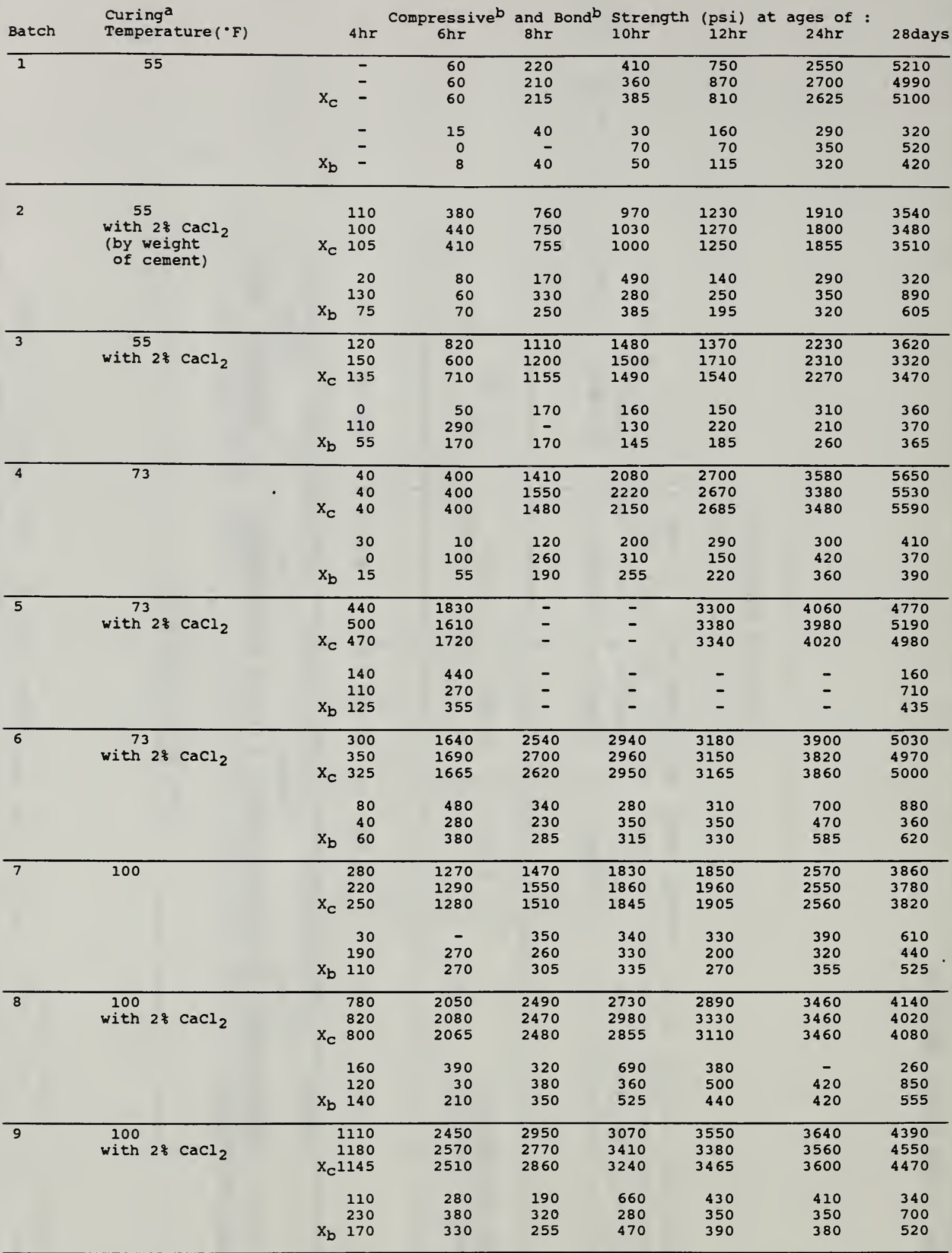

a Bond specimens containing PCC overlays were cured at the indicated temperature for cure durations less than or equal to $24 \mathrm{hr}$. Bond specimens cured 28 days were first cured at the indicated temperature $\left(55,73\right.$, or $\left.100^{\circ} \mathrm{F}\right)$ for $24 \mathrm{hr}$. and then cured at $73^{\circ} \mathrm{F}$ for the remainder of their cure.

b For each batch and at each age, two compressive strengths are listed first followed by the average compressive strength, $x_{C}$, and then two BNI shear bond strengths are listed followed by the average BNL strength, $\mathrm{x}_{\mathrm{b}}$. Compressive and bond strengths were calculated by dividing the failure load (lbf.) by the 12.57 in. 2 cross-sectional area for 4 in. diameter specimens. The 28-day compressive strength of the base concrete was 5280 psi. 
Table 9 Summary of the Direct Shear Bond strength Results from Field Cores Tested Using the IOWA and BNL Test Methods

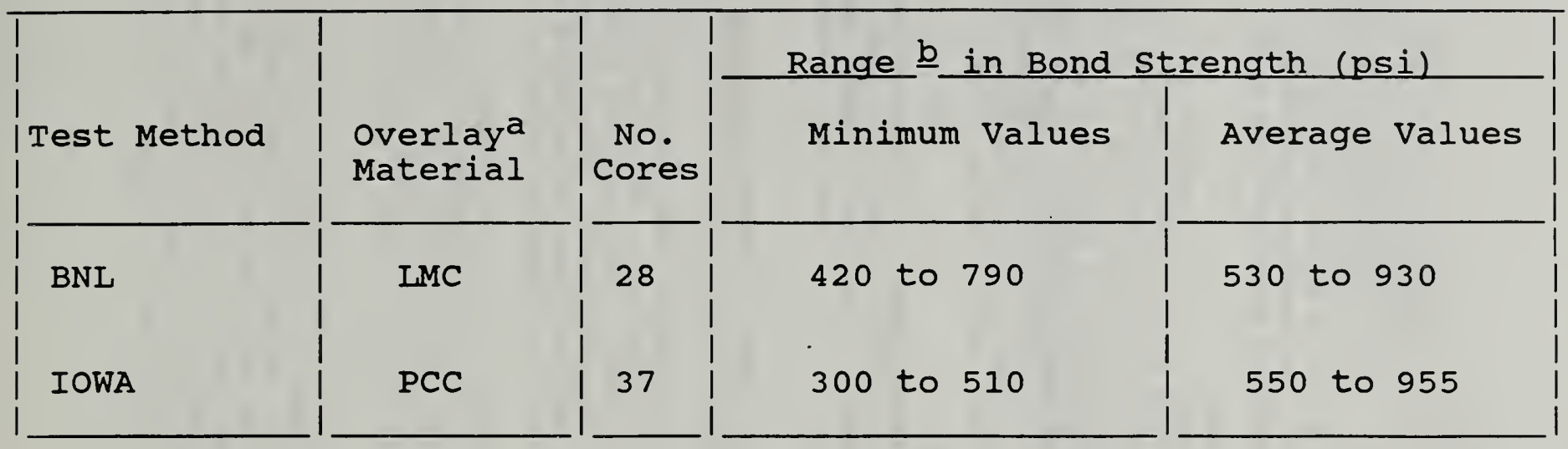

a $\quad$ LMC = latex modified concrete; PCC = portland cement concrete

b The minimum and average values of each data set were determined and the ranges of the minimum and average values were then found (see tables 2 and 3 ). 


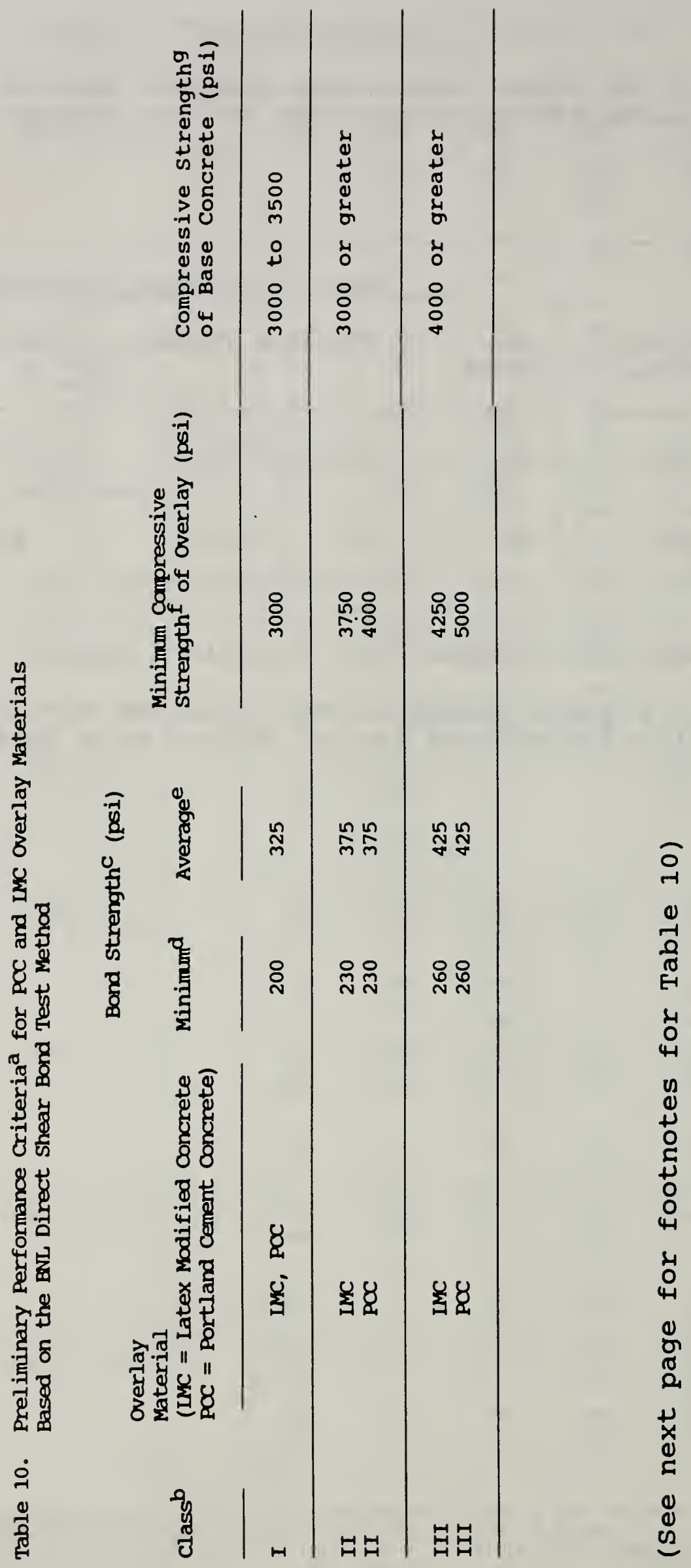


g.

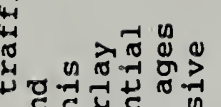
- है क्ष 近和 的 की वृत् † व

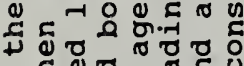

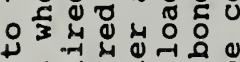
क

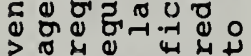
का

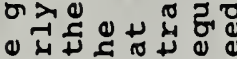
व

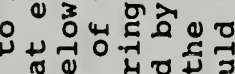
ด \& वे ब

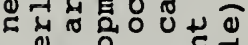

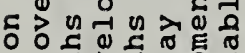
₹

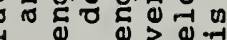

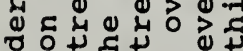

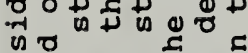

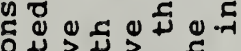

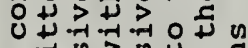
$7 \vec{E}{ }^{3}$ 员 o -7 40 o

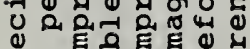

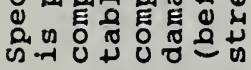

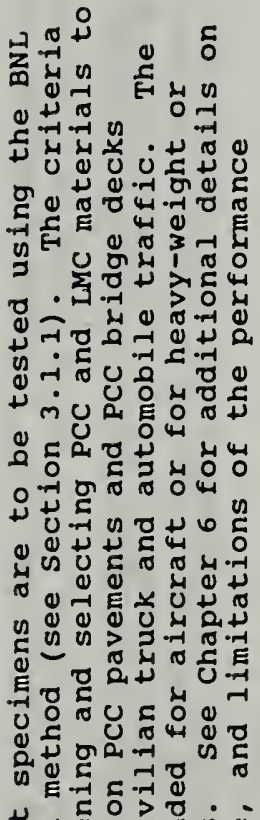

苟药 రீ प्रें क्यु

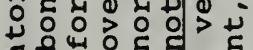
幽出。 กั

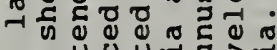

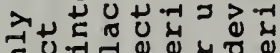
ᄃ

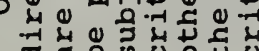

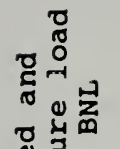

ס

त丮范

.

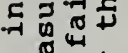

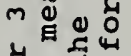

क्ष

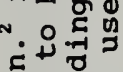

ศึ

임

$\therefore$ 出

冴昆

ำ

牙出㟧员

०ण

대융

幽荡

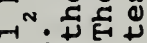

है

牙

ำ

कीन न

की

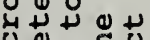

O०

व

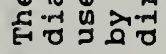

ㅁำ

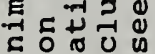

$=8 \mathrm{~g}$ ब

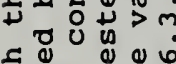

造

๑

ติ

- 0 क

ब

$\pi=\infty$ 范

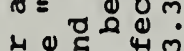

हा

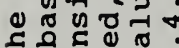

ए

㟧

$4+4$ व

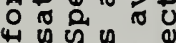

का एँ क क

बi

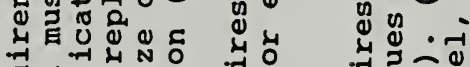

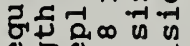

울 500 †

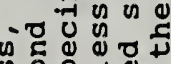

ธ

जूञ

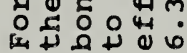

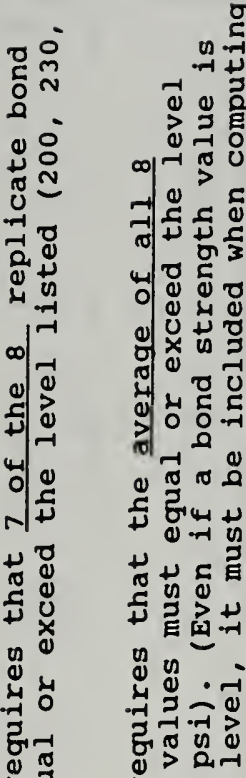

4 近 $=$

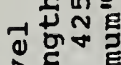

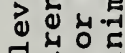

$=$ 员

牙罂=

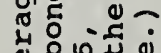

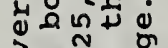

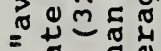

ช.

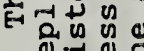

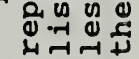

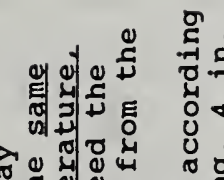

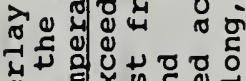

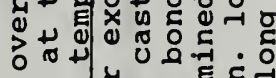

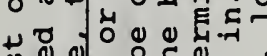

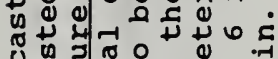

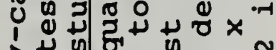

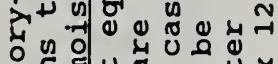

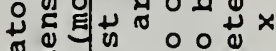

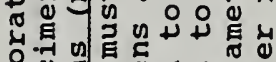

워의

त

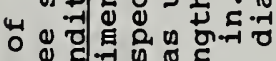

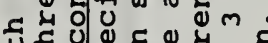

मูำ

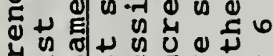

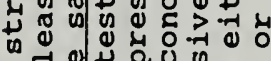

D

>

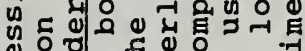

ठ

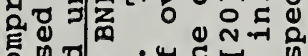

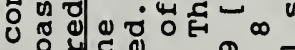

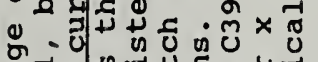

कृष

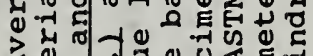

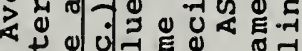

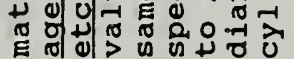

文

की 苟

तेํㅠ ₹

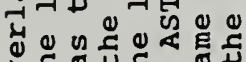

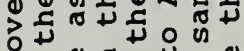

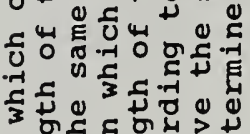

ธ

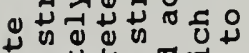

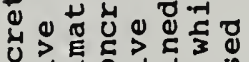

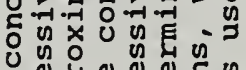

o s.

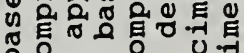

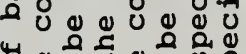

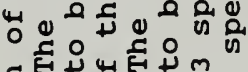

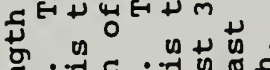

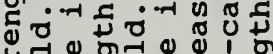

में

का

ए人

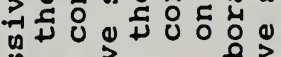

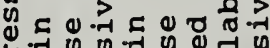

罂

हुㅇำ

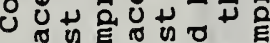

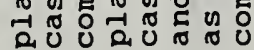

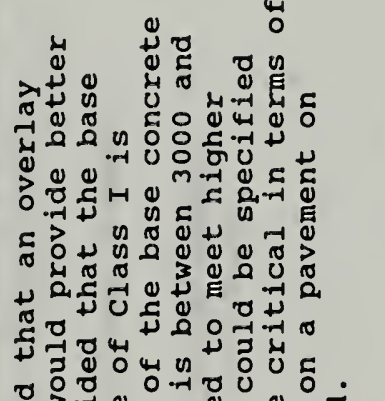

वृ

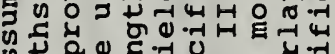

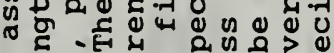

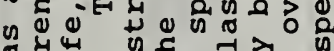

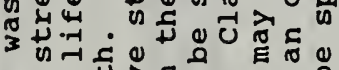

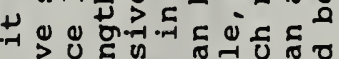

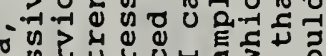

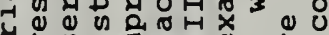
㟧 o

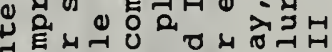

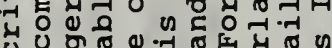

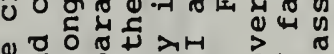

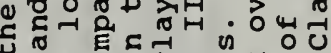
ดृ

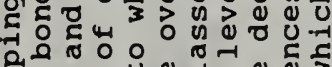

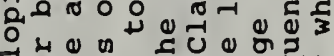

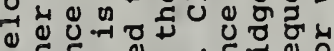
उ कू ญ ช

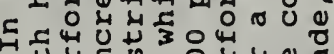
†
भิ ते

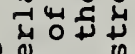
ठิ

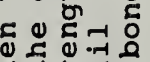

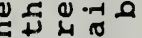

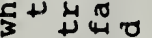
० विं ขै ठึ.

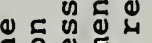
今

is + o ธू 00 \% $>$ 엉 को का एक จ 四面

o o o 至

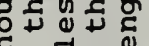
का ये 50 in in मी

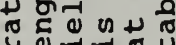
ठำ 7 ज 0 D

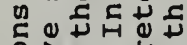
$0 \geqslant 5$ ठै

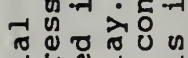
गै पूँ

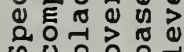

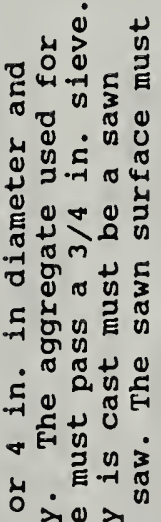

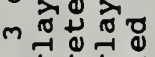

๑ू

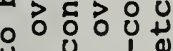

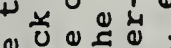

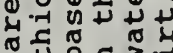
पू

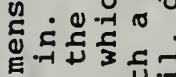
ปิ $\sim$ ช

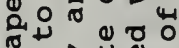
का

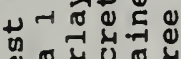
बत

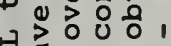
空我记

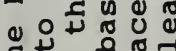

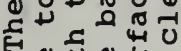

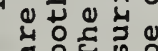

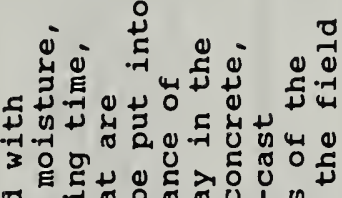
ठ

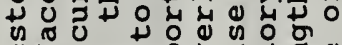

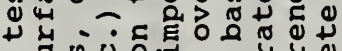
म ช व ठ 。 प्र

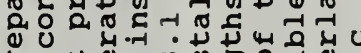

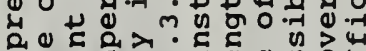
10 ป气

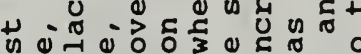

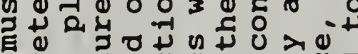
प ต

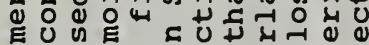
兒 ठ

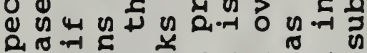

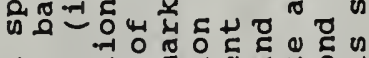

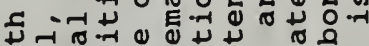
Oتन

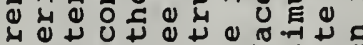

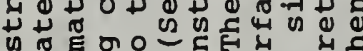
E 5 स

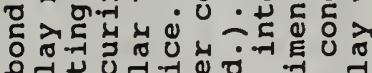
ब च

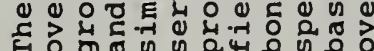



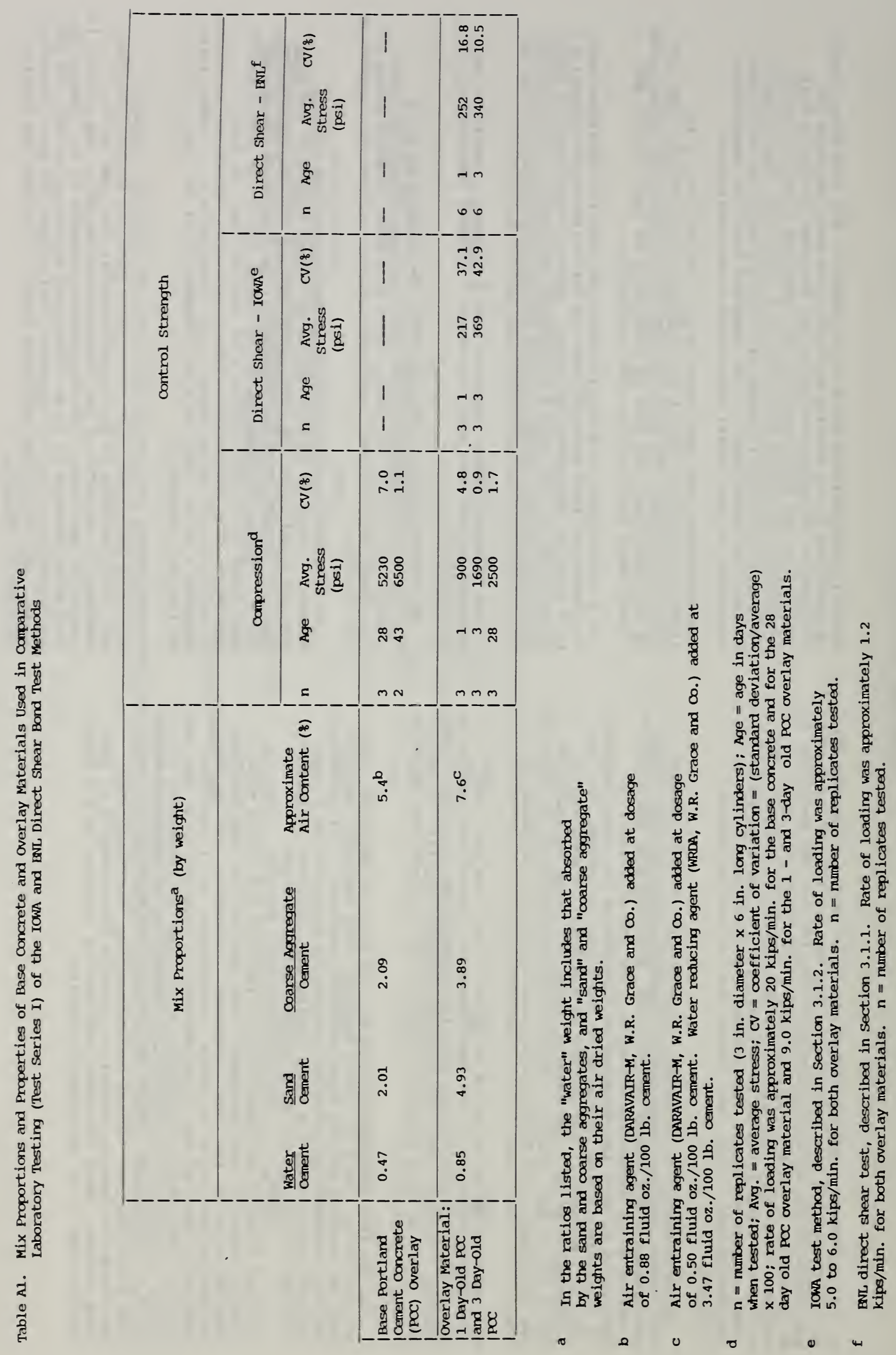

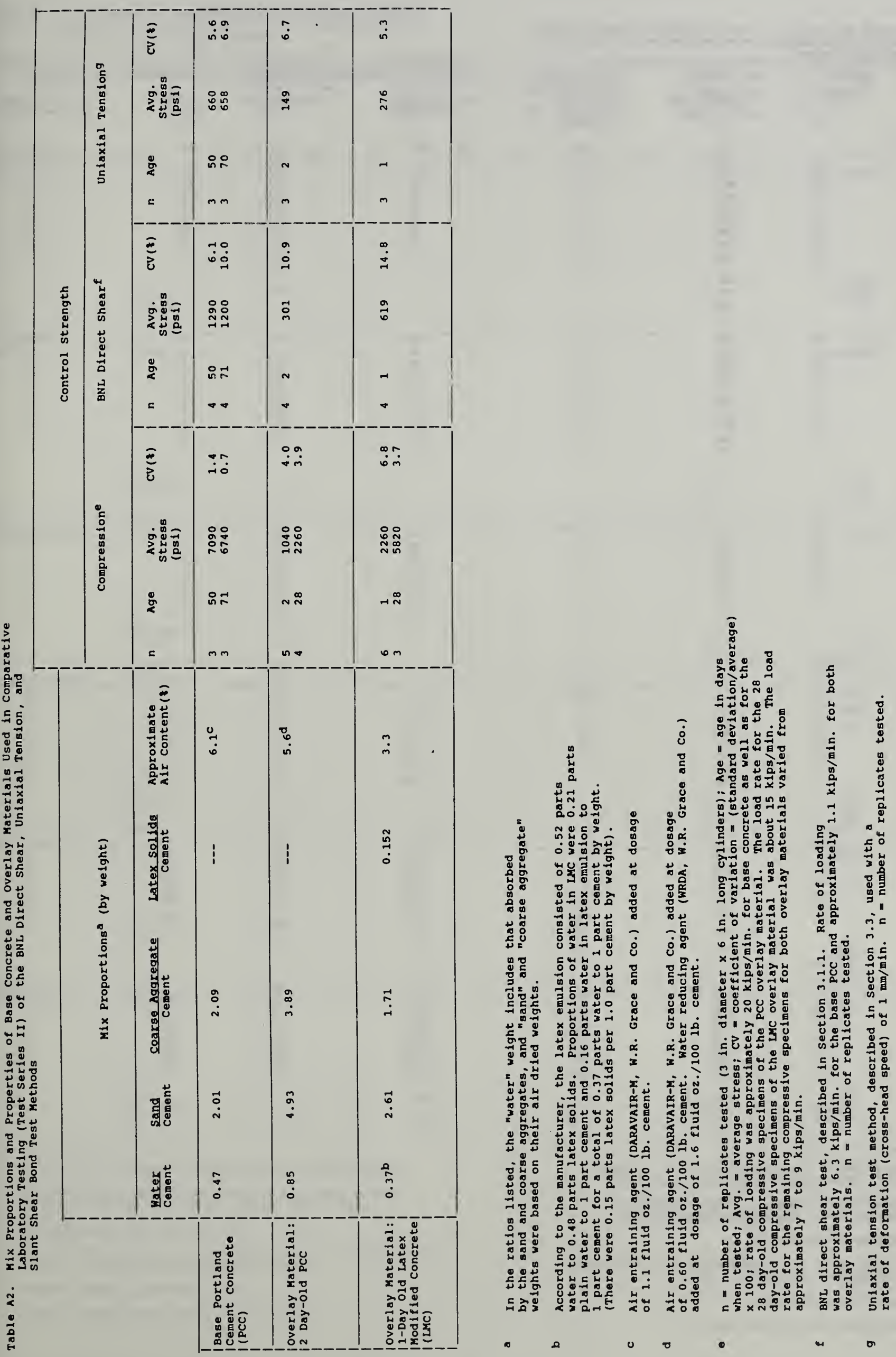
Table B1. Band Strength and Location and Amount of Failure surface for 2 Dayportland cement concrete

Band Test Methad Surface

$\begin{array}{ll}\text { Surface } & \text { Band strength } \\ \text { Preparation } & \text { (psi) Based on } \\ & 7.07 \text { in. } 2 \text { cross }\end{array}$

7.07 in 2 cross Sectional Area.

(1)

221
259
492
267
284
385
248
306

Avg. 4

Std.Dev.

$\mathrm{Cv}(\boldsymbol{z})$

308

89.0
28.9

\begin{tabular}{lll}
\hline Direct shear & Sand & 26 \\
$\mathrm{BNL}^{3}$ & Blasted & 310 \\
& & 334 \\
& & 243 \\
& & 277 \\
& & 385 \\
& & 31 \\
& & 291 \\
& & 412
\end{tabular}

$\begin{array}{ll}\text { Avg. } & 330 \\ \text { Std. Dev. } & 72.6\end{array}$

$\begin{array}{ll}\text { CV (t) } & 72.6 \\ & 22.0\end{array}$
Approximate percentage of Failure surface Area wich Failed:

in overlay

(psi) Basad on

14.14 in. 2

Elliptical Ban Plane Area.

(2)

$\begin{array}{lr}260 & 95 \\ 310 & 100 \\ 334 & 95 \\ 243 & 100 \\ 277 & 95 \\ 385 & 95 \\ 316 & 100 \\ 291 & 100 \\ 412 & 100 \\ 472 & 100\end{array}$

(3) (4) (5)

in Base
concrete

an Band

Material

(5)

in overlay Material

100
90
95
95
95
95
95
100

0
0
5
0
0
0
0
0

0
$10 c$
0
$5 c$
$5 c$
$5 c$
$5 c$
0

(6)

0
$10 c$
0
$5 c$
$5 c$
$5 c$
$5 c$
0

\begin{tabular}{|c|c|c|c|c|c|c|c|}
\hline & $\begin{array}{l}\text { Avg. } \\
\text { Std. Dev. } \\
\text { Cv (t) }\end{array}$ & $\begin{array}{l}330 \\
72.6 \\
22.0\end{array}$ & & & & & \\
\hline \multirow[t]{2}{*}{ Uniaxial Tensian 5} & Sawn & $\begin{array}{l}193 \\
184 \\
187 \\
178 \\
184 \\
200 \\
181 \\
193\end{array}$ & & $\begin{array}{r}100 \\
100 \\
95 \\
100 \\
100 \\
100 \\
100 \\
100\end{array}$ & $\begin{array}{l}0 \\
0 \\
0 \\
0 \\
0 \\
0 \\
0 \\
0\end{array}$ & $\begin{array}{l}0 \\
0 \\
5 r \\
0 \\
0 \\
0 \\
0 \\
0\end{array}$ & $\begin{array}{l}0 \\
0 \\
0 \\
0 \\
0 \\
0 \\
0 \\
0\end{array}$ \\
\hline & $\begin{array}{l}\text { Avg. } \\
\text { Std. Dev. } \\
\text { CV (z) }\end{array}$ & $\begin{array}{r}187.5 \\
7.4 \\
3.9\end{array}$ & & & & & \\
\hline \multirow[t]{2}{*}{ Uniaxial Tension 5} & $\begin{array}{l}\text { Sand } \\
\text { Blasted }\end{array}$ & $\begin{array}{l}207 \\
171 \\
200 \\
187 \\
181 \\
184 \\
181 \\
198\end{array}$ & & $\begin{array}{l}100 \\
100 \\
100 \\
100 \\
100 \\
100 \\
100 \\
100\end{array}$ & $\begin{array}{l}0 \\
0 \\
0 \\
0 \\
0 \\
0 \\
0 \\
0\end{array}$ & $\begin{array}{l}0 \\
0 \\
0 \\
0 \\
0 \\
0 \\
0 \\
0\end{array}$ & $\begin{array}{l}0 \\
0 \\
0 \\
0 \\
0 \\
0 \\
0 \\
0\end{array}$ \\
\hline & $\begin{array}{l}\text { Avg. } \\
\text { Std. Dev. } \\
\text { CV }(t)\end{array}$ & $\begin{array}{r}188.7 \\
11.9 \\
6.3\end{array}$ & & & & & \\
\hline \multirow[t]{2}{*}{ Slant shear 6} & Sawn & $\begin{array}{l}1250 \\
1270 \\
1170 \\
1090 \\
1190 \\
1010 \\
1320\end{array}$ & $\begin{array}{l}623 \\
635 \\
585 \\
544 \\
596 \\
507 \\
662\end{array}$ & $\begin{array}{l}40 \\
25 \\
45 \\
50 \\
35 \\
40 \\
70\end{array}$ & $\begin{array}{l}0 \\
0 \\
0 \\
0 \\
0 \\
0 \\
0\end{array}$ & $\begin{array}{l}60 c \\
75 c \\
55 c \\
50 c \\
65 c \\
60 c \\
30 c\end{array}$ & $\begin{array}{l}0 \\
0 \\
0 \\
0 \\
0 \\
0 \\
0\end{array}$ \\
\hline & $\begin{array}{l}\text { Avg. } \\
\text { Std. Dev. } \\
\text { CV (z) }\end{array}$ & $\begin{array}{c}1190 \\
108 \\
9.1\end{array}$ & $\begin{array}{r}593 \\
53.8 \\
9.1\end{array}$ & & & & \\
\hline \multirow[t]{2}{*}{ Slant Shear 6} & $\begin{array}{l}\text { Sand } \\
\text { Blasted }\end{array}$ & $\begin{array}{l}1180 \\
1230 \\
1190 \\
1210 \\
1180 \\
1200 \\
1240\end{array}$ & $\begin{array}{l}591 \\
613 \\
596 \\
557 \\
589 \\
601 \\
619\end{array}$ & $\begin{array}{l}55 \\
50 \\
55 \\
80 \\
60 \\
75 \\
75\end{array}$ & $\begin{array}{l}0 \\
0 \\
0 \\
0 \\
0 \\
0 \\
0\end{array}$ & $\begin{array}{l}45 c \\
50 c \\
45 c \\
20 c \\
40 c \\
25 c \\
25 c\end{array}$ & $\begin{array}{l}0 \\
0 \\
0 \\
0 \\
0 \\
0 \\
0\end{array}$ \\
\hline & $\begin{array}{l}\text { Avg. } \\
\text { Std. Dev. } \\
\text { CV (t) }\end{array}$ & $\begin{array}{r}1190 \\
40.6 \\
3.4\end{array}$ & $\begin{array}{r}595 \\
20.4 \\
3.4\end{array}$ & & & & \\
\hline
\end{tabular}

$1 \quad c=$ clean break, neither in overlay material nor base concrete;

$r=t h i n$ layer of overlay material achered on base concrete.

2 Failure process produced a separate piece which contained both the overlay material and the base concrete banded together.

3 Loaded at approximately $210016 \mathrm{~b} . / \mathrm{min}$.

4 Avg. = average, std. dev. = standard deviation, $c v=$ coefficient of variation $=$ (standard deviation/average) $\times 100$.

5 Tested at crosshead speed of $1 \mathrm{um} / \mathrm{min}$.

6 Laaded at approximately 7,000 to 9,000 $\mathrm{lbf}$./min. 
Table B2. Band Strength and Location and Amount of Failure surface for 1 Day-old Latex Modified Concrete Overlay Material Banded to 70 Day-Old portland cement Concrete

\begin{tabular}{llll}
\hline Bond Test Method & Surface & Bond strength & Band Strength \\
& preparation & (psi) based an & (psi) based an \\
& & 7.07 in. Cross- & 14.14 in.2 \\
& Sectional Araa. & Elliptioal Band \\
& & Plane Area.
\end{tabular}

(1)

(2)

\begin{tabular}{|c|c|}
\hline $\begin{array}{l}\text { Direct Shaar } \\
\text { ENI, }{ }^{3}\end{array}$ & Sawn \\
\hline
\end{tabular}

$\begin{array}{ll}368 & 0 \\ 351 & 0 \\ 324 & 0 \\ 287 & 0 \\ 335 & 0 \\ 403 & 0 \\ 307 & 0 \\ 422 & 0 \\ 420 & 0\end{array}$

Approximate Fercentage of Failure surface Area which Failed:

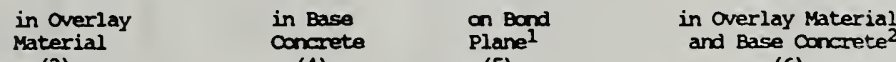

$\begin{array}{ccc}\text { (3) } & \text { Concrete } & \text { Plane } \\ \text { (4) } & \text { (5) } & \text { and Base Can }\end{array}$

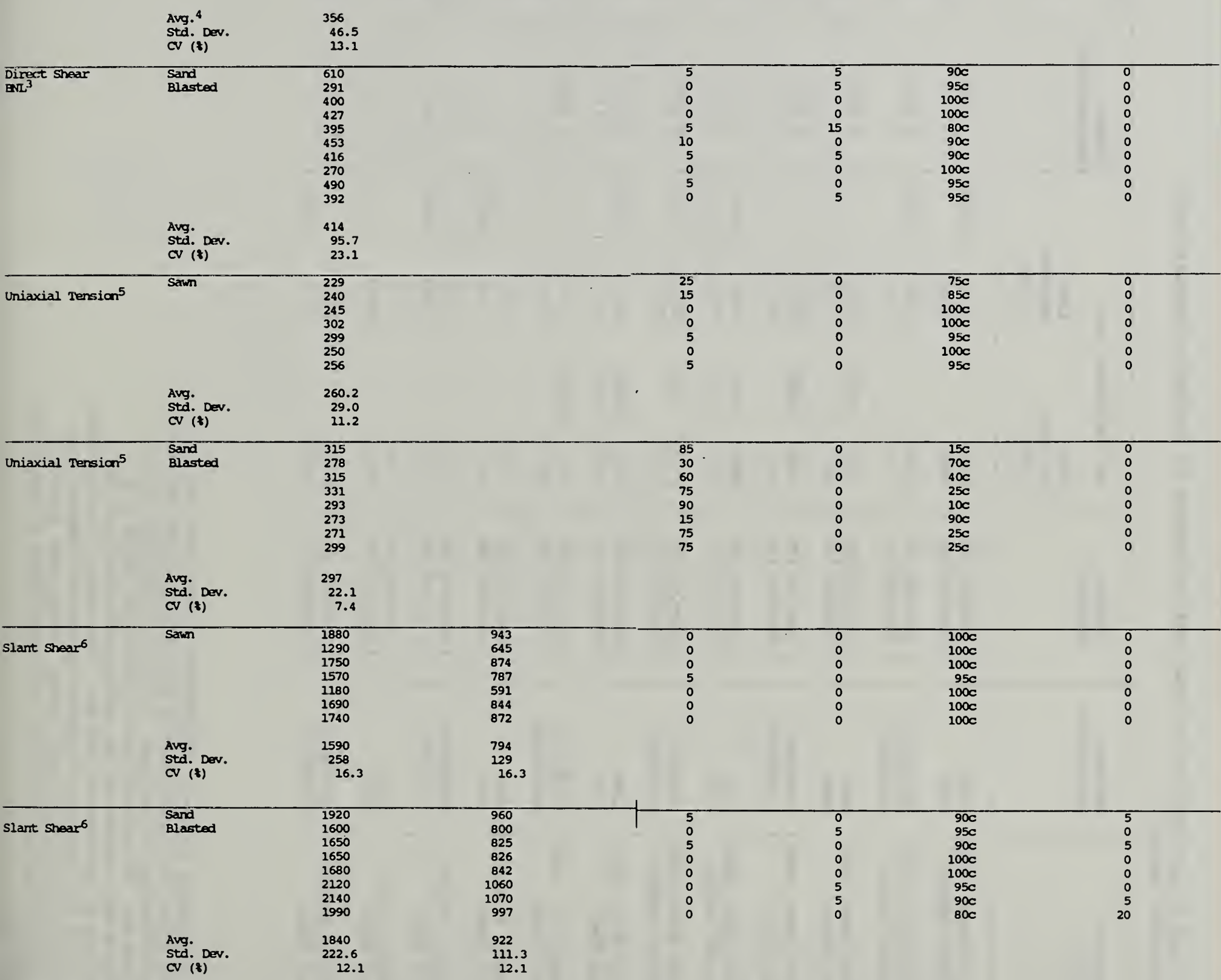

$1 \mathrm{c}=$ clean break, neither in overlay material nor base concrete

2 Failure process produced a separate piece which contained both the overlay material and the base concrete bonded together.

3 Loaded at approximately $1100 \mathrm{lbf} . / \mathrm{min}$.

4 Avg. = average, std. dev. = standard deviation, $\mathrm{Cv}=$ coefficient of variation = (atandard deviationvaverage) $\times 100$.

5 Tested at crosshead speed of 1 mminin.

6 Loaded at approximately 7,000 to $9,000 \mathrm{lbt} . / \mathrm{min}$. 


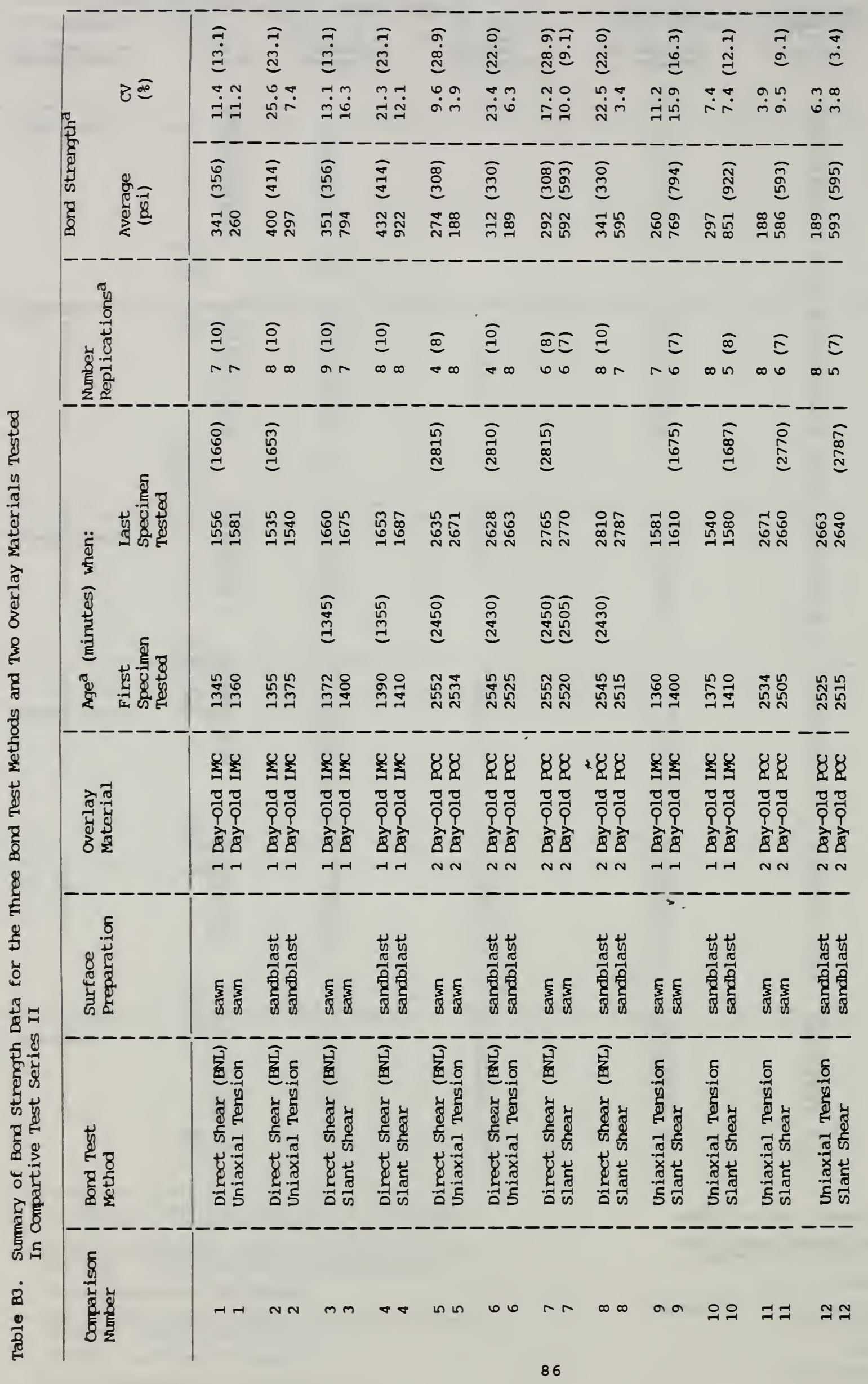


FIGURES 

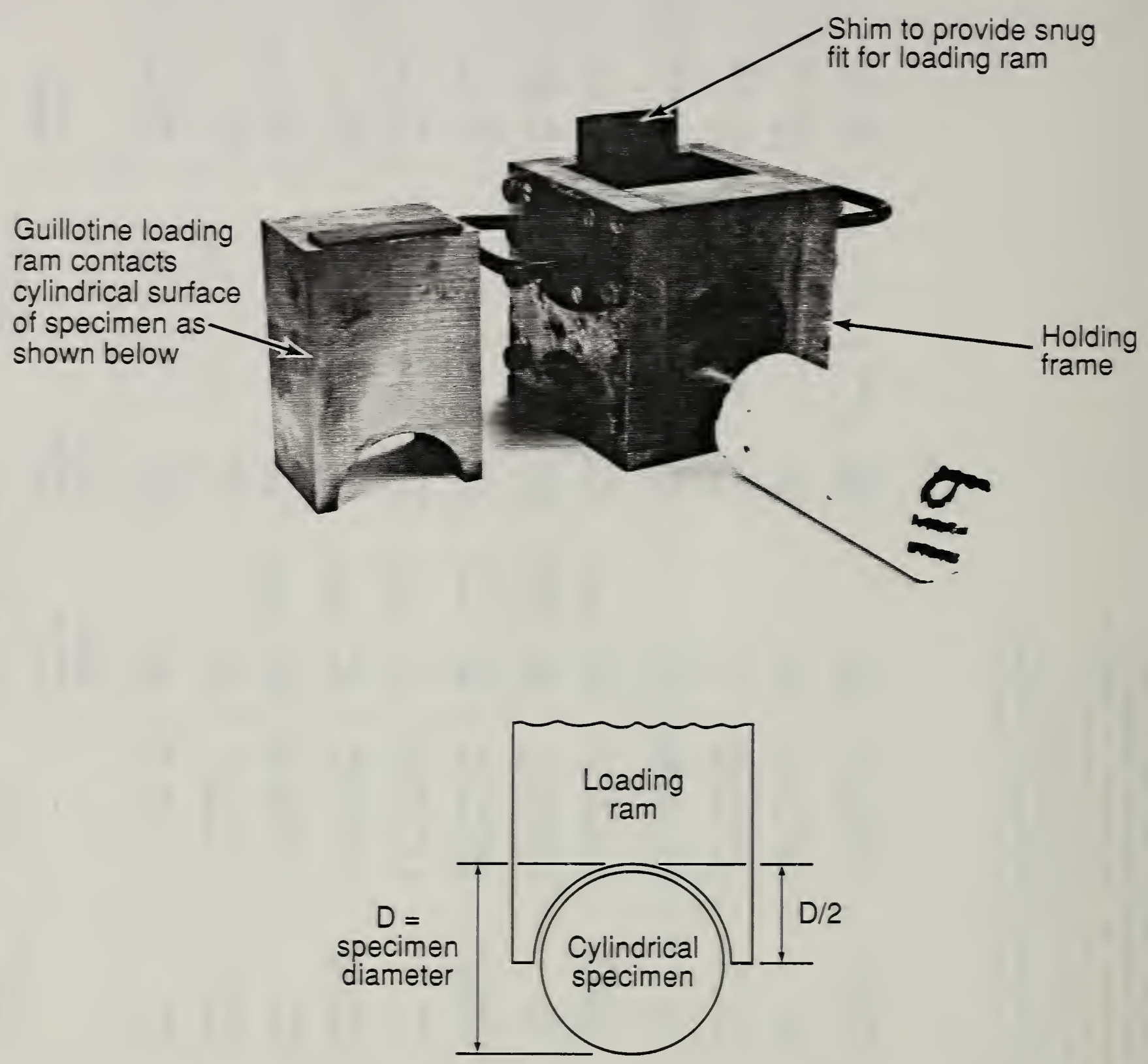

Figure 1. BNL direct shear bond apparatus with holding frame and loading ram. A 3-in. diameter bond specimen is shown prior to inserting it into the holding frame. This test setup was used for all NIST tests (bond specimens, plain overlay material, or base concrete sheared). A somewhat similar test setup was used for the Virginia Transportation Research Council testing - see section 3.1 .1 . and references 12 and 13 . 

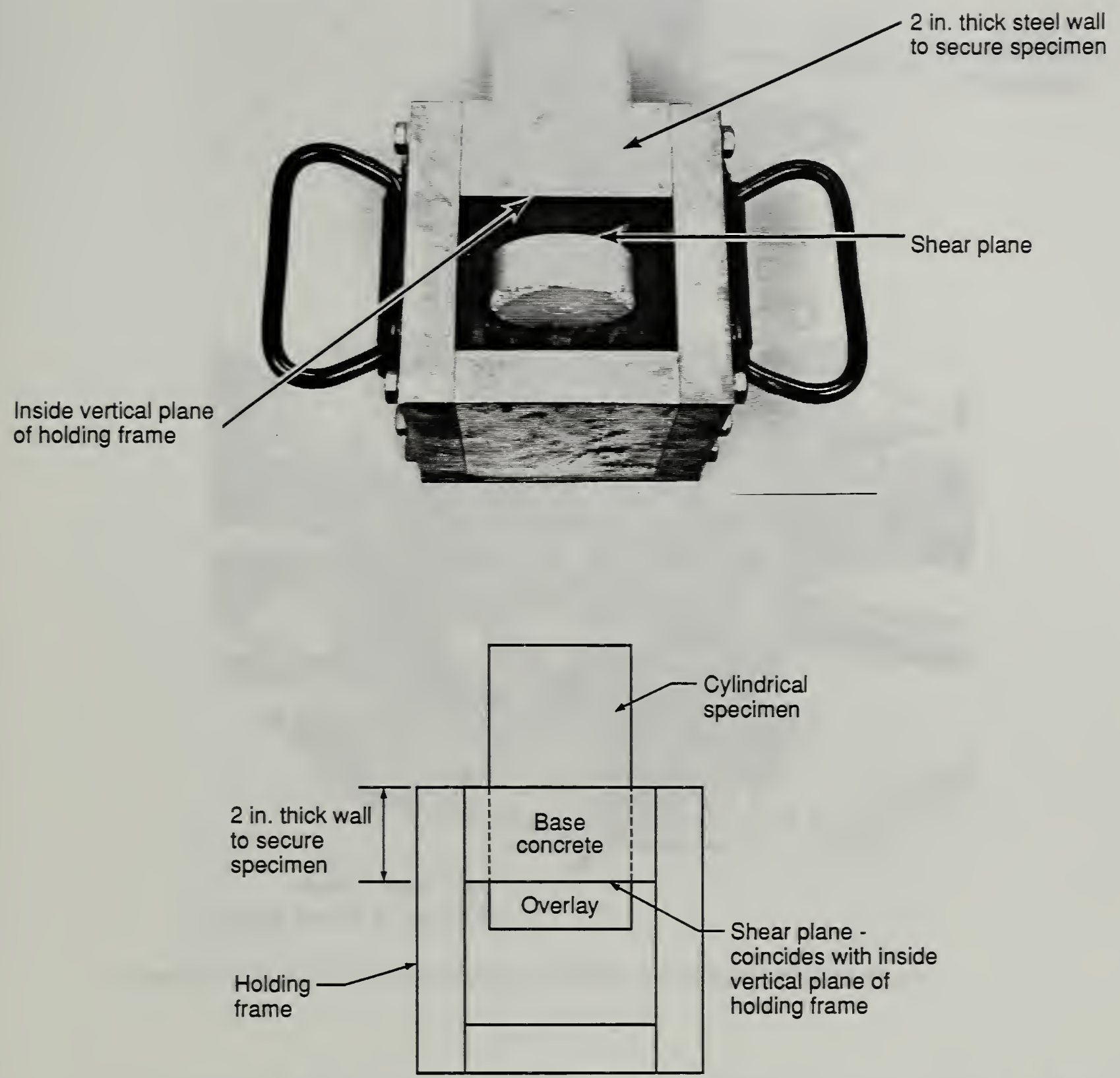

Figure 2. A 3 in.-diameter bond specimen inserted in holding frame showing the 1 in.-thick overlay section to be "guillotined" in direct shear. A 2 in.-thick steel wall thickness was used to hold the the specimen. This was the NIST test setup - see section 3.1 .1 . 

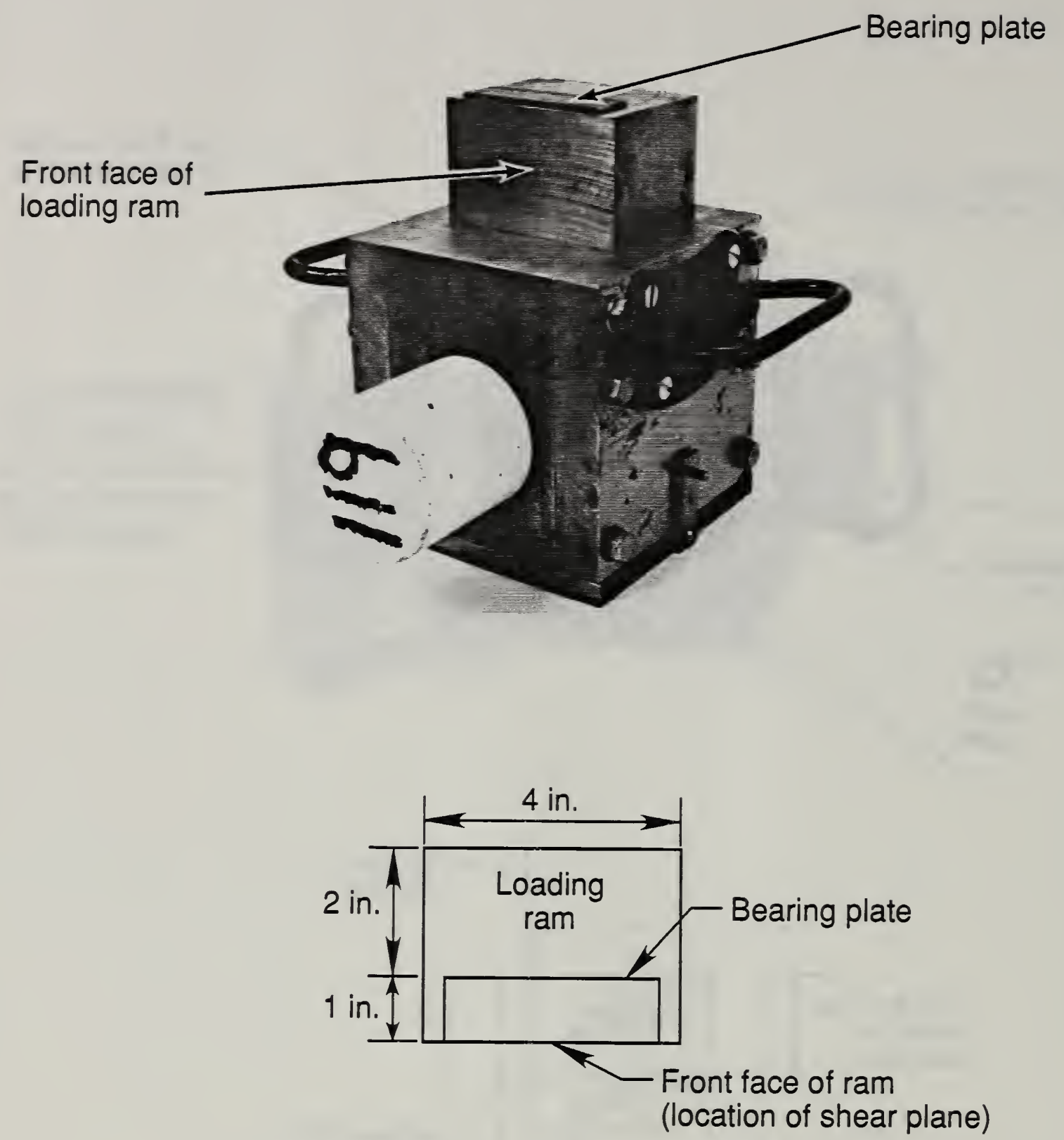

Sketch of bearing plate position on loading ram

Figure 3. BNL direct shear bond test apparatus with a bond specimen in apparatus ready to apply a shear load, by applying a compressive force to the loading ram. Note the use of a 1.0 in.wide by $3 / 16$ in.-thick by $3-1 / 8$ in.-long steel bearing plate which rested on top of the loading ram. The front face of the bearing plate ( $3 / 16$ by $3-1 / 8$ in.) was flush with the front face of the loading ram, and centered with respect to the width of the loading ram, and also centered with respect to the sphericallyseated bearing block (not shown) of the testing machine. (The thickness and length of the bearing plate varied (thickness: 3/16 and $1 / 2$ in.; length: $3-1 / 8$ and 4 in.). A 1 in. width was always used.). The purpose of the plate was to help transmit the applied load to the center of the overlay being sheared. 


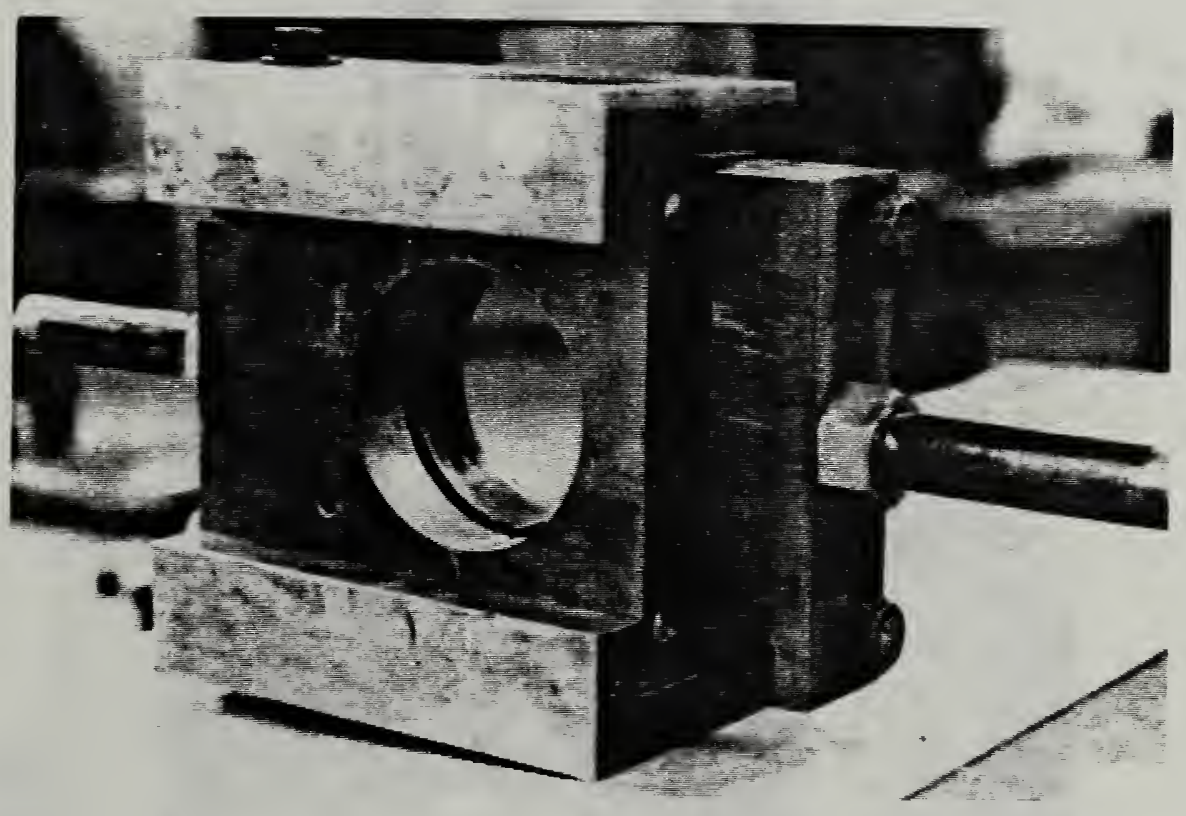

Figure 4. IOWA testing jig, not in testing machine. 


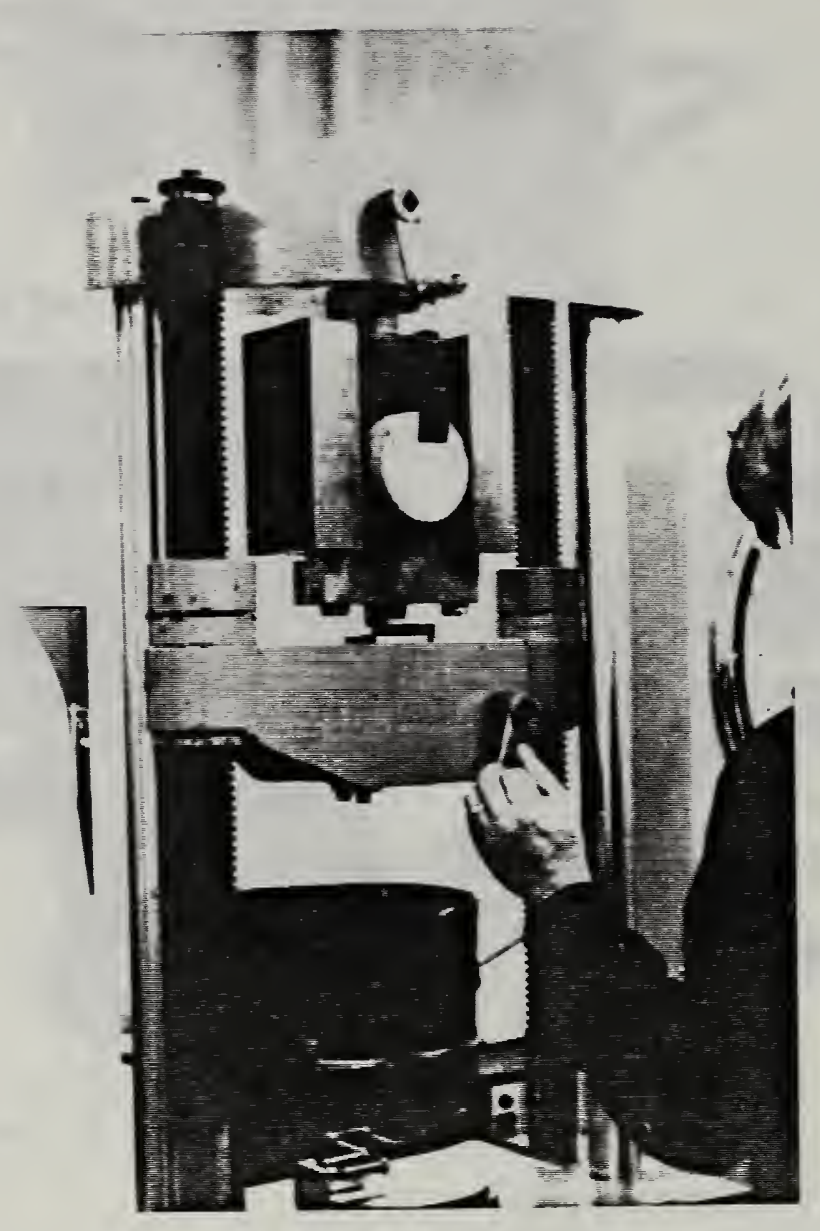

Figure 5. Specimen in IOWA testing jig, which is in testing machine. 


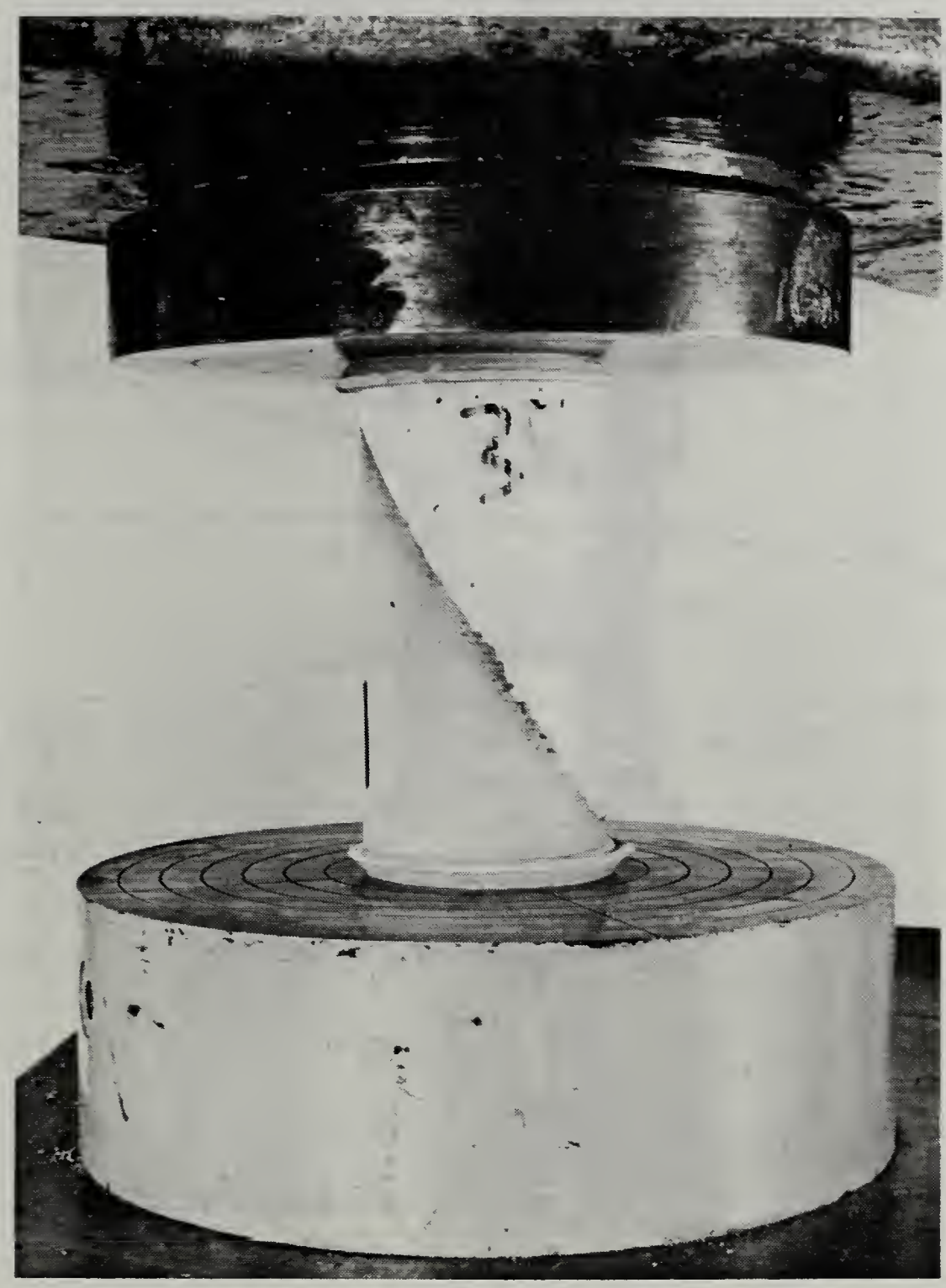

Figure 6. Slant shear bond specimen being compressed. One half of the specimen is base portland cement concrete and the other half is overlay material. 


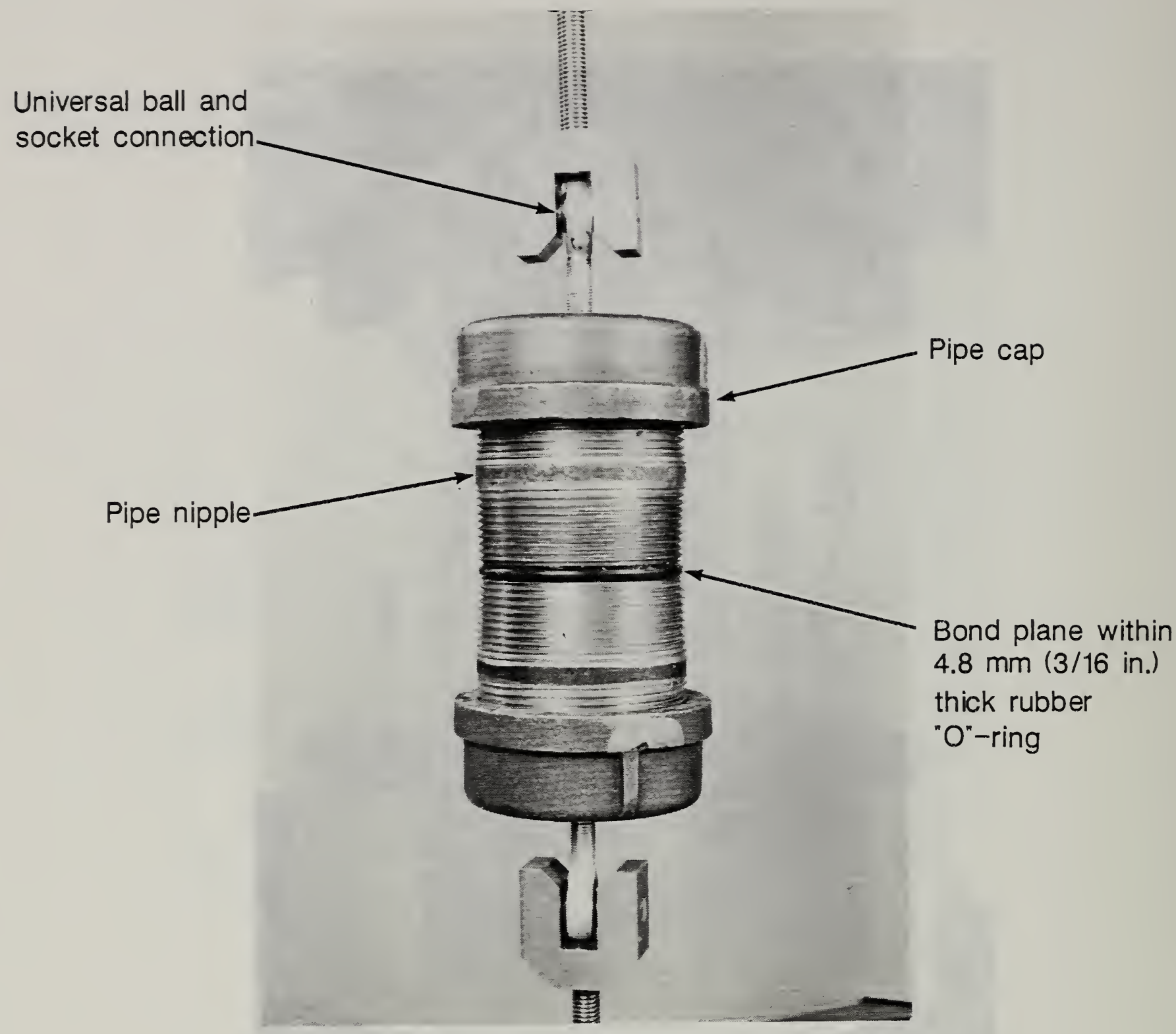

Figure 7. Uniaxial tension bond test setup. Pipe caps were screwed on the pipe nipples, then installed in a screw-driven testing machine, and pulled in tension. Two pipe nipples were used: one was bonded to the base concrete and the other bonded to the overlay material. A rubber "o"-ring provided about $3 / 16$ in. spacing between the pipe nipples at the bond plane. A universal ball and socket connection was used at each end of the specimen (see reference 4 for details). 

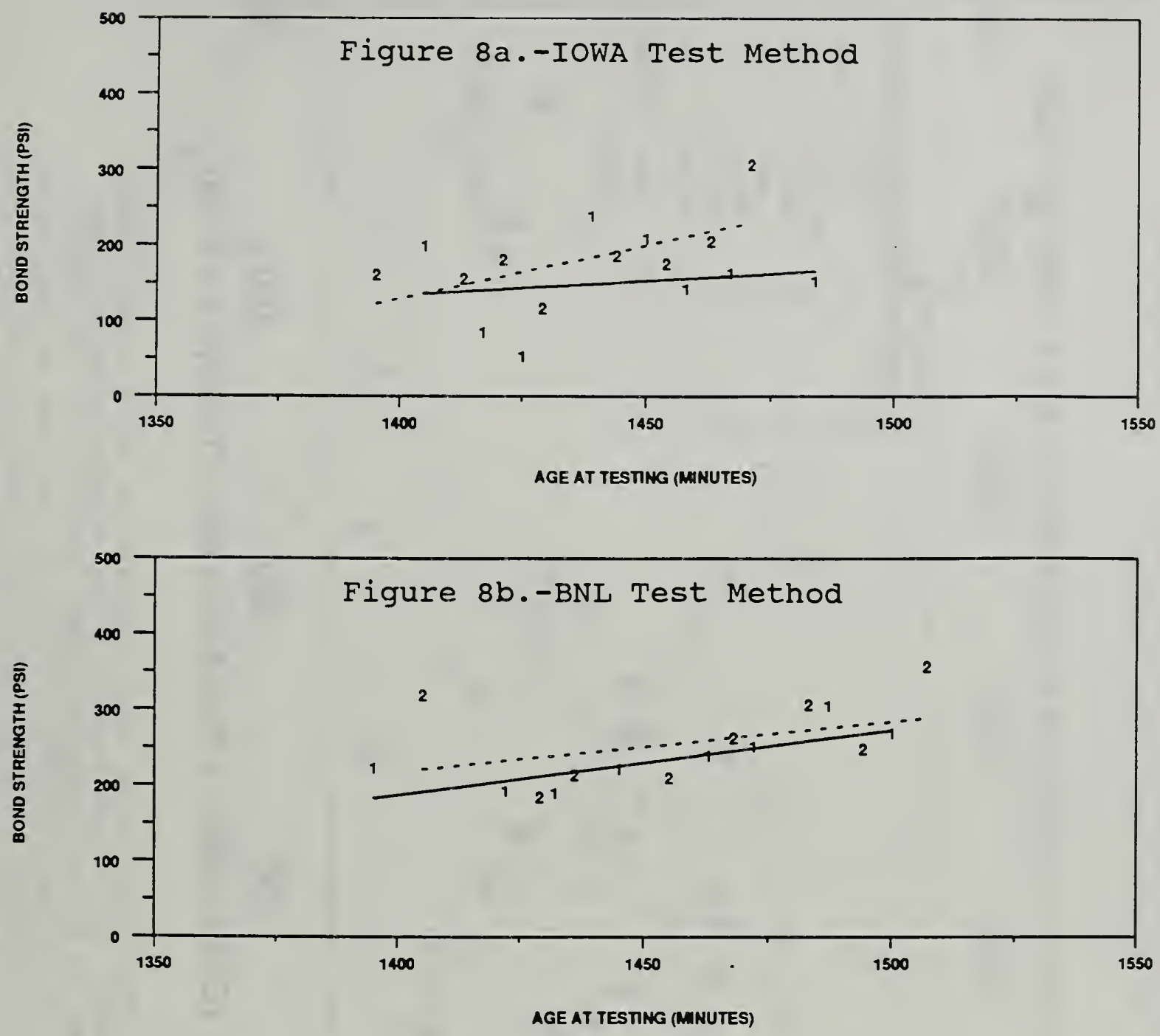

Figure 8. Direct shear bond strength vs. age at testing for 1-Day old PCC overlay material for the IOWA (figure 8a.) and BNL (figure $8 \mathrm{~b}$. ) test methods. The solid lines are the least-squares linear regression lines for specimens with sawn surfaces, where the individual data are shown by the number "I"; similarly, the dashed lines are the least-squares linear regression lines for specimens with sandblasted surfaces, where the individual data are shown by the number " 2 ". 


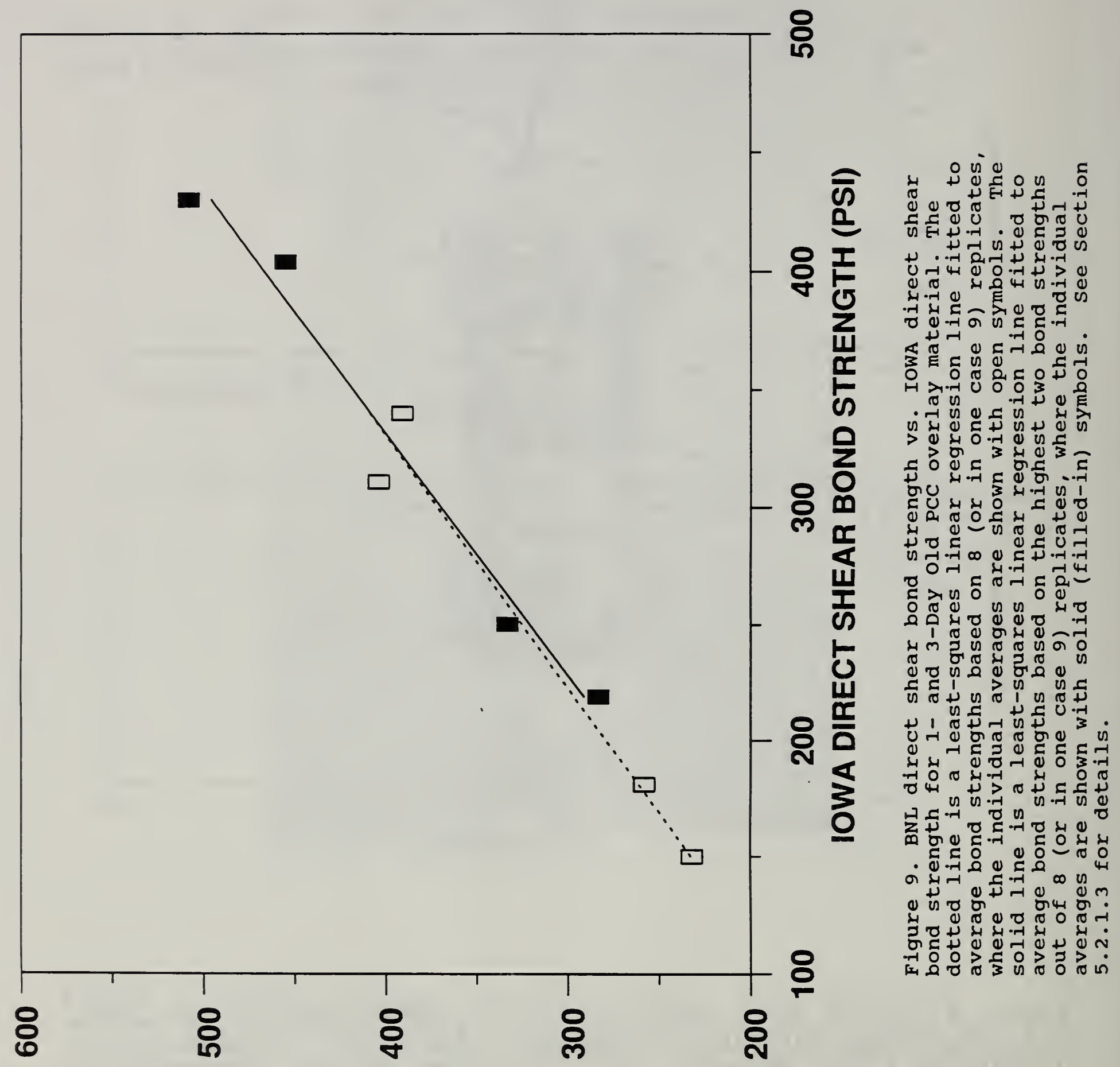

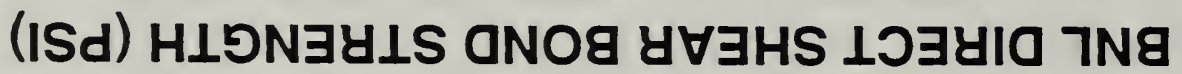




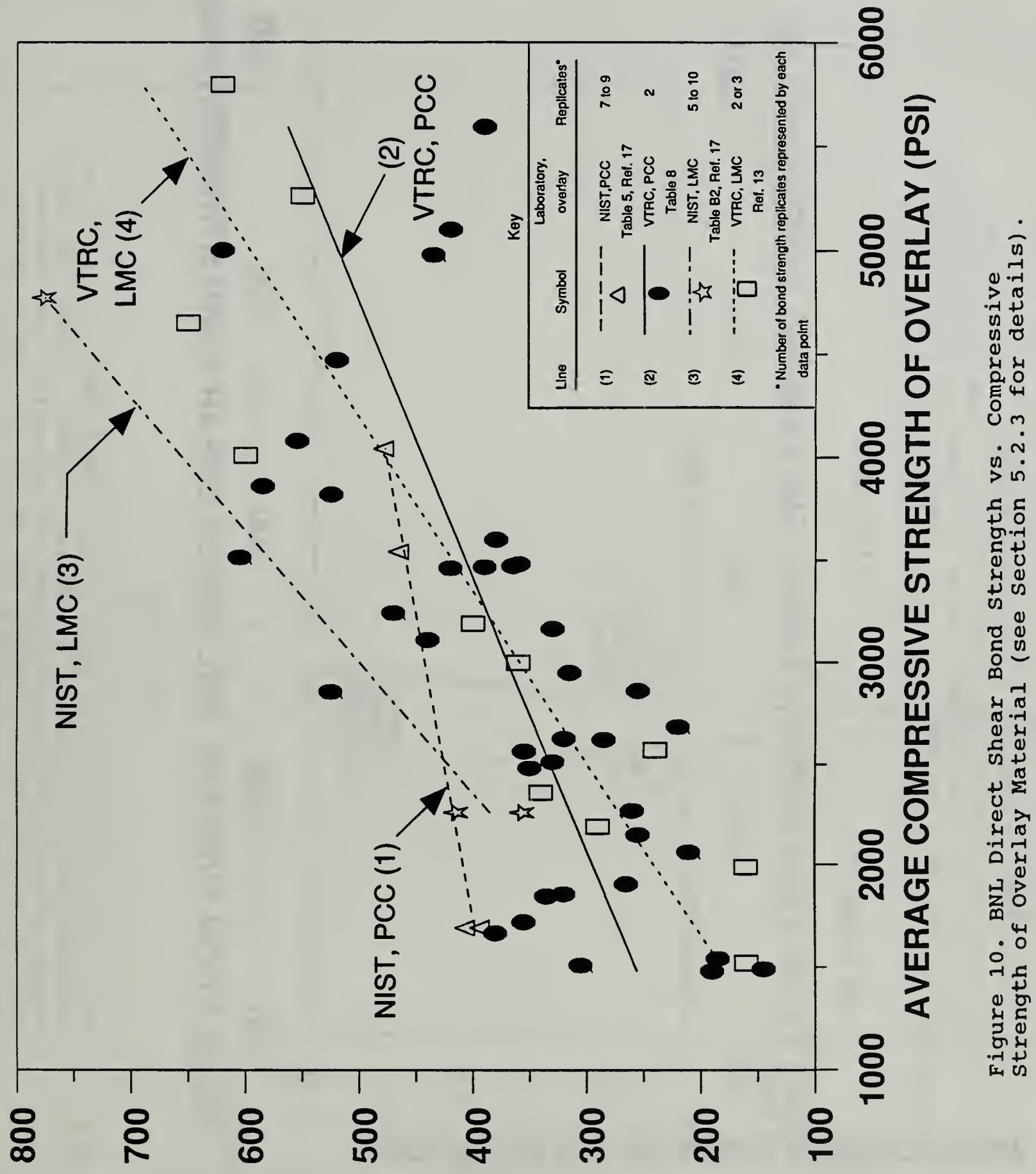

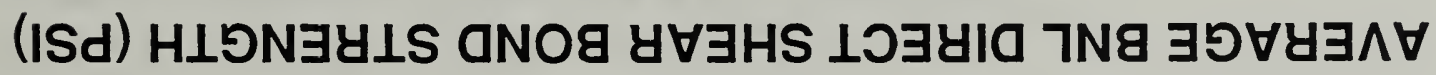




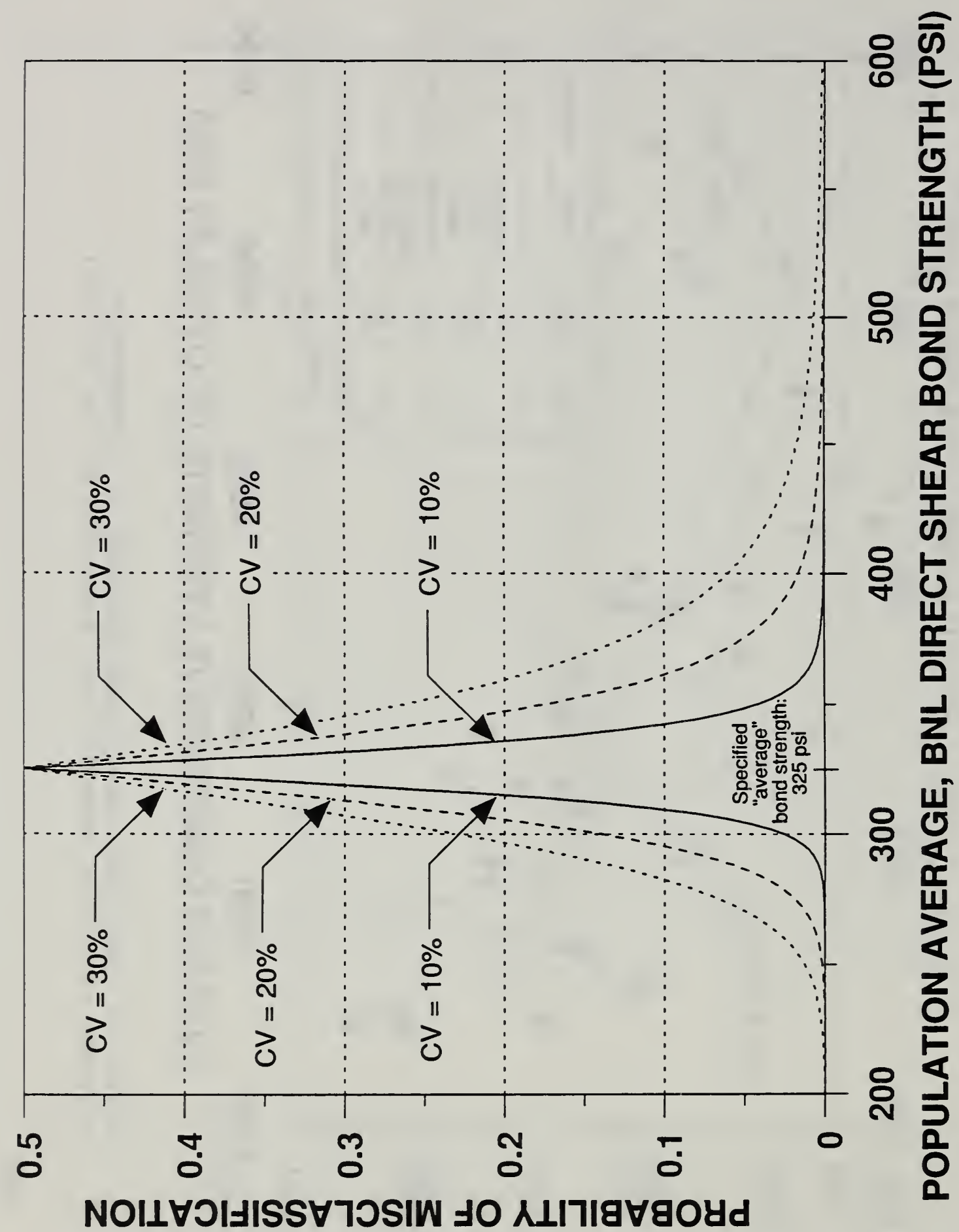

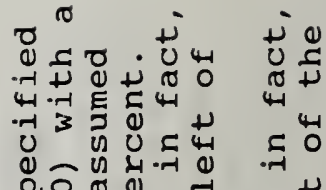

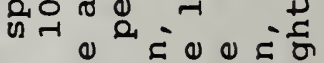
๘ 0 ఖ

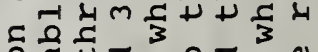
ชั 光 ใ

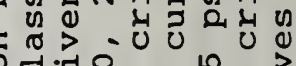

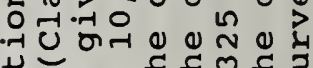

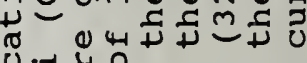
U. ज्ञ

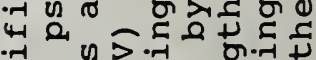

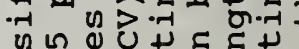
吹

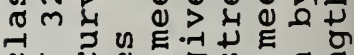

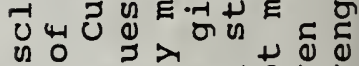

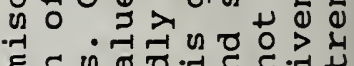
菲敌

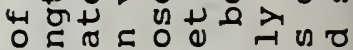

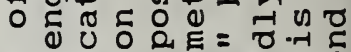

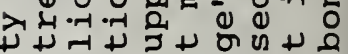

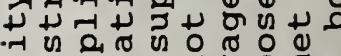

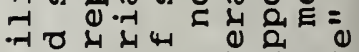

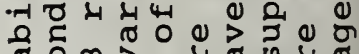
กิ

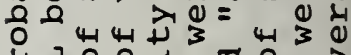

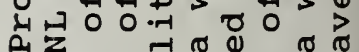
מ

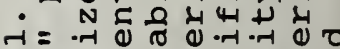
r

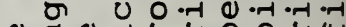

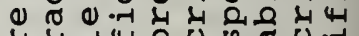

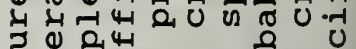

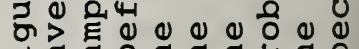

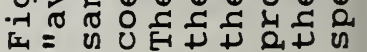




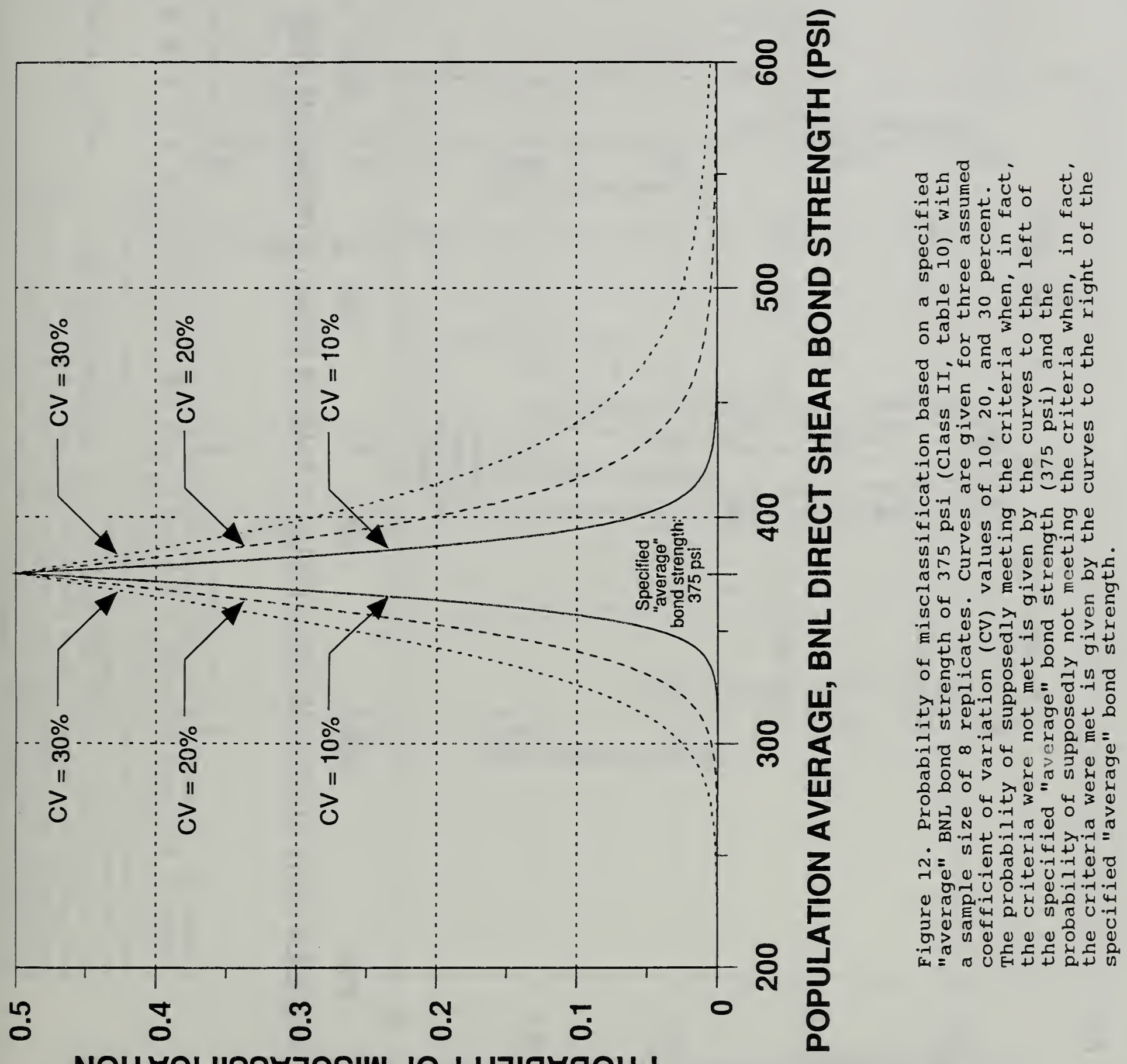




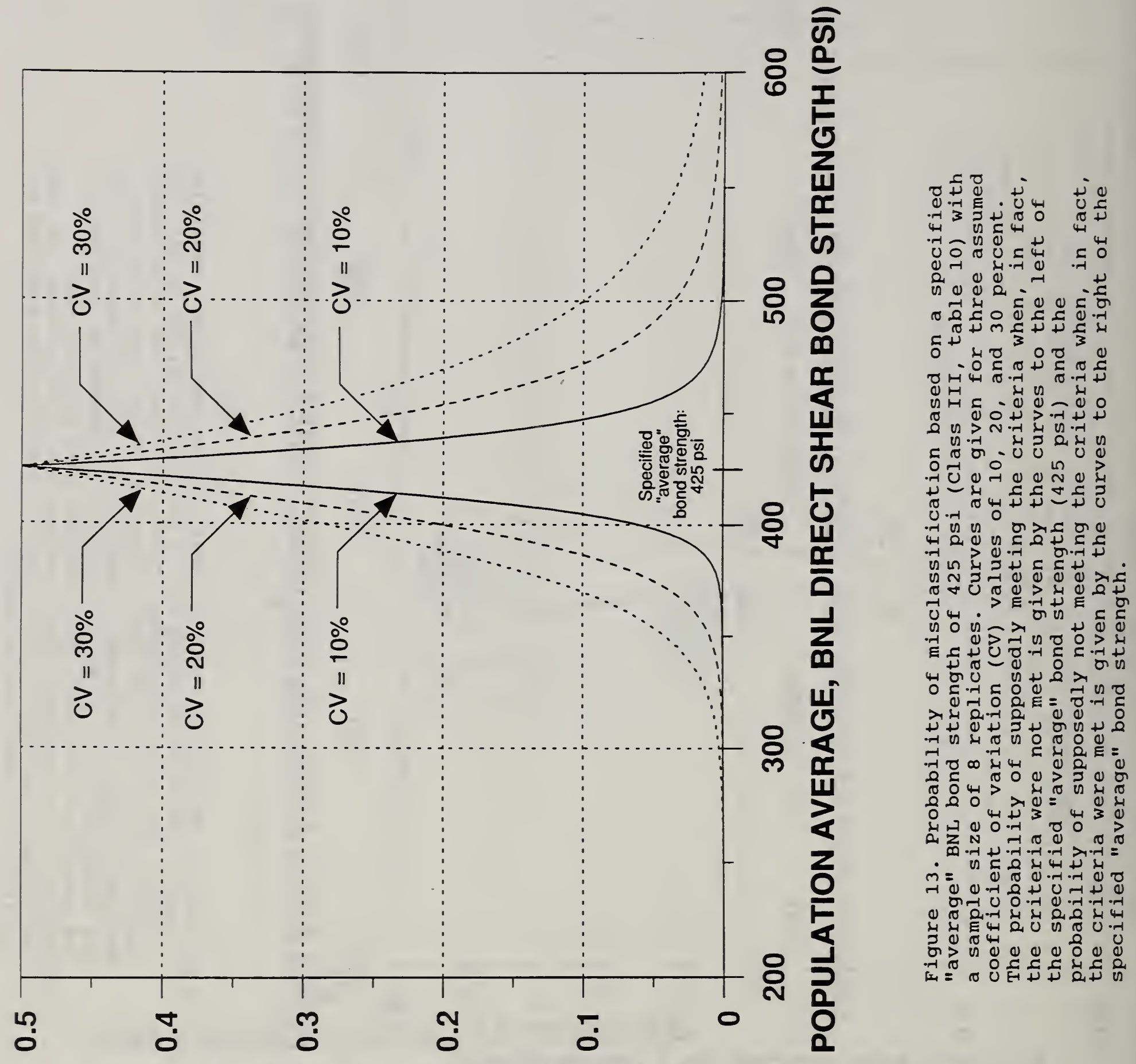

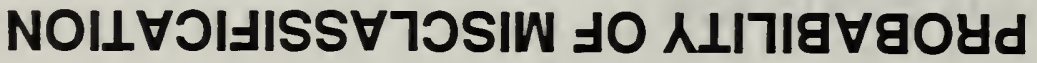



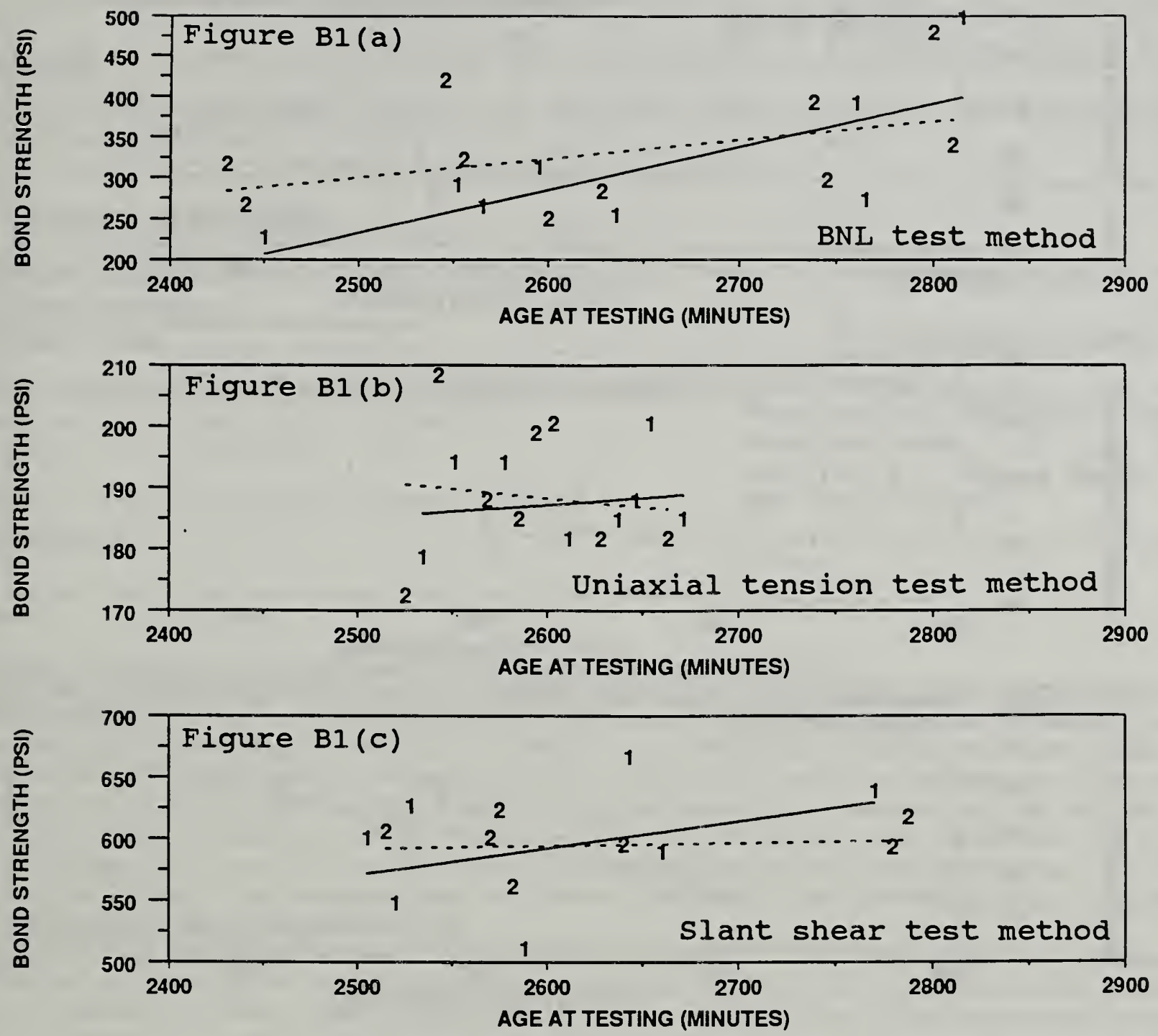

Figure B1. (Appendix B) Bond strength vs. age at testing for 2 Day-old PCC overlay material for the BNL (figure BI(a)), uniaxial tension (figure BI(b)), and slant shear (figure BI(c) bond test methods. The solid lines are the least-squares linear regression lines for specimens with sawn surfaces, where the individual data are shown by the number "1"; similarly, the dashed lines are the least-squares linear regression lines for specimens with sandblasted surfaces, where the individual data are shown by the number "2". 

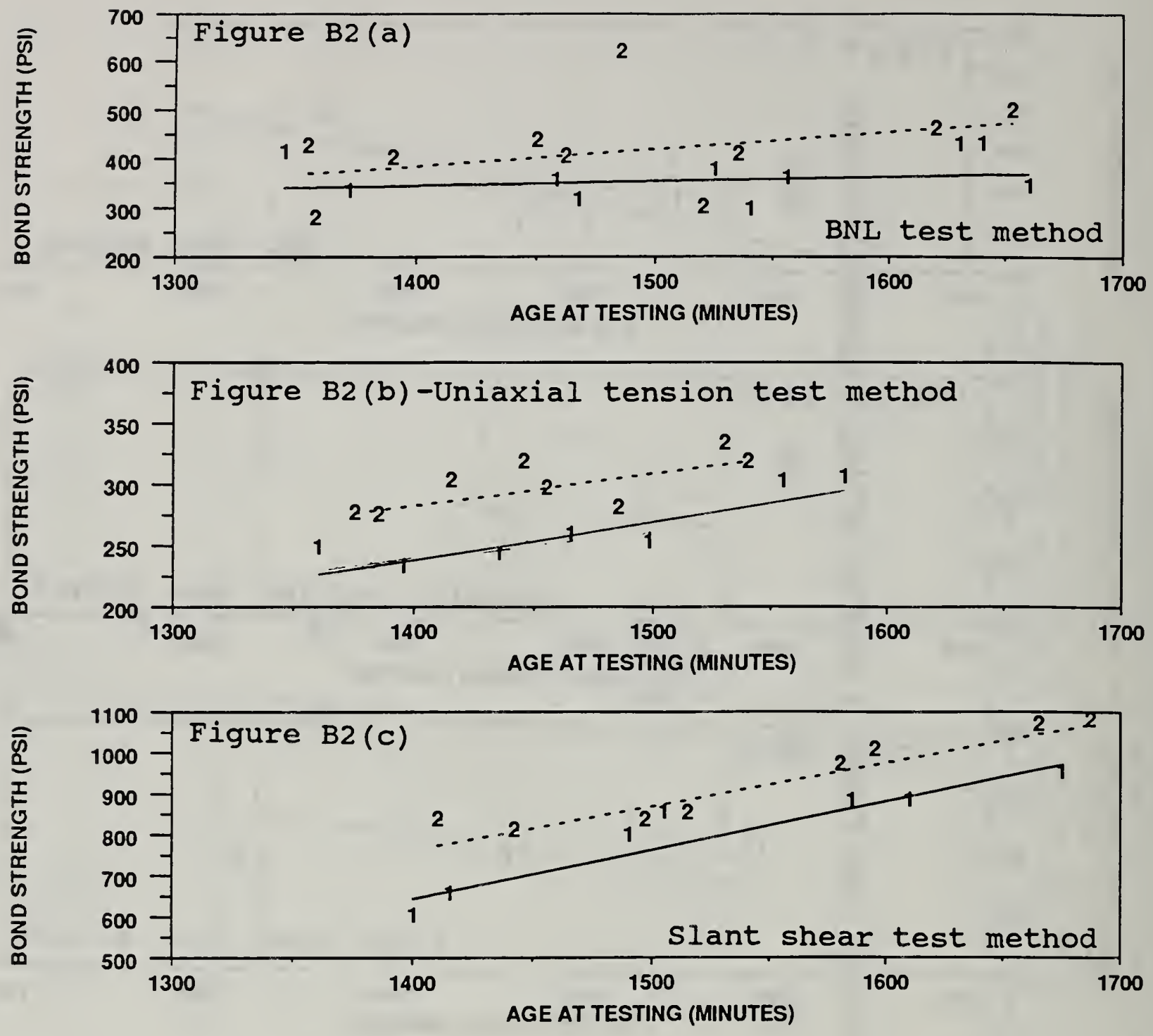

Figure B2 (Appendix B) Bond strength vs. age at testing for 1 Day-Old LMC overlay material for the BNL (figure BI(a)), uniaxial tension (figure BI(b)), and slant shear (figure Bl(c) bond test methods. The solid lines are the least-squares linear regression lines for specimens with sawn surfaces, where the individual data are shown by the number "1"; similarly, the dashed lines are the least-squares linear regression lines for specimens with sandblasted surfaces, where the individual data are shown by the number " 2 ". 


\begin{tabular}{|c|c|c|}
\hline \multirow[t]{4}{*}{$\begin{array}{l}\text { NIST-114A } \\
\text { (REV. 3-89) }\end{array}$} & \multirow[t]{2}{*}{$\begin{array}{l}\text { U.S. DEPARTMENT OF COMMERCE } \\
\text { NATIONAL INSTITUTE OF STANDARDS AND TECHNOLOGY }\end{array}$} & $\begin{array}{l}\text { 1. PUBLCATION OR REPORT NUMBER } \\
\text { NIST IR } 89-4156\end{array}$ \\
\hline & & PERFORMING ORGANIZATION REPORT NUMBER \\
\hline & \multirow[t]{2}{*}{ BIBLIOGRAPHIC DATA SHEET } & 3. PUBLCATION DATE \\
\hline & & NOVEMBER 1989 \\
\hline
\end{tabular}

\section{TITLEAND SUBTITLE}

Preliminary Performance Criteria for the Bond of Portland-Cement and Latex-Modified Concrete Overlays

\section{AUTHOR(S)}

$$
\text { L.I. Knab, M.M. Sprinkel and O.J. Lane, Jr. }
$$

6. PERFORMINO ORGANIZATION (IF JOINT OR OTHER THAN NIST, SEE INSTRUCTIONS)

U.S. DEPARTMENT OF COMMERCE

MATIONAL INSTITUTE OF STANDARDS AND TECHNOLOGY

GAITHERSBURG, MD 20899

7. CONTRACT/GRANT NUMBER

8. TYPE OF REPORT AND PERIOD COVERED

9. SPONSORING ORGANIZATION NAME AND COMPLETE ADDRESS (STREET, CITY, STATE, ZIP) Engineering and Services
HeadquarterS, U.S. Army Corps of Engineer

Washington, DC 20314-1000

U.S. Navy, Naval Facilities Engineers Command Alexandria. VA $22332-2300$

10. SUPPLEMENTARY NOTES
Headquarters, U.S. Air Force, Bolling Air Force Base, DC $20332-5000$

DOCUMENT DESCRIBES A COMPUTER PROGRAM; SF-185, FIPS SOFTWARE SUMMARY, IS ATTACHED.

11. ABSTRACT (A 200-WORD OR LESS FACTUAL SUMMARY OF MOST SIONIFICANT INFORMATION. IF DOCUMENT INCLUDES A SIGMIFICANT BIBLOGRAPHY OR

Preliminary bond-strength performance criteria were developed for screening and selecting portland-cement concrete (PCC) and latex-modified concrete (IMC) materials to be overlaid on PCC pavements and PCC bridge decks subjected to normal civilian truck and automobile traffic. The criteria were developed based on direct shear bond test results from (i) field cores from pavements and bridge decks which were considered to have performed satisfactorily, and (ii) laboratory- and field-cast specimens with PCC and LMC overlay materials. The criteria consist of minimum direct shear bond strength levels and corresponding minimum compressive strength levels. A direct shear "guillotine"-type performance bond test method, developed at the Brookhaven National Laboratories, was specified using laboratory-cast specimens.

The criteria are preliminary because: (i) the criteria are based on very limited field- and laboratory-based bond strengths and should be further verified by being correlated with field performance, including various service conditions (temperature, moisture, wheel loading, etc.)., (ii) the criteria need to be assessed with regard to repeatability within, and reproducibility among laboratories, (iii) the effects of material variables (aggregate, cement, mix design, etc.), surface preparation, placement procejures, curing conditions, and curing duration on the criteria need to be evaluated. Therefore, the criteria are a starting point and should be evaluated on a trial basis; most likely, the criteria will need to be modified as additional field performance results and laboratory experience are obtained.

A notable limitation of the "guillotine" performance test method is its relatively poor precision, as evidenced by relatively large coefficient of variation values associated with the test method. Although the limitation of imprecision exists, the "guillotine" test method is still considered to be the best available performance bond test method for which field performance data exist. Field-performance data need to be obtained for other bond test methods with potentially better precision, such as the uniaxial tension test method, which was 12. also investigated in the laboratory and reported in this report.

Bond Strength; Bridge Decks; Direct Shear Bond Test Method; Latex-Modified Concrete; overlay; Pavement; Performance Criteria; Precision; Portland Cement Concrete; Repair Materials

FOR OFFICIAL DISTRIBUTION. DO NOT RELEASE TO NATIONAL TECHNICAL INFORMATION SEAVCE (NTIS).

ORDER FROM SUPERINTENDENT OF DOCUMENTS, U.S. GOVERNMENT PRINTING OFFICE, WASHINOTON, DC 20402.

OADER FAOM WATIONAL TECHHCAL WFOAMATHON SEAVICE (MTIS), SPAWGFIELD, VA 22161.

14. MUMBER OF PRINTED PAGES

\section{4}

15. PRICE 


